\title{
DETECCIÓN TEMPRANA DE FACTORES DE RIESGO CARDIOVASCULAR RELACIONADOS CON SOBREPESO Y OBESIDAD EN ESCOLARES DEL COLEGIO PAULO VI IED
}
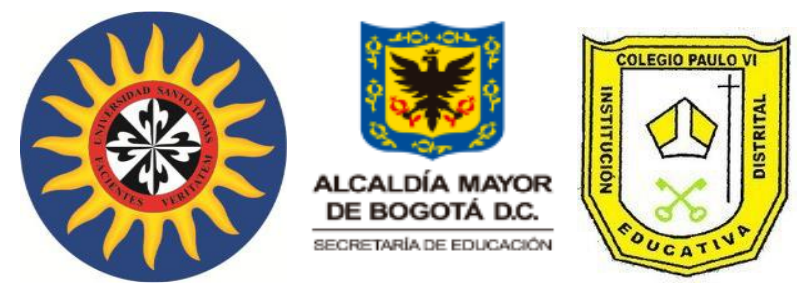

WILLIAM ALBERTO ROJAS SILVA

Una Tesis Presentada Para Obtener El Título De Magíster en Actividad Física Para La Salud Universidad Santo Tomás, Bogotá

\author{
ADRIANA CAMPOS RODRÍGUEZ \\ Director de Trabajo de Grado
}

\begin{abstract}
UNIVERSIDAD SANTO TOMÁS
Facultad de Cultura Física, Deporte y Recreación

Maestría en Actividad Física para la Salud
\end{abstract}

Bogotá, junio de 2018 
Este trabajo de investigación hace parte de la Fase I del Macroproyecto denominado DETECCIÓN TEMPRANA DE LOS FACTORES DE RIESGO CARDIOVASCULAR E IMPLEMENTACIÓN DE ESTRATEGIAS RELACIONADAS CON LA ACTIVIDAD FÍSICA EN ESCOLARES COLOMBIANOS.

Los datos se obtuvieron en el Colegio Paulo VI IED, Localidad Kennedy 


\section{DEDICATORIA}

A Laura Ximena y Daniel, mis hijos

A Ana, mi esposa

A Micaela, mi madre 


\title{
AGRADECIMIENTOS
}

El autor agradece a:

LA UNIVERSIDAD SANTO TOMÁS FACULTAD DE CULTURA FÍSICA, DEPORTE Y RECREACIÓN, por darme la oportunidad de enriquecer mis conocimientos y poder aportar como educador en el cuidado corporal y en la prevención de ECNT en los niños y jóvenes de nuestras comunidades educativas.

La Dra. ADRIANA YOLANDA CAMPOS RODRÍGUEZ, por su dedicación como asesora, y por su compromiso con la elaboración de este proyecto.

\begin{abstract}
A las directivas de la INSTITUCIÓN EDUCATIVA DISTRITAL PAULO VI ubicada en la LOCALIDAD 8 de BOGOTA D.C, por darme la oportunidad de desarrollar y aplicar el proyecto.
\end{abstract}

A los padres de familia y estudiantes de los ciclos 3, 4 y 5 de la jornada de la mañana del colegio Paulo VI IED por su disposición, entusiasmo, colaboración e interés por participar y aportar en el proyecto en beneficio de la adquisición de hábitos de vida saludables, que redunden en una mejor calidad de vida.

Los Docentes DIRECTORES DE GRUPO de preescolar y de grado 5 A 11 del colegio Paulo VI IED JM, por su disposición, acompañamiento y colaboración en la entrega y recolección de los documentos solicitados.

Los DOCENTES DE POSGRADO de la 4 cohorte en Actividad física para la salud por sus valiosos aportes en cada una de las asignaturas orientadas. 


\section{CONTENIDO}

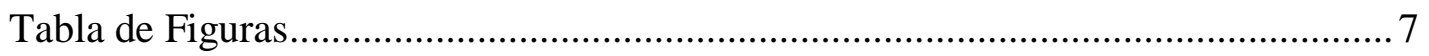

Tabla de ilustraciones ...................................................................................... 8

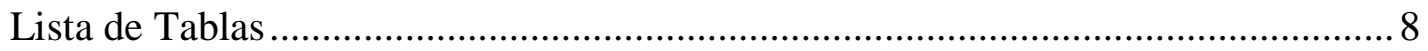

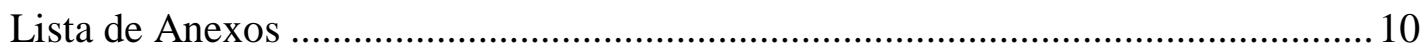

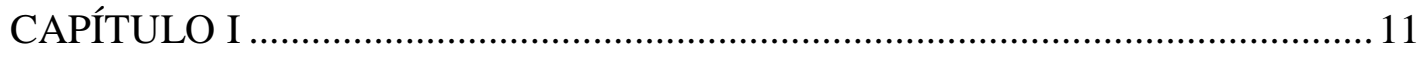

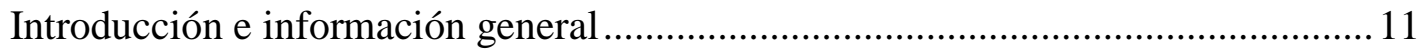

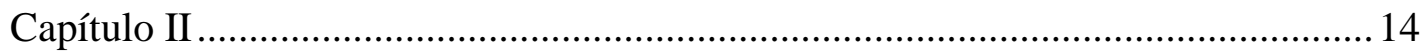

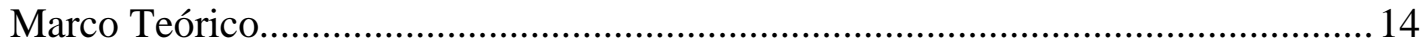

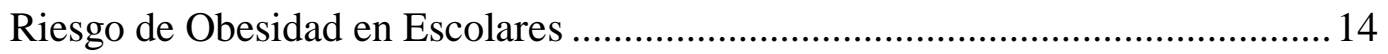

Obesidad en Infantes y Adolescentes ........................................................ 16

Perfil Epidemiológico En Infantes Y Adolescentes (A Nivel Mundial Y En

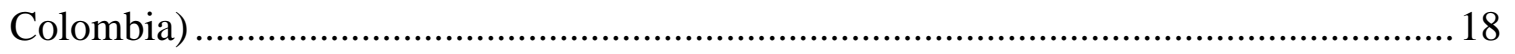

Factores de Riesgo de obesidad Infantil - Adolescente Obesidad - Sobrepeso ...24

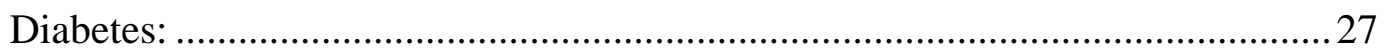

La Obesidad Infantil y la Diabetes ........................................................... 28

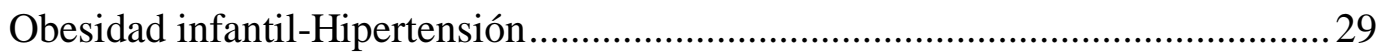

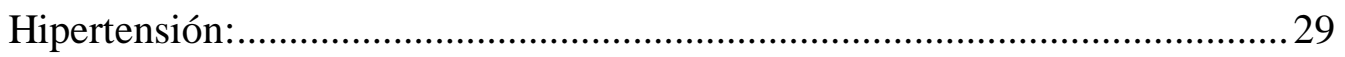

Medición de Factores de Riesgo y Protectores .................................................. 30

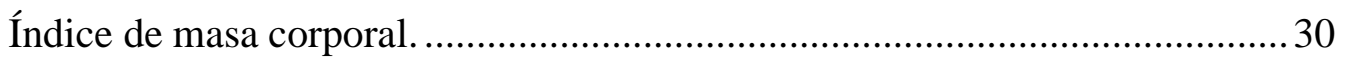

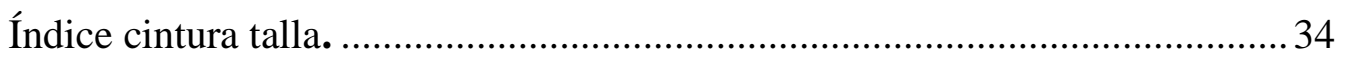

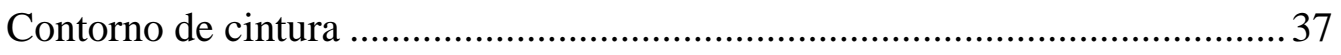

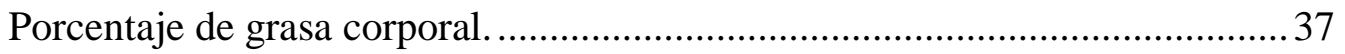

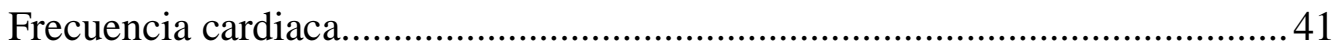

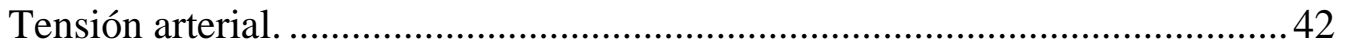




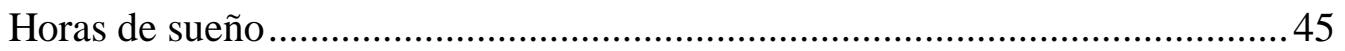

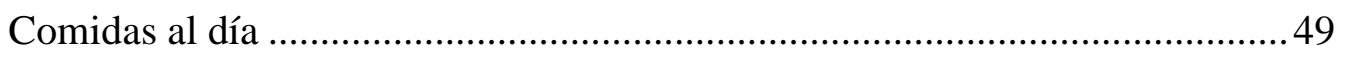

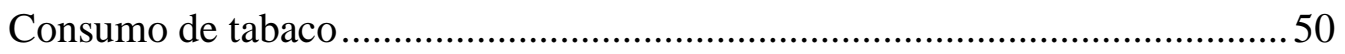

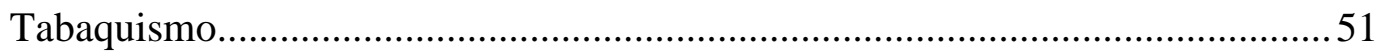

Tabaquismo pasivo ................................................................................ 52

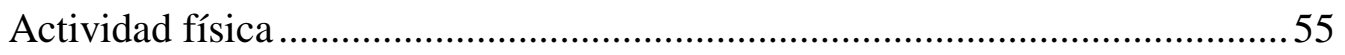

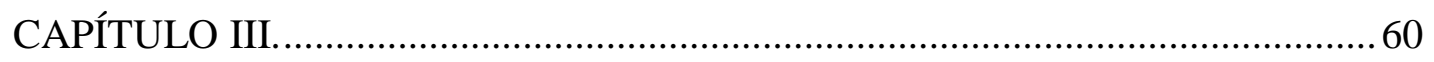

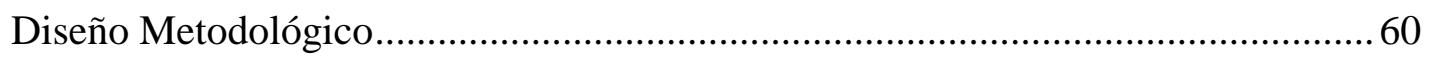

Estudio descriptivo analítico transversal (cross-sectional study)...........................60

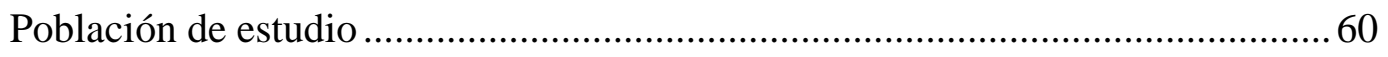

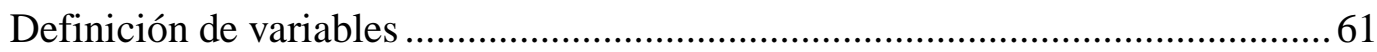

Instrumentos de recolección de la información ........................................................64

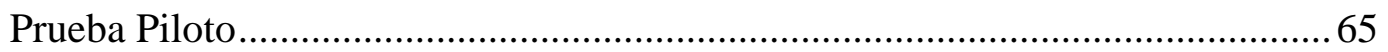

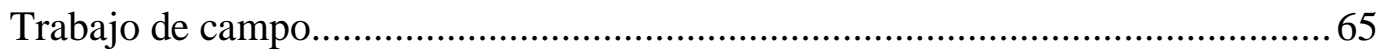

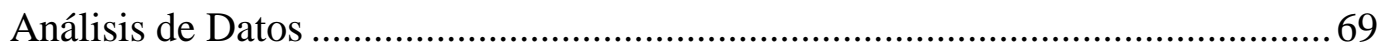

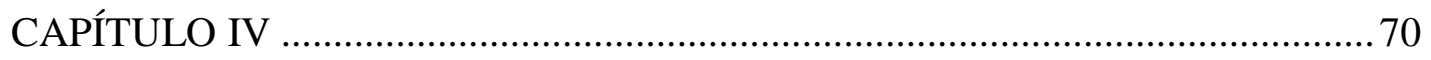

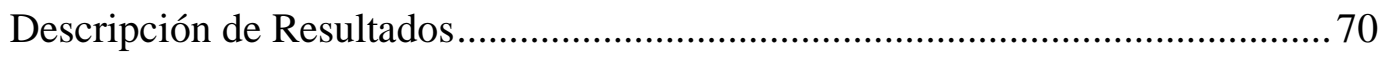

Cruce de variables relacionadas frente al género biológico .................................... 89

Cruces entre variables Antropométricas ..............................................................92

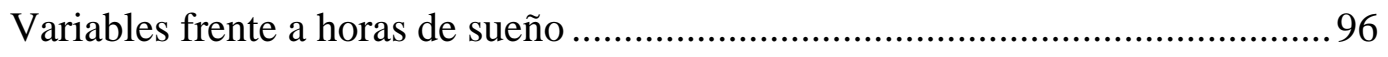

Variables frente a la actividad física extraescolar ................................................. 99

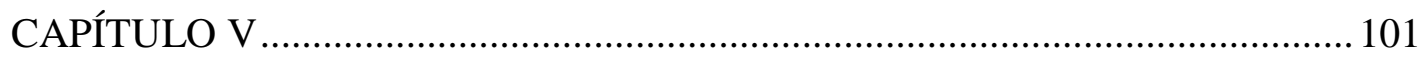

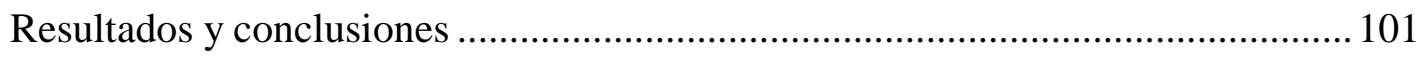

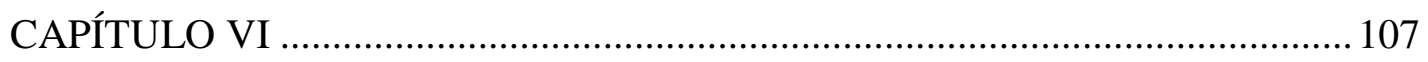

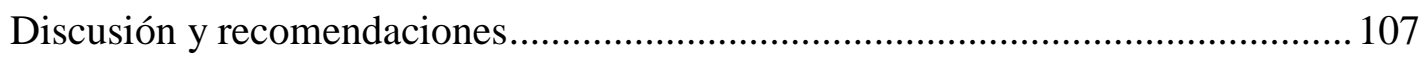




\section{Listas}

\section{Tabla de Figuras}

Figura 1. Porcentaje de obesidad infantil en el mundo....................................... 211

Figura 2. Situación nutricional, niños y adolescentes..........................................2 244

Figura 3. Prevalencia de enfermedades asociadas a la obesidad en infantes y adolescentes 266

Figura 4. Índice de masa corporal Niños y Adolescentes ..................................... 322

Figura 5. Índice de masa corporal Niños y Adolescentes en percentiles................ 322

Figura 6. Distribución de la población según grado escolar.................................. 71

Figura 7. Distribución de la población según la edad ........................................... 72

Figura 8. Distribución de la población según género biológico ..............................73

Figura 9. Distribución de la población según organización del Núcleo familiar .....74

Figura 10. Distribución de la población según antecedentes médicos ...................75

Figura 11. Distribución de la población según consumo de medicamentos ............76

Figura 12. Distribución de la población según horas de sueño ................................77

Figura 13. Distribución de la población según dieta .......................................... 78

Figura 14. Distribución de la población según tabaquismo personal y pasivo ......... 79

Figura 15. Distribución de la población según Actividad física extraescolar ..........80

Figura 16. Distribución de la población según interpretación del IMC .....................81

Figura 17. Distribución de la población según interpretación contorno de cintura.. 82

Figura 18. Distribución de la población según interpretación índice cintura-talla...83

Figura 19. Distribución de la población según interpretación de porcentaje graso.. 84 Figura 20. Distribución de la población según interpretación de FC basal por AHA

Figura 21. Distribución de la población según interpretación de PAS por AHA .....87

Figura 22. Distribución de la población según interpretación de PAD por AHA .... 88 


\section{Tabla de ilustraciones}

Ilustración 1.Patología y tipos de diabetes 28

Ilustración 2. Medición talla $\quad 67$

Ilustración 3. Medición peso $\quad 68$

Ilustración 4. Medición contorno de cintura $\quad 68$

Ilustración 5. Medición presión arterial $\quad 69$

\section{Lista de Tablas}

Tabla 1. Factores de riesgo por escolar según IMC e ICT. .................................... 31

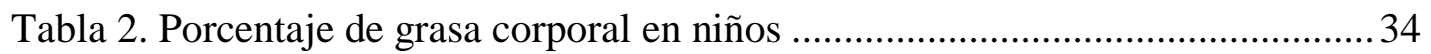

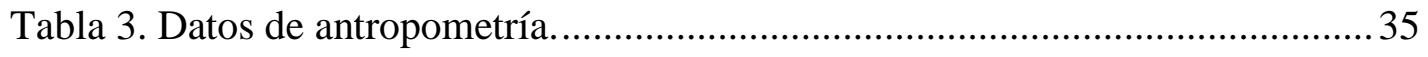

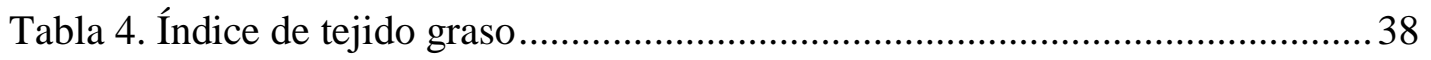

Tabla 5. Porcentaje de grasa corporal en niños .................................................. 38

Tabla 6. Valores para la categorización de la población ......................................... 38

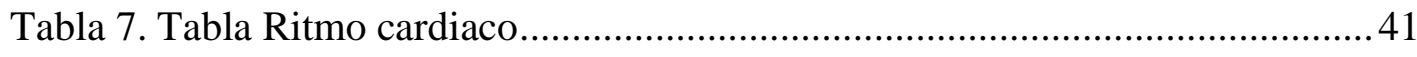

Tabla 8. Tensión arterial, según edad ............................................................... 42

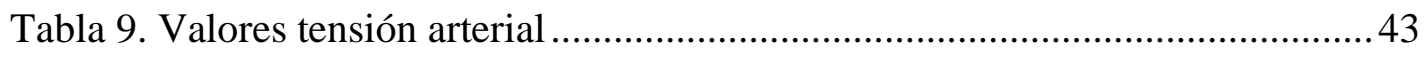

Tabla 10. Límite máximo de presión arterial normal según edad ...........................44

Tabla 11. Clasificación de presión arterial: niños y jóvenes ...................................44

Tabla 12. Horas de sueño recomendadas para niños, según edad ...........................46

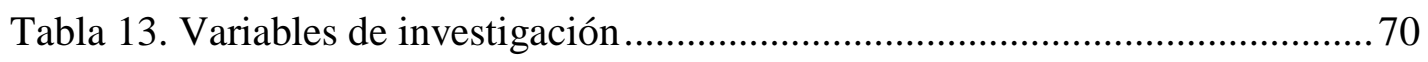

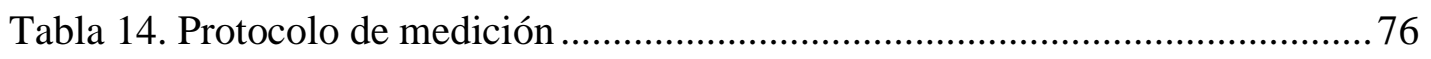

Tabla 15. Distribución de la población según grado escolar ..........................70

Tabla 16. Distribución de la población según edad ...................................... 72

Tabla 17. Distribución de la población según género biológico ......................73

Tabla 18. Distribución de la población según núcleo familiar ....................... 74

Tabla 19. Distribución de la población antecedentes médicos........................75

Tabla 20. Distribución de la población según consumo de medicamentos ..............76

Tabla 21. Distribución de la población según horas de sueño.................................77

Tabla 22. Distribución de la población según dieta................................................ 77 
Tabla 23. Distribución de la población según tabaquismo personal y pasivo ..... 78

Tabla 24. Distribución de la población según práctica de actividad física extraescolar. .79

Tabla 25. Distribución de la población según interpretación del IMC ..................... 80

Tabla 26. Distribución de la población según interpretación contorno de cintura ...81

Tabla 27. Distribución de la población según interpretación índice cintura-talla ....82

Tabla 28. Distribución de la población según interpretación de porcentaje graso. ..83

Tabla 29. Estadísticos de características antropométricas .................................... 84

Tabla 30. Distribución de la población según interpretación de FC basal por AHA 85

Tabla 31. Distribución de la población según interpretación de PAS por AHA .......86

Tabla 32. Distribución de la población según interpretación de PAD por AHA......87

Tabla 33. Estadísticos de características hemodinámicas....................................... 88

Tabla 34. Interpretación del Índice masa corporal y género..................................89

Tabla 35. Pruebas de chi-cuadrado Interpretación del Índice masa corporal y género

Tabla 36. Interpretación del contorno de cintura y género 90

Tabla 37. Pruebas de Chi - cuadrado Interpretación del contorno de cintura y género

Tabla 38. Interpretación del índice cintura-talla con el género 91

Tabla 39. Prueba de Chi cuadrado interpretación del índice cintura-talla con el género .92

Tabla 40. Interpretación del IMC con el contorno de cintura. .92

Tabla 41. Prueba de Chi cuadrado interpretación del IMC con el contorno de cintura

Tabla 42. Interpretación del contorno de cintura con el índice cintura-talla. .93

Tabla 43. Prueba de Chi cuadrado interpretación del contorno de cintura con el índice cintura-talla. .94

Tabla 44. Interpretación del IMC con el índice cintura-talla..................................94

Tabla 45. Prueba de Chi cuadrado interpretación del IMC con el índice cintura-talla 
Tabla 46. Prueba de Chi cuadrado interpretación del IMC con el índice cintura-talla .95

Tabla 47. Interpretación del IMC con las horas de sueño ......................................96

Tabla 48. Prueba de chi cuadrado interpretación del IMC con las horas de sueño ..96

Tabla 49. Interpretación horas de sueño con contorno de cintura ............................97

Tabla 50. Prueba de chi cuadrado interpretación horas de sueño con contorno de

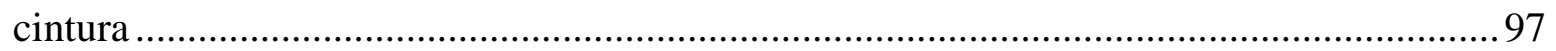

Tabla 51. Interpretación horas de sueño con cintura-talla ....................................98

Tabla 52. Prueba de chi cuadrado interpretación horas de sueño con cintura-talla.98

Tabla 53. Interpretación IMC y Actividad física extraescolar...............................99

Tabla 54. Prueba de chi cuadrado interpretación IMC y Actividad física

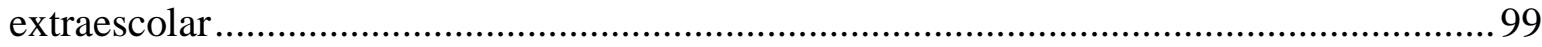

Tabla 55. Interpretación contorno de cintura y Actividad física extraescolar ........ 100

Tabla 56. Prueba de chi cuadrado interpretación contorno de cintura y Actividad

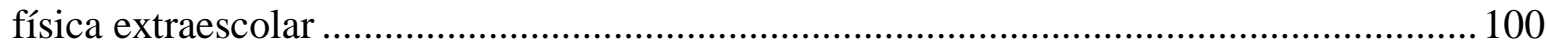

Tabla 57. Interpretación índice cintura-talla y Actividad física extraescolar ......... 100

Tabla 58. Prueba de chi cuadrado interpretación índice cintura-talla y Actividad física extraescolar 101

\section{Lista de Anexos}

Anexo 1. Consentimiento informado................................................................ 116

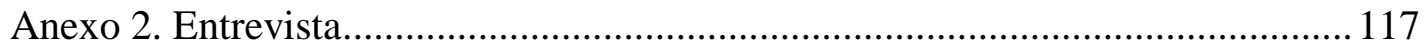




\section{CAPÍTULO I}

\section{Introducción e información general}

Este trabajo de investigación hace parte de la Fase I del Macro proyecto denominado "Detección temprana de los factores de riesgo cardiovascular e implementación de estrategias relacionadas con la actividad física en escolares colombianos". El mismo se desarrolló en el Colegio Paulo VI IED de la localidad Kennedy de Bogotá.

El objetivo general del macro proyecto es determinar la distribución y frecuencia de los factores de riesgo y protectores para la salud cardiovascular en escolares colombianos con el fin de implementar estrategias de prevención primaria relacionadas con la actividad física en el ámbito escolar; en el caso particular de este proyecto, se desarrolló la fase I correspondiente a la detección del riesgo en los escolares del colegio. Para esta fase los objetivos específicos propuestos son: Determinar el riesgo cardiovascular de los escolares a partir de la medición de características antropométricas; determinar el riesgo cardiovascular de los escolares a partir de la medición de variables hemodinámicas; identificar factores como el sueño, el número de comidas al día, la actividad física extraescolar que inciden sobre la salud cardiovascular y establecer la relación entre factores de riesgo y protectores de la salud cardiovascular en los escolares.

La salud cardiovascular de los escolares colombianos se encuentra en riesgo, en virtud del incremento de las enfermedades crónicas no transmisibles a edades cada vez más tempranas aunado con la falta de compromiso por parte del sistema educativo hacia el fomento de actividad física dentro del ámbito escolar bajo los estándares requeridos para generar un cambio real del perfil epidemiológico de la población.

Es así como, a pesar de las múltiples investigaciones realizadas alrededor del tema, no se ha generado un cambio en la morbimortalidad, al contrario, las cifras emanadas por la ENSIN en el 2010 (Instituto Colombiano de Bienestar Familiar, 2010) muestran un incremento exponencial de los factores de riesgo que llevan a los niños y adolescentes a adquirir enfermedades tales como sobrepeso, obesidad, hipertensión y muerte súbita. De la 
misma forma, no se ha creado en los niños, hábitos saludables relacionados con horas de sueño óptimas, nutrición adecuada y actividad física que logren generar en ellos un equilibrio energético que impacte de forma positiva su salud.

En el año 2015, la UNESCO publicó un documento relacionado con la Educación Física de Calidad en el cual propone el fomento de una alfabetización física que promueva la generación de estilos y hábitos saludables a partir de los principios de igualdad, protección y participación significativa.

Es decir se propone una educación física que posibilita la participación inclusiva, la cual es realizada por el individuo durante todo el ciclo de vida permitiéndole alcanzar aptitudes, confianza y entendimiento de la importancia del movimiento corporal consciente, necesario para su salud y bienestar.

Lo anterior, genera una responsabilidad desde la formación de talento humano de pregrado y posgrado en la Actividad Física para la Salud, que a través de sus intervenciones generen un impacto positivo en la salud pública.

El Colegio Paulo VI es una institución distrital ubicada en el barrio Tequendama, localidad de Kennedy, el cual ofrece educación completa; es decir, dos grados de preescolar, nueve grados de básica (dividida en cinco de básica primaria y cuatro de básica secundaria) y dos años de media vocacional. Esto significa que el estudiante permanece en la institución durante 13 años.

El colegio cuenta con 2545 estudiantes matriculados, divididos en dos jornadas: en la Jornada mañana 1359 y en la jornada tarde 1186 estudiantes.

La clase de Educación Física (deporte, recreación, tiempo libre activo dirigido) en el colegio PauloVI se desarrolla en una (1) hora semanal para preescolar, dos (2) horas para los ciclos 1 a 5, lo cual representa un total de 80 horas en el año escolar. Adicionalmente los estudiantes de la media vocacional (solo un curso) cuentan con 8 horas más de clase en contra jornada, en lo que actualmente es llamado Programas deportivos en articulación con el SENA. En este espacio académico, a los estudiantes de décimo y once se les oferta dentro del énfasis la opción de escoger entre tres líneas. Los que escogen la línea de deportes tienen la posibilidad de desarrollar la competencia laboral para desempeñarse como asistentes en programas deportivos. 
De esta forma se implementó en el colegio la primera fase de la investigación de la Maestría de Actividad Física para la Salud, denominada IMPLEMENTACIÓN DE ESTRATEGIAS DESDE LA EDUCACIÓN FÍSICA A PARTIR DE LA DETECCIÓN TEMPRANA DE LOS FACTORES DE RIESGO CARDIOVASCULAR EN ESCOLARES DEL DISTRITO CAPITAL.

Esta investigación tiene como objetivo implementar estrategias desde la educación física para la modificación de hábitos de vida saludable a partir de la detección temprana de los factores de riesgo cardiovascular en escolares del Distrito Capital. En su primera fase, la investigación busca detectar el riesgo cardiovascular de los escolares de 5 a 19 años, a partir de la medición de variables antropométricas, cardiovasculares y básicas de comportamiento del sueño, de tabaquismo, de actividades extraescolares y de alimentación. 


\section{Capítulo II}

\section{Marco Teórico}

\section{Riesgo de Obesidad en Escolares}

Existen enfermedades silenciosas en la modernidad, una de ellas es la obesidad, que es un fenómeno que crece en estos tiempos, por cuanto se da una combinación de sedentarismo y sobrepeso que representan un problema para la salud pública, esto se dio inicialmente en los países desarrollados, pero se ha ido expandiendo a nivel mundial, la tendencia de la prevalencia de la obesidad y su impacto ha aumentado en la sociedad, especialmente en los últimos tiempos, al respecto dice (Braguinsky, 2002)

El sobrepeso y la obesidad son un problema de salud pública, que afecta tanto a países desarrollados como en vías de desarrollo, cuya etiología incluye factores genéticos, tempranos (bajo peso al nacer, malnutrición fetal, diabetes gestacional, otros), metabólicos, sicosociales y ambientales (Braguinsky, 2002)

Es decir que no es una cuestión netamente económica o de posicionamiento geográfico, sino que, según las estadísticas de la Organización Mundial de la Salud (OMS), esta se viene duplicando en todo el mundo desde 1980. La globalización, la mejora condiciones económicas y hábitos alimentarios cambiantes en los países en desarrollo son un factor de riesgo responsable para del rápido aumento de la obesidad. Actualmente, las estimaciones muestran que el sobrepeso en los niños está aumentando en los países en desarrollo países, y obviamente en los países desarrollados.

En todo el mundo, el número de lactantes y niños pequeños (de 0 a 5 años) que padecen sobrepeso u obesidad aumentó de 32 millones en 1990 a 41 millones en

2016. Solo en la Región de África de la OMS, el número de niños con sobrepeso u obesidad aumentó de 4 a 9 millones en el mismo periodo. En los países en desarrollo con economías emergentes (clasificados por el Banco Mundial como países de ingresos bajos y medianos) la prevalencia de sobrepeso y obesidad infantil entre los niños en edad preescolar supera el 30\%. Si se mantienen las tendencias actuales, el número de lactantes y niños pequeños con sobrepeso aumentará a 70 millones para 2025. (OMS, s.f. ) 
Mientras tanto, uno de los causantes de este aumento desmesurado, es la ingesta de energía densa en alimentos que contienen alto contenido de grasa, sal y azúcares, mientras, baja la ingesta de micronutrientes y los hábitos de estilo de vida sedentario que se han convertido en un riesgo para el sobrepeso y la obesidad en relación con el aumento de la urbanización y la explosión demográfica.

Por otro lado, los enfoques de promoción en salud basados en la escuela, como mejorar la actividad física de los niños, la ingesta de frutas y verduras, son en parte útiles para minimizar el riesgo de obesidad infantil, ya que los estudios indican que alrededor del $50-80 \%$ de los niños que desarrollan la obesidad temprano en la vida, terminan volviéndose obesos en la vida adulta convirtiéndose en una enfermedad crónica que conduce a la morbilidad, como el riesgo de presión arterial alta, diabetes, enfermedad respiratoria, dislipidemia, tumor y trastornos ortopédicos.

En las condiciones descritas, normalmente, los infantes responden por medio de señales de satisfacción, de tal manera que la ingesta de calorías es la necesaria para su cuerpo, sin embargo, con la explosión demográfica, el crecimiento de las ciudades y los hábitos de vida sedentarios, facilitan comer en exceso y no desarrollar actividad física frecuente, esto se evidencia en la industria cultural que promociona un estilo de vida estándar para la población, por medio de comerciales en medios; televisión, revistas, periódicos, la internet, en palabras de (Adorno \& Morin, 2006), es un efecto de la creación de los medios del arte; la televisión, la radio, los periódicos que se asocian a las masas.

Los alimentos que promocionan en comerciales de televisión y otros anuncios son muy llamativos conduciéndolos a elegirlos siendo ricos en azúcar, sal y grasas polinsaturadas y a menudo vienen en tamaños de porciones grandes, estos factores pueden llevarlos a ingerir más calorías de las que necesitan antes de que se sientan llenos. Y esto sumado a las actividades que implican la exposición a una pantalla; como ver televisión, juegos, mensajes de texto y jugar en la computadora requieren muy poca energía, tomando el lugar de la actividad física. Otros factores en el ambiente del niño que también pueden conducir a padecer de obesidad, son la familia, los amigos y el entorno escolar los que ayudan a moldear la dieta y las opciones de ejercicio del niño. Ya que el alimento puede utilizarse como una recompensa o para consolarlo. Estos hábitos aprendidos pueden 
conducirlos a tener la dificultad de romperlos más adelante en la vida. Sin desconocer la genética, las afecciones médicas y los trastornos emocionales como factores que pueden aumentar el riesgo de obesidad para un niño.

La obesidad es reconocida como una enfermedad crónica de origen multifactorial prevenible que se caracteriza por acumulación excesiva de grasa o hipertrofia general del tejido adiposo en el cuerpo; es decir, cuando la reserva natural de energía de los humanos se incrementa hasta un punto en que pone en riesgo la salud o la vida. El sobrepeso y la obesidad son el quinto factor principal de riesgo de defunción humana en el mundo. (OMS, 2017)

\section{Obesidad en Infantes y Adolescentes}

Dentro de los estudios hechos por la OMS a nivel global se dice que un niño puede ser considerado obeso cuando por lo menos un $10 \%$ de su masa corporal, se encuentra por encima del peso recomendado con respecto a su estatura y morfología. Dentro de estos estudios la OMS asigna unos patrones de medida para poder definir cuando se presenta morbilidad por obesidad en lactantes, niños y adolescentes, según los “patrones de crecimiento infantil" (talla/estatura para la edad, peso para la edad, peso para la talla, peso para la estatura e índice de masa corporal para la edad) (OMS, 2017) y para los datos de referencia sobre crecimiento entre los 5 y los 19 años (índice de masa corporal para la edad). Estos términos tomaron fuerza cuando esta organización, presento los informes, para declararla una enfermedad global en aumento.

Dentro de esta misma vía queda claro que los actores cercanos a los niños y adolescentes; padres, maestros y cuidadores tengan claro que la obesidad o el sobrepeso es una acumulación anormal o excesiva de grasa que puede ser perjudicial para su salud, de esta manera se puede definir la obesidad como; "una enfermedad crónica que se caracteriza por el aumento de peso producido por la acumulación excesiva de grasa en una magnitud tal que compromete la salud" (Sociedad argentina de nutrición, s.f. ) 
En este referente de la obesidad, los niños con esta condición tienen más probabilidad de sufrir de enfermedades como la diabetes tipo 2, asma, dificultades para respirar, problemas musculares, dificultades cardiacas, así como problemas psicológicos y aislamiento social.

En ese sentido dice (Rodríguez, 2011) citando el informe de El British Medical Journal que en su publicación "Manejo de la obesidad infantil basado en la evidencia” del año 2001, confirma que la obesidad persistente en la infancia se asocia con un estilo de vida que favorece el desarrollo de otras enfermedades: enfermedades cardiovasculares, DBT II, osteoartritis, cánceres de mama y digestivos, desórdenes de la 6 piel, agravamiento de las enfermedades reumáticas, asma y otros problemas respiratorios. También aumenta el riesgo de desarrollar hiperinsulinismo, hipertensión y dislipidemias en la infancia.

Así mismo en el año 2017, es decir 16 años después del informe citado de la Gran Bretaña, la organización Mundial de la Salud (OMS, 2016) formuló nuevos elementos a tener en cuenta para hacer frente al fenómeno de la obesidad infantil, que viene al alza, afectando a millares de niños en el mundo, estas son unos referentes para los profesionales de la salud, con el ánimo de ayudar a identificar y ayudar a los niños que se encuentran en esta situación.

Estos parámetros se enuncian a continuación:

Incluyen medidas de peso y estatura, una evaluación de los hábitos alimenticios y consejos para los padres. Con alrededor de 42 millones de menores de 5 años con obesidad, o sobrepeso a nivel mundial, la OMS ha calificado la situación como una epidemia global que afecta tanto a países ricos como a los menos desarrollados. La OMS también insiste en proporcionar consejería a los padres y cuidadores sobre nutrición y actividad física, incluyendo la promoción y apoyo para la lactancia materna. (ONU - OMS, 2017)

Ahora bien, es cierto el problema de la obesidad infantil es un problema se ha planteado desde el estado físico, también habría que decir que dentro de los cambios hormonales que sobrellevan los infantes en su etapa adolescente, llevan a que aparezcan 
nuevas enfermedades asociadas, que los lleva a ver en la comida una manera de calmar la ansiedad, presentado problemas en su relacionamiento con sus pares e inclusive sufrir de depresión, según la (Unicef, 2011)en su informe sobre el panorama de la adolescencia este es un problema que viene en aumento y se convierte en un campanazo de alerta para entender la magnitud del problema de la obesidad en niños y adolescentes a nivel global, para que los estados puedan tomar las medidas adecuadas para atenuar sus efectos en el lapso de 20 años que está generación estará dentro de condiciones productivas.

Para entender mejor esta situación (Mustillo, 2003) de la Duke University Medical Center dice que se debe "estudiar la interacción entre los componentes internos y externos

del cuerpo humano. Sus observaciones concluyen que la obesidad conduce con frecuencia a un estigma social que puede dar lugar a la aparición de la depresión”, ya que con la imagen que genera un cuerpo obeso, puede afectarse la capacidad del adolescente para lograr interactuar con sus amigos, generando un aislamiento capaz de llevar a este individuo inclusive hasta el suicidio por no obtener aceptación de sus pares.

Por otra parte, según (Vásquez, Olivares Cortez, \& Santos, 2008) el concepto de obesidad por ansiedad se puede definir como el "conjunto de acciones que establecen la relación del ser humano con lo que come" los niños que sufren de depresión clínica, comen mayores cantidades de alimentos y pierden en entusiasmo por la actividad física y debido a que no queman calorías (Reyes, Pérez García, Loya Méndez, \& Hidalgo Ruzzante, 2016), se hacen obesos.

De igual manera también se ha observado que puede ser parcialmente neuroendocrina. El eje HPA (hipotálamo, Hipófisis y suprarrenal) segrega una hormona del estrés, llamada cortisol. Esta hormona es crucial en el metabolismo de la energía, entre otras funciones. El lado negativo de sus actividades es el depósito de grasa corporal en el abdomen. (Papponetti, s.f.), es decir que hay una relación de lo endocrino con lo físico que se evidencia en la imagen propia que genera el adolescente su propio cuerpo.

\section{Perfil Epidemiológico En Infantes Y Adolescentes (A Nivel Mundial Y En}

\section{Colombia)}


El fenómeno del cual se viene hablando viene aumentando en el mundo, se ha convertido en un problema moderno de la salud, es por ello que los esfuerzos de los estados están canalizados a partir de la OMS que está encargada de hacer los encargos de política pública global, respaldada por los estados miembros, en total 193 países que buscan la calidad de la salud de sus habitantes y en especial de las generaciones futuras, niños, adolescentes que tendrán un relevo generacional.

Para disminuir el impacto que tiene la obesidad infantil en Nueva Zelanda (Gluckman, 2017) dice que acabar con la obesidad infantil debe ser un imperativo para los estados, es por ello que en 2016 se creó una comisión científica que se encargara de canalizar los esfuerzos estatales en la materia como medida urgente, así mismo (Nishtar, 2016), fundadora Presidente de Heartfile, integrante de la Organización, planteó recomendar a los gobiernos medidas de protección en salud que busquen evitar que los lactantes, los niños y los adolescentes sufran de obesidad, buscando que el sistema de salud detecte en un tiempo acorde a la prevención la obesidad en niños y adolescentes.

Dentro de los fines sugeridos por los científicos están los de reducir el riesgo de morbilidad y mortalidad debido a las enfermedades no transmisibles, atenuar los efectos psicosociales negativos de la obesidad tanto en la infancia como en la edad adulta para poder limitar el riesgo en futuras generaciones por obesidad. El proceso tuvo una duración de dos años para para tratar de hallar una respuesta a los alarmantes niveles de obesidad y sobrepeso infantil a nivel mundial.

En el informe de la Comisión se presenta una serie de recomendaciones a los gobiernos cuya finalidad es revertir el aumento de movilidad por obesidad en menores de cinco años, se prevé que son alrededor de 41 millones de niños de este grupo poblacional (0-5 años) son obesos o padecen sobrepeso, está situación es visible especialmente en los países de ingresos bajos y medios, es por ello que a continuación se enuncian las recomendaciones dadas.

Recomendaciones:

1. Garantizar la elaboración de información y directrices sobre nutrición adecuadas y adaptadas a contextos específicos, tanto para adultos como para niños, y su difusión 
por medios sencillos, comprensibles y accesibles para todos los grupos de la sociedad.

2. Establecer un impuesto eficaz sobre las bebidas azucaradas.

3. Aplicar el Conjunto de recomendaciones sobre la promoción de alimentos y bebidas no alcohólicas dirigida a los niños, con objeto de reducir la exposición de los niños y los adolescentes a la promoción e influencia de los alimentos malsanos.

4. Elaborar perfiles de nutrientes para identificar los alimentos y bebidas malsanos.

5. Impulsar la cooperación entre los Estados Miembros para reducir los efectos de la promoción transfronteriza de bebidas y alimentos malsanos.

6. Poner en marcha un sistema mundial normalizado de etiquetado de nutrientes.

7. Poner en marcha un etiquetado del frente del envase fácil de interpretar apoyado en la educación del público para que tanto los adultos como los niños tengan conocimientos básicos en materia de nutrición.

8. Exigir que en entornos como escuelas, centros de cuidados infantiles e instalaciones y eventos deportivos frecuentados por niños se creen ambientes de alimentación sana.

9. Incrementar el acceso a alimentos sanos en grupos de población desfavorecidos

Según el informe, muchos niños crecen hoy en día en entornos que propician el aumento de peso y la obesidad. Los procesos de globalización y urbanización están contribuyendo a la creciente exposición a entornos no saludables (obesogénicos) en los países de ingresos altos, medianos y bajos y en todos los grupos socioeconómicos. Se ha observado que la comercialización de bebidas no alcohólicas y alimentos malsanos es uno de los principales motivos del aumento del número de niños con sobrepeso y obesos, sobre todo en el mundo en desarrollo, véase en la figura 1 (Organización Mundial de la Salud, 2016) 
Según este informe de la OMS entre 1990 y 2014, la prevalencia del sobrepeso entre los niños menores de cinco años pasó de un 4,8\% a un 6,1\% y el número de niños afectados, de 31 a 41 millones. En los países de ingresos medianos bajos el número de niños con sobrepeso se multiplicó por más de dos en ese mismo periodo, pasando de 7,5 a 15,5 millones. En 2014, casi la mitad de todos los niños menores de cinco años con sobrepeso y obesidad (48\%) vivían en Asia, y una cuarta parte de ellos (25\%) en África. El número de niños menores de cinco años con sobrepeso prácticamente se ha duplicado en África desde 1990, pues ha pasado de 5,4 a 10,3 millones. (Organización Mundial de la Salud, 2016)

Figura 1. Porcentaje de obesidad infantil en el mundo

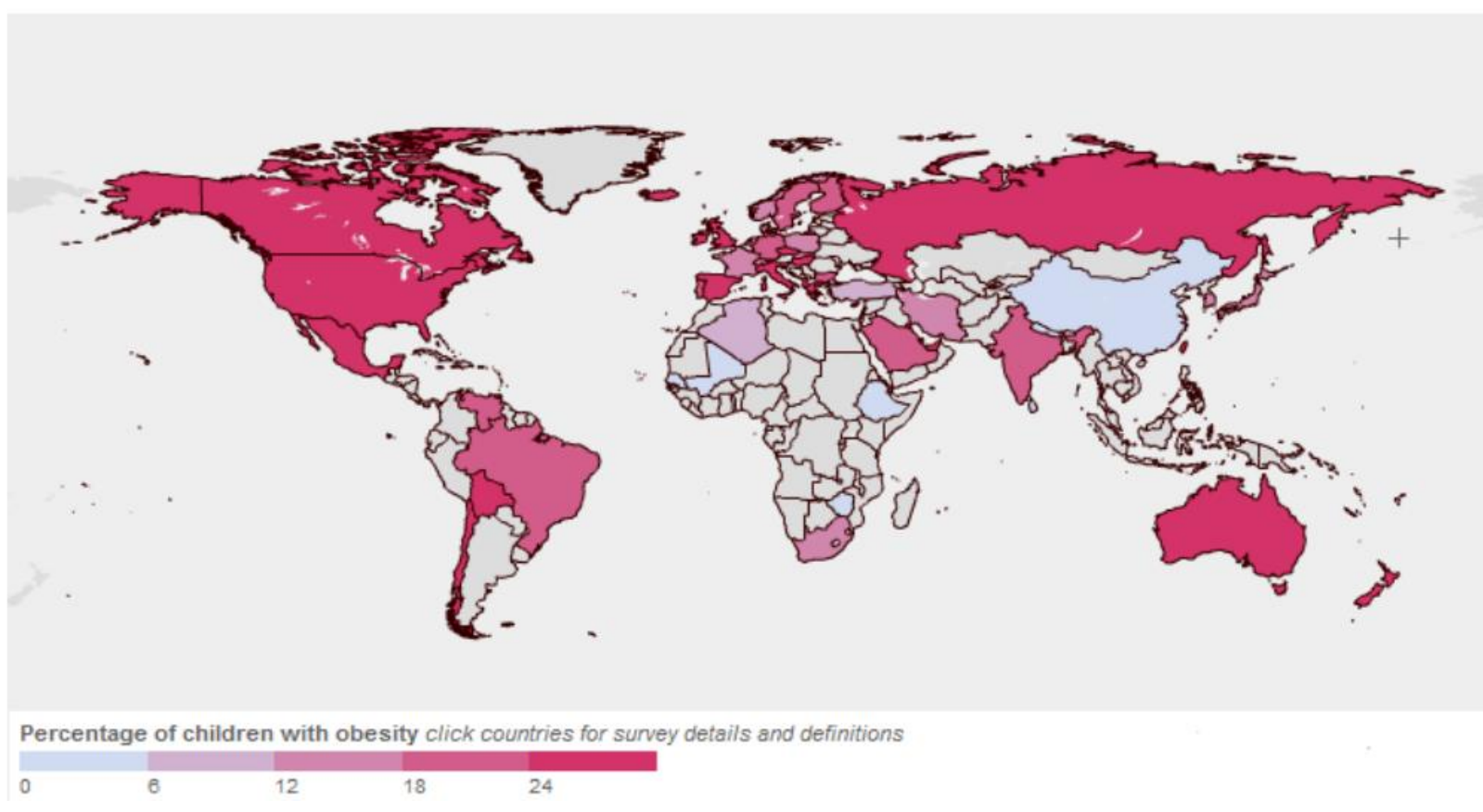

Fuente: IASO . https://www.google.com.co/sarch (2012)

Ahora bien, si se tratase de revisar cuales son los elementos que se deben tener en cuenta dentro de los elementos que hacen parte del ciclo de la enfermedad, habría que nombrar los siguientes que según la OMS hacen parte de los actores a tener en cuenta para formular un plan para paliar la situación: 1. Obesidad Pediátrica - prevención y control. 2.Niño. 3.Conducta Alimentaria. 4.Hábitos Alimenticios. 5.Ejercicio. 6.Dieta. 7.Promoción de la Salud. 8.Programas Nacionales de Salud. 
En el caso colombiano, el ministerio de salud formulo inicialmente la Encuesta Nacional de la Situación Nutricional en Colombia (ENSIN), contratada por él (Ministerio de salud, 2015) fue el instrumento utilizado para tomar como referencia sobre la estadística respecto al tema de obesidad.

la encargada de realizar la operación estadística de referencia nacional en torno a la situación nutricional de la población colombiana; se desarrolla a partir del 2005 de manera quinquenal y hace parte de las encuestas poblacionales de interés estratégico para la política pública, su objetivo fundamental es estimar la prevalencia de los principales problemas nutricionales que afectan a la población colombiana y algunos de sus determinantes como insumo que brinde información de gran importancia para apoyar la toma de decisiones políticas y técnica en su intervención. (Ministerio de salud, 2015)

Como antecedente se puede poner el informe del año 2010 se realizó un estudio poblacional de cobertura nacional con representatividad urbana y rural, para 6 regiones, 14 subregiones y 32 departamentos arrojando los siguientes resultados:

El 51,2\% de la población adulta colombiana padece sobrepeso u obesidad, siendo los departamentos de San Andrés y Providencia y Guaviare, los que presentan las prevalencias más elevadas (65,0 y 62,1\%, respectivamente). Así mismo, el 17,1\% de la población infantil entre los 5 y 17 años tiene exceso de peso, siendo los valores de este indicador de 31,1 y 23,7\% en las islas de San Andrés y Providencia y en la ciudad de Cali, respectivamente.14 El incremento del exceso de peso ha sido especialmente notorio en la población infantil de 5 a 9 años, la cual pasó de tener una prevalencia del 14,3\% en el año 2005, a 18,9\% en 2010.1. La prevalencia de sobrepeso u obesidad ha aumentado un 25,9\% en el último quinquenio. • Uno de cada 6 niños y adolescentes presenta sobrepeso u obesidad; esta relación aumenta a medida que se incrementa el nivel del SISBEN y el nivel educativo de la madre (9,4\% en madres sin educación vs $26.8 \%$ en madres con educación superior). El exceso de peso es mayor en el área urbana 19,2\% que en el 13,4\% rural. Los departamentos con mayores prevalencias de sobrepeso u obesidad con 31,1\% San 
Andrés, 22,4\% Guaviare y 21,7\% Cauca. (Instituto Colombiano de Bienestar Familiar, 2010)

En 2015 la Encuesta poblacional ENSIN desarrollo un proceso de muestreo probabilístico de conglomerados y polietápico, teniendo como objetivo la población tomada en cuenta fue de las áreas urbanas y rurales de 1.122 municipios de 32 departamentos de Colombia, arrojó resultados por departamentos que se exponen a continuación:

El informe con relación al sobre peso por departamento, en la región central para escolares de 5 a 12 años se encuentra Risaralda con 29,8\%, Quindío 29,2\%, Antioquia 28,1, Huila 27,0\%, Tolima 25,4\%, Caldas 25,1\% y Caquetá 25,0\%. Para los rangos de edades entre 13 y 17 años se encuentra exceso de peso en Caquetá 27,0\%, Huila 23,9\%, Quindío 22, $2 \%$, Antioquia 21,1\%, con sobre peso Caldas 17,6\%, Risaralda 17,4\%, Tolima 15,9\%. con Según índice de riqueza y etnia el exceso de peso en mayor se presenta en la opción sin pertenencia étnica e índice de riqueza alto. Entre adolescentes entre 13 y 17 años el exceso de peso se da en mujeres con un porcentaje de 21,2\% y para los hombres $14,8 \%$. En 2010 se encontraban en 15,5\% y para 2015 aumentó 17,9 \% con un aumento de 2,4 puntos porcentuales. (Ministerio de salud, 2015)

Una vez revisados los datos, es claro que la obesidad se está convirtiendo en un mal endémico en la población colombiana (ver en la figura 2), va en aumento, pero sorprendentemente la tasa de desnutrición infantil viene disminuyendo, esto es significativo e importante, ya que ayuda a determinar los elementos de morbilidad y morfológicos a tener en cuenta dentro del perfil epidemiológico que caracteriza y determina la población a intervenir por medio de la prevención de acuerdo a las recomendaciones ya mencionadas por la OMS. 


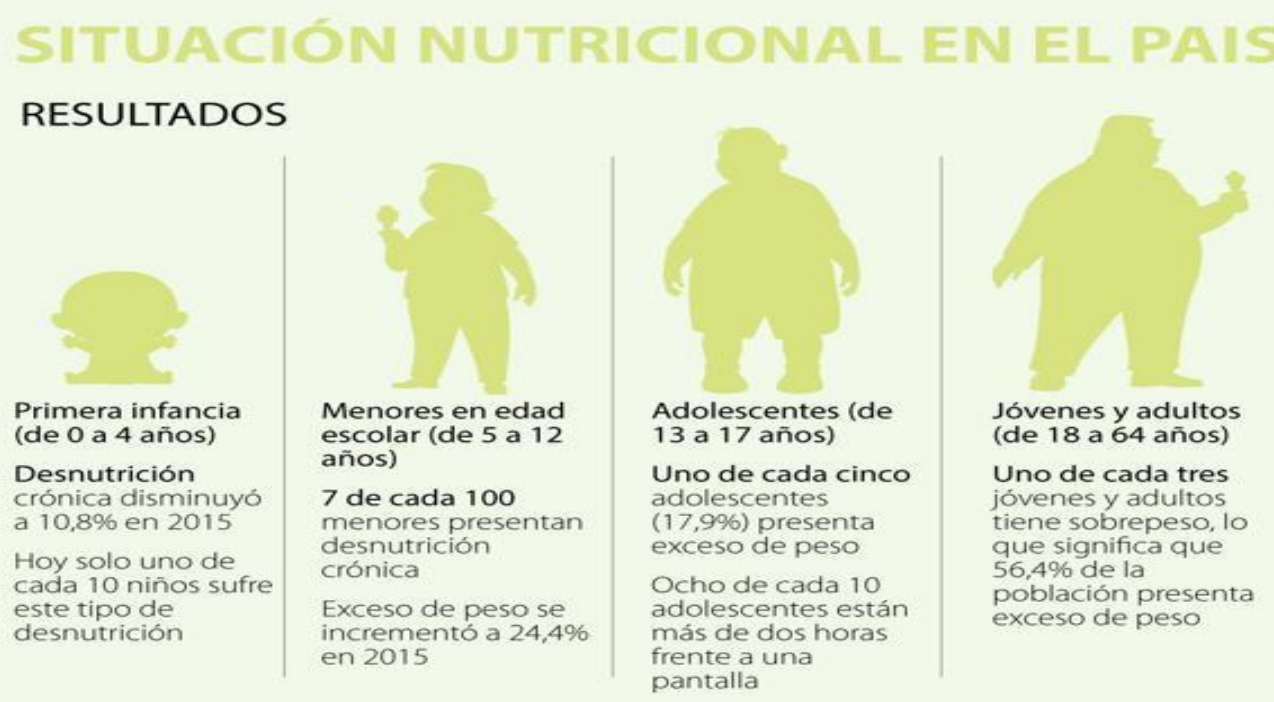

Fuente: Ensin 2015

Fuente: $\quad$ https://www.larepublica.co/economia/uno-de-cada-10-ninos-tienendesnutricion-cronica-en-el-pais-segun-ensin-2572214 (2012)

Es una comparación dentro de los elementos poblacionales que se pueden intervenir y que requieren de atención para lograr una manera de prevenir desde los más pequeños la obesidad mórbida, así como lograr que no es un fenómeno que avance de manera desproporcionada por medio de la repetición de costumbres que puedan ser heredadas, es decir se debe cambiar la cuestión cultural para obtener resultados en la materia.

\section{Factores de Riesgo de obesidad Infantil - Adolescente Obesidad - Sobrepeso}

La OMS define en el informe para acabar con la obesidad cuando se puede hablar de sobrepeso; referido al Índice de Masa Corporal (IMC), igual o superior a 25, Obesidad: IMC igual o superior a 30

En ese sentido, la obesidad infantil puede tomarse como una enfermedad caracterizada por un cumulo de grasa neutra en el tejido adiposo superior al $20 \%$ del peso corporal de una persona en dependencia de la edad, la talla, y el sexo debido a un balance 
energético positivo mantenido durante un tiempo prolongado se asocia con una mayor probabilidad de obesidad muerte y discapacidad en la etapa adulta.

La causa fundamental del sobrepeso y la obesidad es un desequilibrio energético entre calorías consumidas y gastadas, a nivel mundial ha ocurrido lo siguiente: Un aumento en la ingesta de alimentos de alto contenido calórico que son ricos en grasa; y un descenso en la actividad física lo que se asocia con el sedentarismo, estilos de vida, hábitos y costumbres

Numerosos informes señalan que la prevalencia de obesidad en niños y adolescentes se ha incrementado notablemente en las últimas dos décadas, de tal manera que se ha convertido en un problema de salud pública.

Estudios epidemiológicos han identificado factores que en etapas tempranas pueden influir en el desarrollo de la obesidad en los niños y adolescentes como son: el peso materno (malnutrición), diabetes gestacional. Bajo peso al nacer, incremento notable en los primeros meses de vida, alimentos complementarios no recomendables en remplazo de la leche materna, gestantes fumadoras, bajo nivel educativo de los padres, factores no modificables, sedentarismo, costumbres y hábitos culturales.

Hoy en día se reconoce que esos individuos pueden llegar a ser adultos obesos con las complicaciones que aumentan el riesgo de morbilidad y mortalidad, es por ello que se ha señalado que la acumulación excesiva de grasa corporal que caracteriza a los sujetos con obesidad se asocia a cambios morfológicos y fisiológicos del tejido adiposo.

En estos niños y adolescentes se incrementa el riesgo de enfermedad cardiovascular, hipertensión arterial, diabetes; todo esto puede aumentar el desarrollo de problemas graves de salud en la etapa adulta (Cardiopatías, insuficiencia Cardiaca, Infartos, trombosis, problemas de circulación en miembros inferiores.

Desde el punto de vista respiratorio son frecuentes las apneas durante el sueño, menor tolerancia al ejercicio, tendencia a fatigas, dificultad en realización de actividades físicas y/o deportivas, desarrollar asma, aumentar síntomas asmáticos.

Es frecuente en ellos el síndrome metabólico, que se puede manifestar a partir de los ocho años de edad y se caracteriza por un conjunto de síntomas en el cuerpo humano; estos son: obesidad, colesterol y triglicéridos elevados, disminución de lipoproteínas de alta densidad, alteraciones del metabolismo de carbohidratos (glucosa en ayunas, tolerancia a la 
glucosa alterada o diabetes mellitus, a continuación, en la ilustración 3 se pueden evidenciar la prevalencia de los riesgos asociados a la obesidad en niños y adolescentes en Colombia, según (Reyes, Pérez García, Loya Méndez, \& Hidalgo Ruzzante, 2016) estos factores dentro la línea de medida estándar que lo componen las condiciones promedio de un joven según la OMS y su IMC que determina cuáles son las enfermedades que se presentan en los niños.

Figura 3. Prevalencia de enfermedades asociadas a la obesidad en infantes y adolescentes

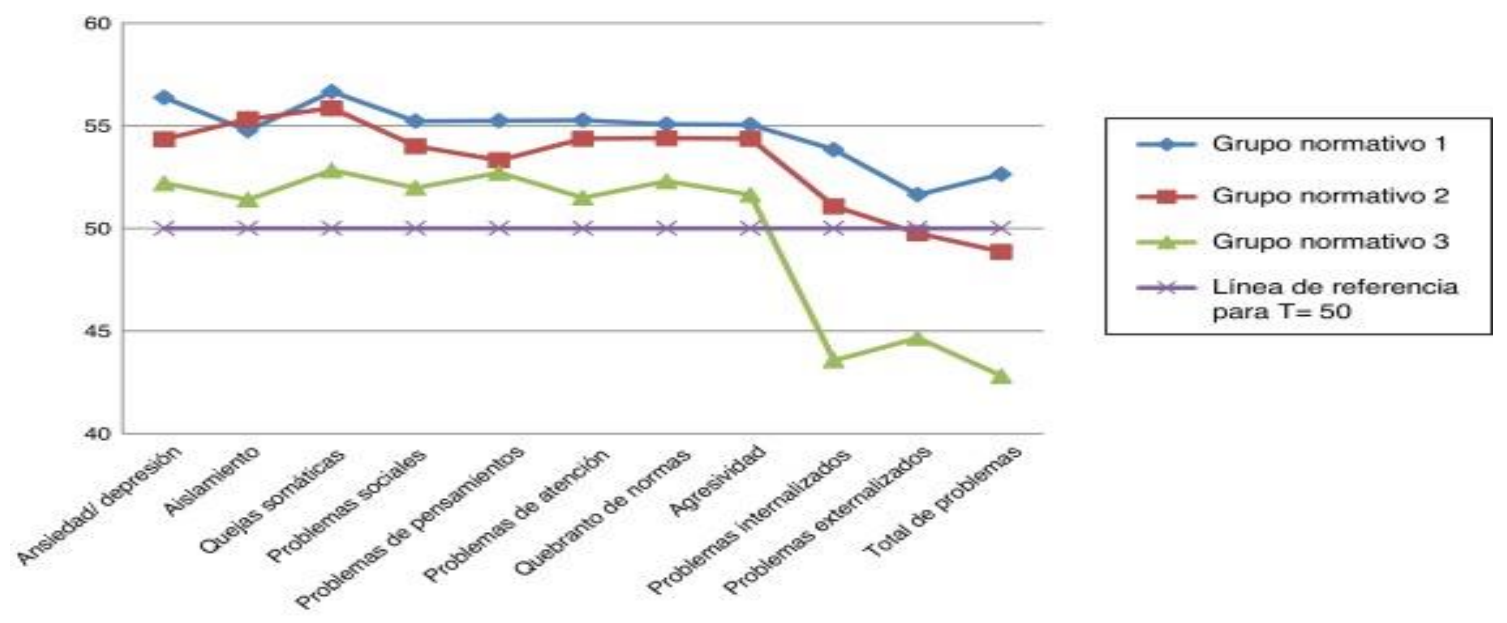

Fuente: http://www.elsevier.es/es-revista-revista-latinoamericana-psicologia-205articulo-perfiles-psicopatologicos-ninos-obesos-desnutridos-S012005341500062X (2016)

Así mismo, en un informe científico se definen otras patologías asociadas a la morbilidad por obesidad

El aumento de peso corporal predispone a deformidades ortopédicas; como: Genu Valgo, Coxa Vara, Deslizamientos epifisiarios de la cabeza del fémur, arcos planos e inflamación de la placa de crecimiento en los talones. Presentan una tendencia a madurar prematuramente (los niños con sobrepeso de causa exógena), su edad ósea esta generalmente más avanzada, la terminación del crecimiento suele ocurrir más tempranamente. Las niñas suelen tener Menarquia prematuramente, ciclos menstruales irregulares, y posibles problemas de fertilidad en la etapa adulta. (Milian, 2009) 
Es por ello que son frecuentes los trastornos hepáticos y biliares, así como el hígado graso, colelitiasis, anemia por déficit de hierro debido a las prácticas dietéticas con alimentación elevada en calorías. En otro frente, desde el ámbito comportamental la depresión aparece, especialmente en la adolescencia, en donde se aísla de manera voluntaria de su grupo de pares por la baja autoestima que le produce su figura y la percepción que tiene de sí mismo.

Lo anterior confirma según (Hernández, 2011), que el sobrepeso y la obesidad están asociados a múltiples factores que se convierten en riesgos que afectan de manera negativa la salud de niños y adolescentes, llevando a que sean muchas enfermedades asociadas que en secuencia actúan sobre un individuo en donde influyen factores genéticos, ambientales y conductuales.

Los factores genéticos, rigen la capacidad o facilidad de acumular energía en forma de grasa tisular y menor facilidad deliberarla en forma de calor, lo que se denomina elevada eficiencia energética del obeso, se produce porque a largo plazo el gasto energético que presenta el individuo es inferior que la energía que ingiere. (Achor, Benítez Cima,, \& Bravo, 2009)

\section{Diabetes:}

Esta enfermedad según la (OMS, 2017) se puede definir como "una enfermedad crónica en la cual el cuerpo no puede regular la cantidad de azúcar, puede ser causada por muy poca producción de insulina o resistencia a la misma", a continuación, se muestra su patología (ver ilustración 1) 


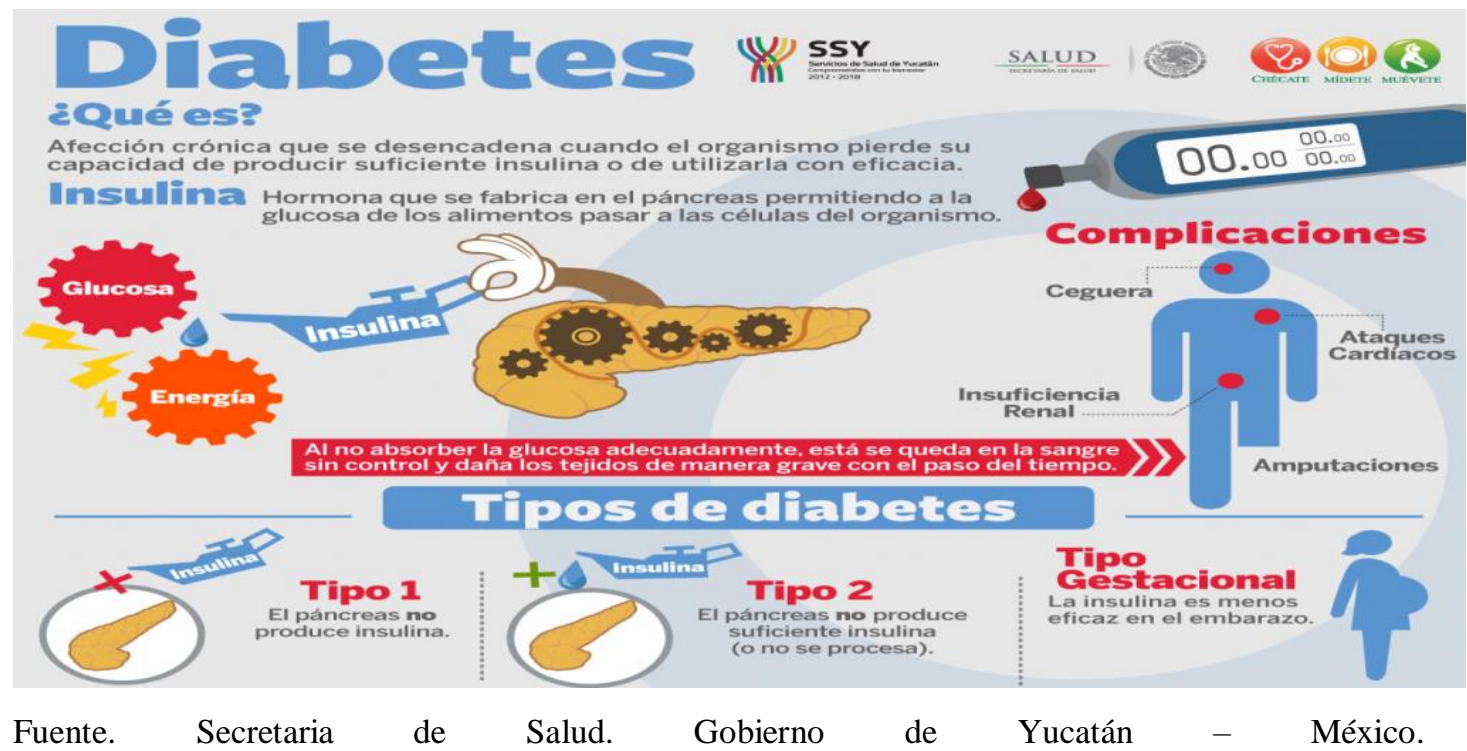

http://salud.yucatan.gob.mx/infografias/diabetes/ (2014)

\section{La Obesidad Infantil y la Diabetes}

La obesidad y el sobrepeso en niños y adolescentes se asocian con múltiples enfermedades entre ellas la Diabetes de Tipo 1 y Tipo 2. Que ayudan en la elevación de los niveles de azúcar como se puede evidenciar en la ilustración 1.

Esta enfermedad tiene etapas, una se declara no dependiente de insulina, esta se da en la etapa adulta, pero, debido a la morbilidad por obesidad en aumento debido a los altos porcentajes de sobrepeso y obesidad en niños y adolescentes donde el cuerpo es resistente a la insulina o no la sintetiza eficazmente. En los últimos 10 años se ha incrementado la prevalencia de Diabetes Mellitus tipo 2, y generalmente está asociada a la obesidad en adolescentes y se correlaciona de manera directa con la insulinemia basal y estimulada por glucosa, y negativa con la sensibilidad a la insulina.

Se sugieren cuatro líneas de evidencia:

1. La sensibilidad a la insulina en niños pre púber y púber se correlaciona inversamente con el IMC y el porcentaje de grasa corporal. 
2. La obesidad severa se asocia con altos índices (21-25\%) de intolerancia a la glucosa en niños pre púberes y en adolescentes.

3. El aumento de IMC en niños se correlaciona con el desarrollo del síndrome metabólico (obesidad, hipertensión, hiperinsulinemia y dislipidemia) y, en consecuencia, con Diabetes Mellitus tipo 2 y enfermedad cardiovascular. (Baron \& Márquez, 2010)

La diabetes y el sobrepeso como ya se ha mencionado anteriormente puede comenzar en la temprana infancia, pasar a la adolescencia e incrementar el riesgo a la intolerancia a la glucosa y diabetes tipo 2 en la adultez.

En ese sentido dicen (Baron \& Márquez, 2010) que la obesidad visceral también va acompañada de incremento de ácidos grasos libres en ayuno y posprandiales. Los ácidos grasos que fluyen en la circulación provocan acumulación de triglicéridos hepáticos, producción excesiva de lipoproteínas de muy baja densidad y, de manera secundaria reducción de las concentraciones de lipoproteínas de alta densidad (HDL)

Los incrementos en las concentraciones de glucosa se agudizan por la resistencia a la insulina y por la acción del factor del crecimiento de insulina en el músculo esquelético. En adolescentes obesos, la cantidad de triglicéridos en los músculos varia con la masa grasa visceral

\section{Obesidad infantil-Hipertensión}

\section{Hipertensión:}

Según la OMS es el término que se utiliza para determinar la presión arterial alta, que puede ser dado por el exceso de grasa corporal que contribuye a elevar la presión arterial desde la infancia en un estudio de la Universidad Nacional de Colombia se ha comprobado que por cada 10 kilos de peso ganado se produce un incremento de la tensión arterial de unos 2-3 mm Hg, lo cual aumenta el riesgo cardiovascular, y la grasa acumulada, especialmente la ubicada a nivel abdominal para la composición corporal. Además de 
causar hipertensión, el sobrepeso y la obesidad en niños y adolescentes como se mencionó anteriormente causa otras patologías asociadas a lo cardiovascular.

\section{Medición de Factores de Riesgo y Protectores}

Las mediciones que toman lugar en el estudio para detectar los factores de riesgo y protectores de riesgo cardiovascular relacionado con sobrepeso y obesidad en escolares, son:

\section{Índice de masa corporal.}

De acuerdo a la Organización mundial de la salud (OMS) se puede definir el índice de masa corporal (IMC) como "un indicador simple de la relación entre el peso y la talla que se utiliza frecuentemente para identificar el sobrepeso y la obesidad en los infantes." (OMS, 2017.), es por ello que el presente estudio se centra en estudiantes entre los 6 y los 19 años teniendo como referente el índice de masa corporal como instrumento de diagnóstico inicial de tipo clasificatorio de los estudiantes según su peso.

Este instrumento de medición del IMC sirve para utilizarlo en saber cómo se calcula, esto a través de la siguiente formula: dividiendo el peso de una persona en kilos por el cuadrado de su talla en metros $\left(\mathrm{kg} / \mathrm{m}^{2}\right)$.

Dado que inicialmente se ha pensado el IMC como un instrumento de medición para adultos, las tablas de clasificación más comunes incluyen categorías como: peso insuficiente, peso normal, sobrepeso grado I, sobrepeso grado II (pre- obesidad), obesidad de tipo I, obesidad de tipo II, obesidad de tipo III (mórbida), obesidad de tipo IV (extrema). Sin embargo, tomando en cuenta la muestra- población objeto de este estudio, adoptamos la propuesta de la OMS para medición de niños y adolescentes.

El índice de masa corporal (IMC) se usa comúnmente como un marcador sustituto de la adiposidad. Sin embargo, el IMC indica el peso por altura sin considerar las diferencias en la composición corporal y la contribución de la grasa corporal al peso corporal total. 
Estas categorías de medición permiten evaluar la información por genero inicialmente y cruzando información en relación al IMC con respecto a la edad de la población. De esta forma se hace una medición más adecuada que tiene en cuenta las diferencias y las expectativas para niños/adolescentes y niñas/adolescentes. La información en las gráficas se triangula utilizando percentiles de medición que proveen una información más completa.

Tabla 1. Factores de riesgo por escolar según IMC e ICT.

\begin{tabular}{|c|c|c|c|c|c|c|c|c|c|c|c|c|}
\hline \multirow{2}{*}{$\begin{array}{c}\text { Frecuencia de } \\
\text { anomalías }\end{array}$} & \multicolumn{2}{|c|}{0} & \multicolumn{2}{|c|}{1} & \multicolumn{2}{|c|}{2} & \multicolumn{2}{|c|}{3} & \multicolumn{2}{|c|}{4} & \multicolumn{2}{|c|}{5} \\
\hline & $\mathrm{n}$ & $\%$ & $\mathrm{n}$ & $\%$ & $\mathrm{n}$ & $\%$ & $\mathrm{n}$ & $\%$ & $\mathrm{n}$ & $\%$ & $\mathrm{n}$ & $\%$ \\
\hline Escolares con & & & & & & & & & & & & \\
\hline $\begin{array}{l}\mathrm{IMC}=75 \mathrm{y}= \\
84,9\end{array}$ & 4 & 14.8 & 3 & 11.1 & 3 & 11.1 & 2 & 7.4 & 2 & 7.4 & 1 & 3.7 \\
\hline $\begin{array}{l}\text { Escolares con } \\
\mathrm{IMC}=85\end{array}$ & 2 & 7.4 & 3 & 11.1 & 3 & 11.1 & 4 & 14.8 & - & - & 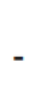 & - \\
\hline $\begin{array}{l}\text { Escolares con } \\
\mathrm{ICT}=0.50 * *\end{array}$ & - & & - & & 3 & 11.1 & - & & - & & - & \\
\hline $\begin{array}{l}\text { Escolares con } \\
\mathrm{ICT}=0.51 * *\end{array}$ & 6 & 22.2 & 6 & 22.2 & 3 & 11.1 & 6 & 22.2 & 2 & 7.4 & 1 & 3.7 \\
\hline
\end{tabular}

Escolares con IMC $>75 \mathrm{v}<84.9=15$. Escolares con IMC $>85=12 . \mathrm{N}=27$. Significativo ${ }^{(* *)}$ cuando $\mathrm{p}<0.01$.

Fuente: https://tabasco.gob.mx/sites/default/files/users/ssaludtabasco/921.pdf (2010)

Clasificación antropométrica del estado nutricional para niñas, niños y adolescentes de 5 a 17 años, según el indicador y punto de corte. Indicador Punto de corte (desviaciones estándar DE.) Clasificación Antropométrica Tipo de Uso Talla para la Edad (T/E) $\geq-1$ Talla Adecuada para la Edad. Individual y Poblacional $\geq-2$ a $<-1$ Riesgo de Retraso en Talla. $<-2$ Talla Baja para la Edad o Retraso en Talla. IMC para la Edad (IMC/E)* > +2 Obesidad $>+1 \mathrm{a} \leq+2$ Sobrepeso $\geq-1 \mathrm{a} \leq+1$ IMC Adecuado para la Edad $\geq-2 \mathrm{a}<-1$ Riesgo de Delgadez < -2 Delgadez *En el IMC para la Edad, +1(DE) es equivalente a un IMC de $25 \mathrm{Kg} / \mathrm{m} 2$ a los 19 años y, +2 (DE) es equivalente a un IMC de $30 \mathrm{~kg} / \mathrm{m} 2$ en la misma edad, lo cual guarda relación con el IMC utilizado en la clasificación antropométrica nutricional de los adultos. 
Figura 4. Índice de masa corporal Niños y Adolescentes Indice de Masa Corporal - NIÑOS y ADOLESCENTES Patrones de crecimiento de la OMS 2007 - 5 a 19 años (percentiles)

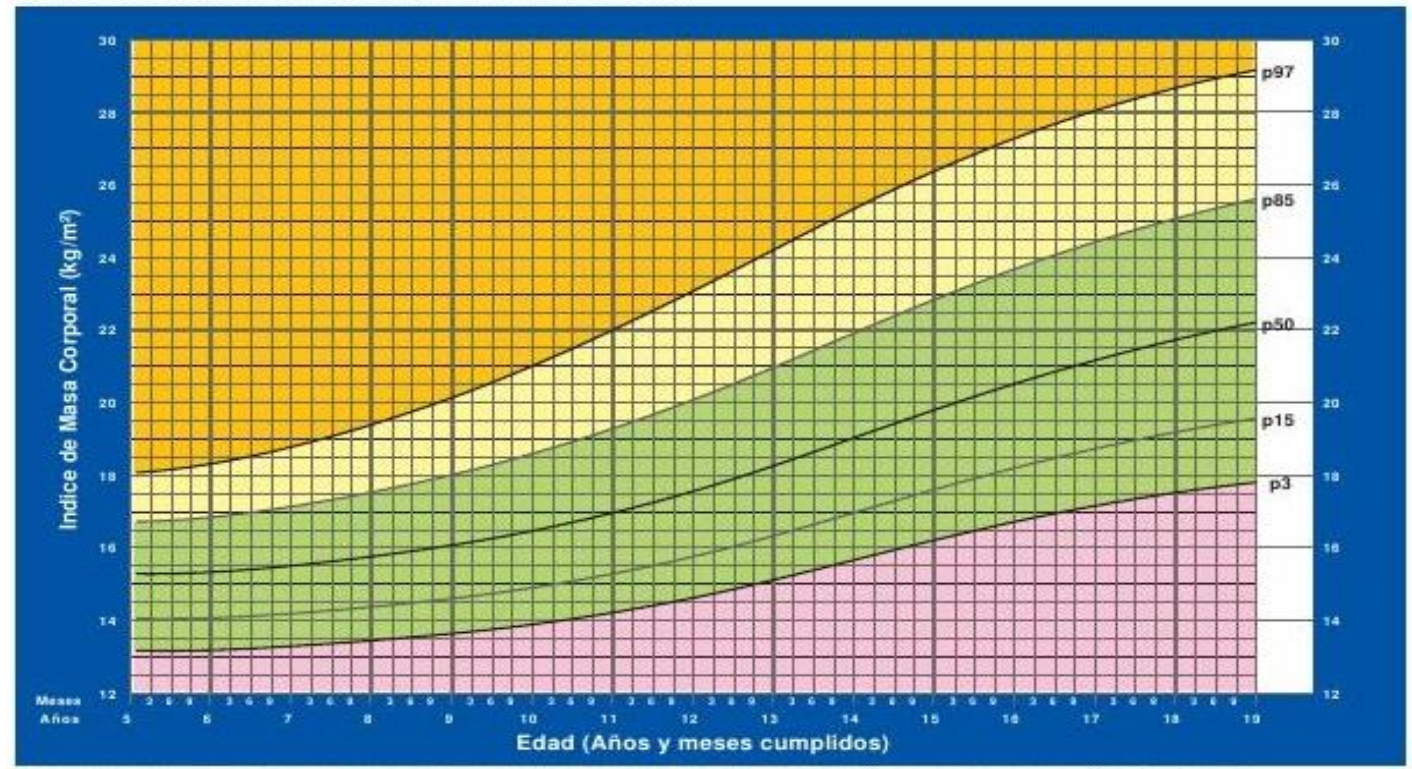

Fuente: OMS (2007)

Figura 5. Índice de masa corporal Niños y Adolescentes en percentiles

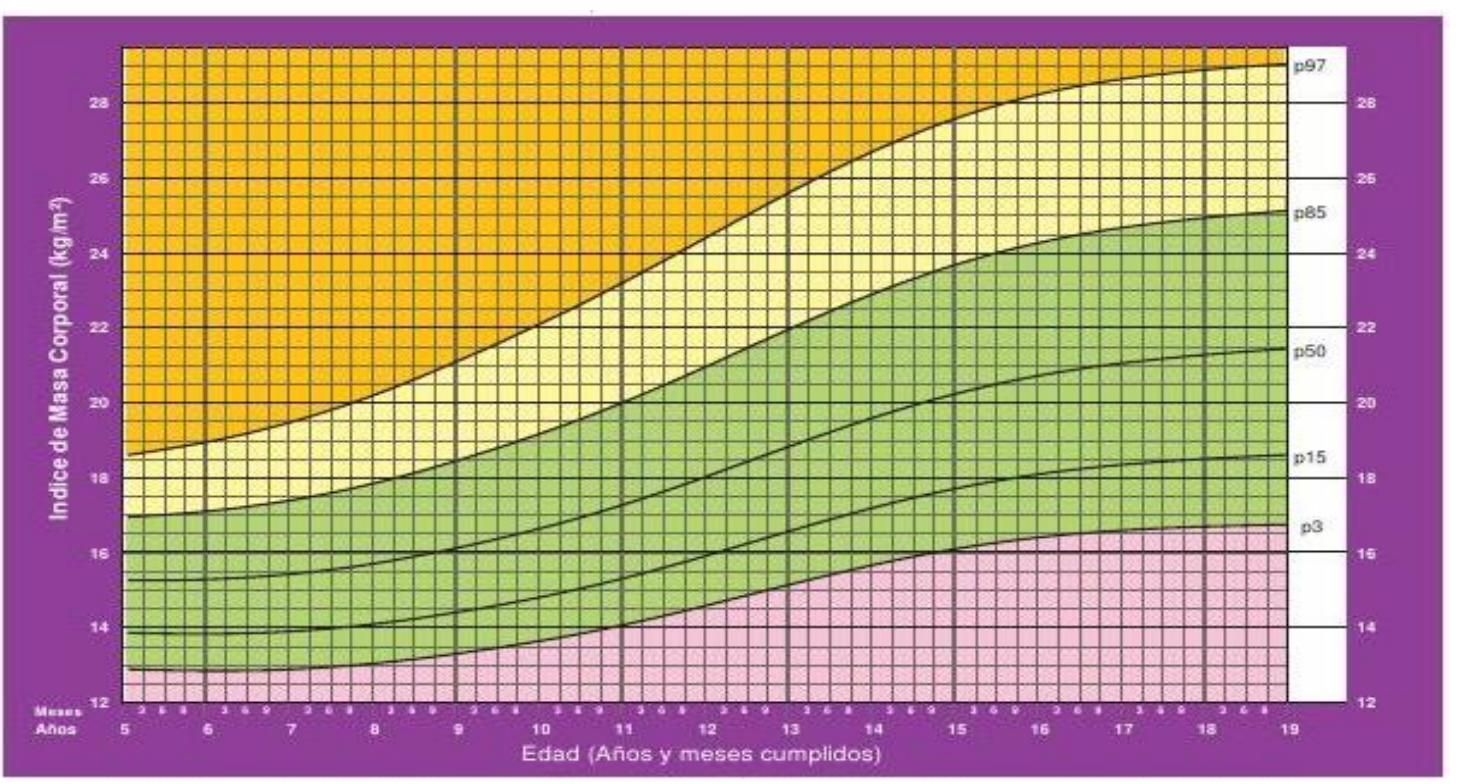

Fuente: OMS (2007) 
El índice de masa corporal (IMC) es una medida del peso de una persona con respecto a su estatura. Es más, un indicador que una medición directa de la grasa corporal total de una persona. El IMC, la mayoría de las veces, se correlaciona con la grasa corporal total, esto significa que a medida que aumenta la puntuación de IMC, también lo hace la grasa corporal total de una persona.

La (OMS, s.f. ) define a un adulto que tiene un IMC entre 25 y 29.9 como sobrepeso, un adulto que tiene un IMC de 30 o más se considera obeso - un IMC menor de 18.5 se considera bajo peso, y entre 18.5 a 24.9 un peso saludable, el IMC en un individuo se calcula mediante el uso de una fórmula matemática. También se puede estimar utilizando tablas en las que se puede hacer coincidir la altura en pulgadas con el peso en libras para estimar el IMC. Hay calculadoras convenientes disponibles en los sitios de Internet que también ayudan a calcular el IMC.

La fórmula es $-\mathrm{IMC}=($ Peso en kilogramos) dividido por (Altura en metros al cuadrado) un puntaje de IMC normal es uno que cae entre 18.5 y 24.9. Esto indica que una persona está dentro del rango de peso normal para su altura (Instituto Nacional del Corazón, los Pulmones y la Sangre de los Estados Unidos, 2016). Una tabla de IMC se utiliza para categorizar a una persona con bajo peso, normal, con sobrepeso u obesidad.

\section{Valores IMC en niños y adolescentes}

Para la búsqueda del percentil se tuvo en cuenta el género, la edad y el IMC, utilizando las tablas de IMC para niños y adolescentes sugeridas por la (OMS)

Se utilizó la medida del Percentil. Es la posición de un individuo respecto al dado por una población de referencia, expresada en términos de qué porcentaje del grupo de individuos es igual o diferente. 
Los valores en que se clasifica la población tienen un rango de ubicación que va: por debajo de percentil 3; entre 3 al 15; entre 16 al 50; entre 51 al 85; entre 85 al 97; y superior al percentil 97. (Kaufer-Horwitz \& Toussaint, 2008)

Para cada dato se asignó una clasificación por colores

Tabla 2. Porcentaje de grasa corporal en niños

COLOR

COLOR ROSADO

COLOR VERDE

COLOR VERDE

COLOR VERDE

COLOR AMARILLO

COLOR NARANJA

Fuente de elaboración: Propia
VALORACIÓN

bajo peso

Normal

Normal

Normal

Sobrepeso

Obesidad

\section{UBICACIÓN}

por debajo de 3

3 al 15

16 al 50

51 al 85

85 al 97

Superior al percentil 97.

A continuación, se describe el índice de cintura talla, y su importancia para este estudio.

\section{Índice cintura talla.}

El índice de cintura talla (ICA) se define como la relación entre la medida del perímetro de la cintura y la altura, el cual se expresa en las mismas unidades de longitud. Entre las ventajas de su uso se pueden datar entre otras que "en el consenso internacional entre organizaciones de 2009 se propuso al índice cintura talla como el mejor predictor para el desarrollo de los componentes del síndrome metabólico” (Muñoz, 2010, pág. 5), de igual forma se determinó "el aumento de la grasa intra abdominal como indicador sensible de riesgo para enfermedad crónica” (Muñoz, 2010, pág. 5). 
Tabla 3. Datos de antropometría.

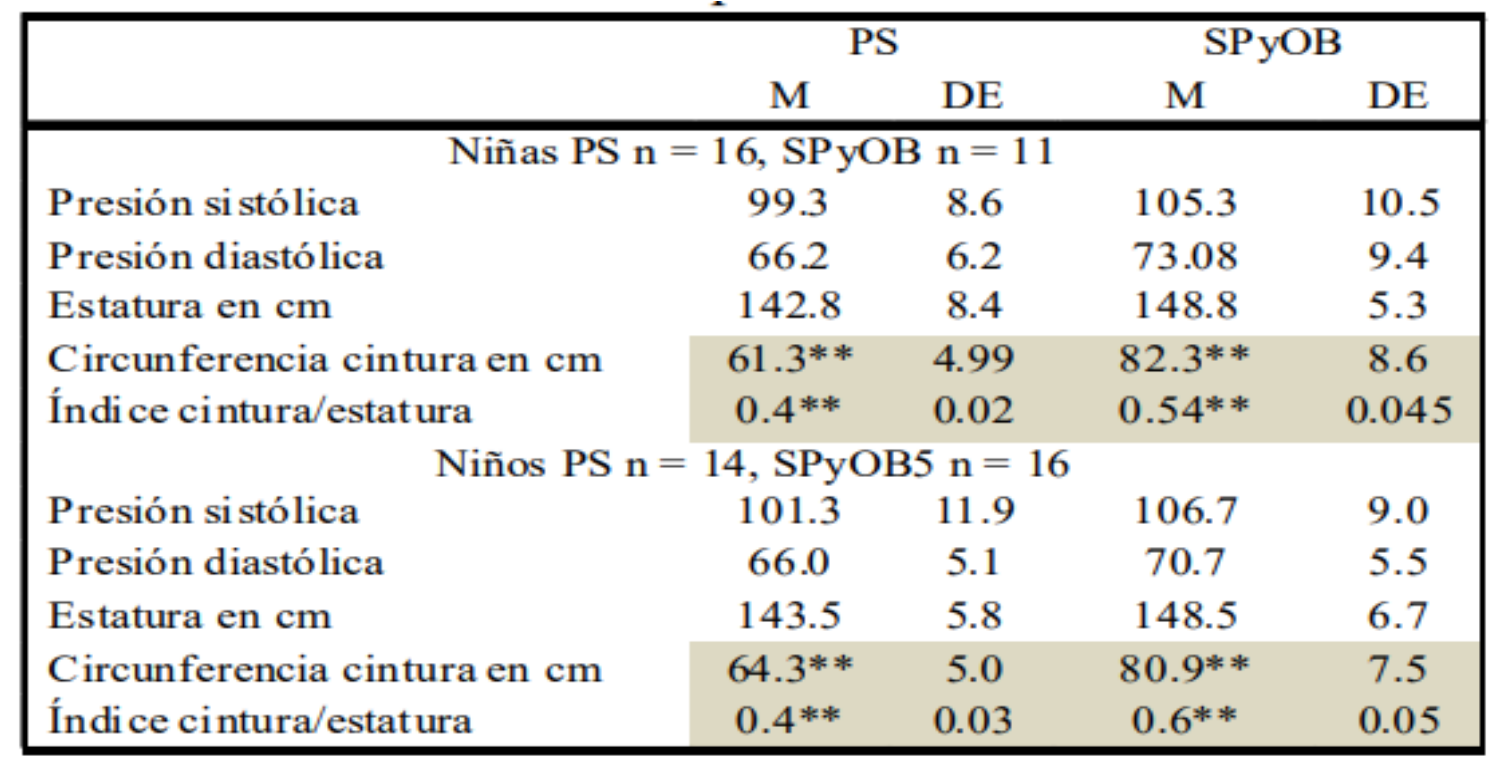

Fuente: https://tabasco.gob.mx/sites/default/files/users/ssaludtabasco/921.pdf (2014)

Por ser un instrumento de medición se debe hacer de la forma adecuada, el ICA se calcula dividiendo la circunferencia de la cintura entre la altura del sujeto, ambas mediciones en las mismas unidades. ICA=cintura/altura (Universoformulas).

La circunferencia de la cintura se considera una buena estimación de la grasa corporal, especialmente de sus depósitos de grasa internos, y de su probabilidad de desarrollar enfermedades relacionadas con el peso.

Los profesionales de la salud a menudo usan el IMC y la circunferencia de la cintura para evaluar si alguien tiene sobrepeso u obesidad y para evaluar su riesgo de enfermedad cardiovascular y de diabetes.

Llevar exceso de grasa corporal alrededor de la cintura es más un riesgo para la salud que si tuviera peso en sus caderas y muslos. La circunferencia de la cintura tiene una mejor estimación de la grasa visceral, la peligrosa grasa interna que recubre los órganos. Por lo tanto, es un predictor más preciso del riesgo cardiovascular, la diabetes tipo 2 en las mujeres y el síndrome metabólico. 
Para conocer su nivel de riesgo, es importante medir la circunferencia de su cintura con precisión, de esa manera se coloca la cinta métrica directamente sobre la piel, o sobre no más de una capa de ropa ligera.

El lugar correcto para medir la cintura es la mitad de camino entre la costilla más baja y la parte superior de la cadera, esto está más o menos en línea con el ombligo, respirando normalmente y midiendo que la cinta esté ajustada, sin apretar la piel, esto lleva a que se considere que hay una relación entre la circunferencia de la cintura y el riesgo de enfermedad cardiovascular

Estos son los umbrales de circunferencia de la cintura que indican un mayor riesgo de enfermedad:

Si es mujer:

su riesgo aumenta a $80 \mathrm{~cm}$ o más su riesgo es alto a $88 \mathrm{~cm}$ o más

Si es hombre:

su riesgo aumenta a $94 \mathrm{~cm}$ o más su riesgo es alto a $102 \mathrm{~cm}$ o más

Limitaciones de la circunferencia de la cintura

La circunferencia de la cintura es menos precisa en algunas situaciones, incluido el embarazo; donde la persona tiene una condición médica que involucra la ampliación del abdomen; para ciertos grupos étnicos; y para niños y jóvenes.

Si bien la circunferencia de la cintura y el IMC son indicadores importantes de riesgo, muchos otros factores también contribuyen a la enfermedad, existen otras formas de mejorar el estado de salud en la población, que incluyen:

- dejar de fumar

- aumentar la actividad física

- mejorar la dieta 
- reducir el consumo de alcohol

- tratar otros factores de riesgo como la presión arterial alta y el colesterol alto - asegurando que duermas lo suficiente.

Para finalizar este apartado es conveniente recordar que, el aumento de la actividad física y una dieta mejorada ayudarán a reducir su riesgo de enfermedad y tendrán beneficios para la salud que no están directamente relacionados con la pérdida de peso.

\section{Contorno de cintura}

Se puede considerar este concepto como una línea arbitraria que rodea la parte más estrecha de la cintura, así como la ropa que cubre la cintura, siendo esta la circunferencia del cuerpo en la cintura.

La circunferencia de la cintura es un simple control para saber si existe exceso de grasa corporal alrededor de su medio, ya que donde este localizada la grasa puede ser una señal importante del riesgo de desarrollar problemas de salud continuos, es por ello que tener exceso de grasa corporal alrededor la cintura es más un riesgo para la salud que si tuviera peso en sus caderas y muslos.

Independientemente de la altura o contextura, para la mayoría de los adultos, una medida de cintura superior a $94 \mathrm{~cm}$ para hombres y $80 \mathrm{~cm}$ para mujeres es un indicador del nivel de depósitos de grasa internos que recubren el corazón, los riñones, el hígado, los órganos digestivos y el páncreas. Esto puede aumentar el riesgo de enfermedad cardíaca y accidente cerebrovascular. La medición de la cintura ayuda a evaluar el riesgo midiendo la cantidad de grasa que se lleva en su centro. Se puede utilizar junto con la medición de su índice de masa corporal (IMC). En conjunto, estas herramientas dan una indicación de su riesgo relacionado con el exceso de grasa corporal.

\section{Porcentaje de grasa corporal.}

El porcentaje de grasa es el indicador de la cantidad de grasa que contiene el cuerpo, este permite conocer la cantidad de grasa que se tiene de exceso y esta incrementa el riesgo de sufrir enfermedades como hipertensión, diabetes y fallo cardiaco. 
Se utiliza la siguiente ecuación para determinarlo

Tabla 4. Índice de tejido graso

\begin{tabular}{|c|c|}
\hline Hombres & \% grasa $=106.5$ X ICT -28.36 \\
\hline Mujeres & \% grasa $=89.73$ X ICT -15.14 \\
\hline
\end{tabular}

Fuente: Sociedad española de pediatría (2011)

Tabla 5. Porcentaje de grasa corporal en niños

\begin{tabular}{|c|c|c|c|c|}
\hline & Peso bajo percentil & $\begin{array}{c}\text { Peso normal percentil } \\
(\geq 5 \text { y }<55)\end{array}$ & $\begin{array}{c}\text { Sobrepeso percentil } \\
(\geq 85 \text { y } 95)\end{array}$ & $\begin{array}{l}\text { Obesidad } \\
\text { percentil }(\because 95)\end{array}$ \\
\hline Niños de 6 años & $\%$ & $\%$ & $\%$ & $\%$ \\
\hline Hombres & 3.1 & 53.1 & 21.9 & 21.9 \\
\hline Muieres & 14.6 & 56.1 & 12.2 & 17.1 \\
\hline Total & 9.6 & 54.8 & 16.4 & 19.2 \\
\hline \multicolumn{5}{|l|}{ Nĩuos de 7 años } \\
\hline Hombres & 2 & 51 & 16.3 & 30.6 \\
\hline Muieres & 8.2 & 72.1 & 8.2 & 11.5 \\
\hline Total & 5.5 & 62.7 & 11.8 & 20 \\
\hline \multicolumn{5}{|l|}{ Niños de 8 años } \\
\hline Hombres & 3.4 & 44.1 & 27.1 & 25.4 \\
\hline Muieres & 4.1 & 32.7 & 26.5 & 36.7 \\
\hline Total & 3.7 & 38.9 & 26.9 & 30.6 \\
\hline \multicolumn{5}{|l|}{ Niños de 9 años } \\
\hline Hombres & 4.6 & 49.2 & 20 & 26.2 \\
\hline Mujeres & 12.5 & 52.5 & 20.0 & 15 \\
\hline Total & 7.6 & 50.5 & 20 & 21.9 \\
\hline \multicolumn{5}{|l|}{ Niños de 10 años } \\
\hline Hombres & 3.9 & 56.9 & 11.8 & 27.5 \\
\hline Mujeres & 15.2 & 59.1 & 10.6 & 15.2 \\
\hline Total & 10.3 & 58.1 & 11.1 & 20.5 \\
\hline \multicolumn{5}{|c|}{ Niños de 11 años $\mathrm{y}$ más } \\
\hline Hombres & 2 & 20 & 32 & 46 \\
\hline Mujeres & 5.1 & 40.7 & 25.4 & 28.8 \\
\hline Total & 3.7 & 31.2 & 28.4 & 36.7 \\
\hline Hombres otal & 3.3 & 45.4 & 21.6 & 29.7 \\
\hline
\end{tabular}

Fuente:https://scielo.conicyt.cl/scielo.php?script=sci_arttext\&pid=S071795022013000400020

Tabla 6. Valores para la categorización de la población

Criterio de evaluación

Rango masculino
Rango femenino

$>10>15$

$10.01-20$

$15.01-25$

Adecuado

$20.01-25$

25.01-30

$>25.01$

$>30.01$

Excesivamente alto 
Fuente: Criterios De Evaluación Según Durenberg (2013)

La composición corporal es la proporción de masa libre de grasa y grasa en su cuerpo. Una composición corporal saludable es aquella que incluye un menor porcentaje de grasa corporal y un mayor porcentaje de masa libre de grasa, que incluye músculos, huesos

y órganos, la composición corporal se mide para evaluar su nivel de salud y estado físico. A menudo, tendrá la composición corporal medida al comienzo de un programa de adelgazamiento o de adecuación de peso y se controlará periódicamente para controlar su progreso.

El cuerpo se compone de dos tipos de masa: grasa corporal y masa libre de grasa, la grasa corporal se puede encontrar en el tejido muscular, debajo de la piel (grasa subcutánea) o alrededor de los órganos (grasa visceral). Es por ello importante aclarar que tener grasa en el cuerpo es normal, y necesaria para el desarrollo de la actividad metabólica, así como para el cuidado de la salud en general, esta también es llamada grasa esencial y ayuda a proteger los órganos internos, almacenas reservas para obtener energía y regula importantes hormonas del cuerpo, pero también puede tener un exceso de almacenamiento de grasa tanto corporal como no esencial.

La masa sin grasa incluye huesos, agua, músculos, órganos y tejidos. También se puede llamar tejido magro. Estos tejidos son metabólicamente activos, quemando calorías para obtener energía, mientras que la grasa corporal no lo es.

El porcentaje de grasa corporal es una medida de la composición del cuerpo que indica qué parte del peso de su cuerpo es grasa, este esta es una masa libre de grasa, se han formulado rangos normales de grasa corporal, que son diferentes para hombres y mujeres.

Los atletas tienden a tener menos grasa corporal, lo que puede ser beneficioso para el rendimiento en deportes como correr y andar en bicicleta, sin embargo, tener un porcentaje de grasa corporal extremadamente bajo es un problema de salud, la tríada para la atleta femenina aumenta el riesgo de lesiones y problemas de salud, además que incluye trastornos de la alimentación, amenorrea y disminución de la masa ósea con un mayor riesgo de fracturas por estrés y osteoporosis. 
De acuerdo a lo anterior, se dice que se encuentra en el cuerpo una cantidad excesiva en porcentaje de grasa corporal, esta puede mejorar la composición del cuerpo al ganar masa corporal magra mediante la construcción de músculos y huesos, y mediante la pérdida de los excesos que no son beneficios para el cuerpo.

Uno de los factores asociados con el estado de salud, se refiere a las arritmias generalmente se dividen en dos categorías: ventricular y supraventricular. Las arritmias ventriculares ocurren en las cámaras inferiores del corazón, llamadas ventrículos. Las arritmias supraventriculares ocurren en el área sobre los ventrículos, generalmente en las cámaras superiores del corazón, llamadas aurículas. Los latidos irregulares pueden ser demasiado lentos (bradicardia) o demasiado rápidos (taquicardia).

\section{Bradicardia}

La bradicardia es una frecuencia cardíaca muy lenta de menos de 60 latidos por minuto. Sucede cuando el impulso eléctrico que le indica al corazón que se contraiga no se forma en el marcapasos natural del corazón, el nódulo sinoauricular (nódulo SA), o no se envía a las cámaras inferiores del corazón (los ventrículos) a través de los canales adecuados.

La bradicardia afecta con mayor frecuencia a las personas de edad avanzada, pero puede afectar incluso a los más jóvenes, siendo causado por una de dos fuentes: el sistema nervioso central no indica que el corazón necesita bombear más, o el nodo SA puede dañarse. Este daño podría estar relacionado con enfermedades del corazón, envejecimiento, defectos hereditarios o congénitos, o podría ser causado por ciertos medicamentos, incluidos los utilizados para controlar las arritmias y la presión arterial alta.

\section{Taquicardia}

La taquicardia es una frecuencia cardíaca muy rápida de más de 100 latidos por minuto. Las muchas formas de taquicardia dependen de dónde comienza la frecuencia cardíaca rápida. Si comienza en los ventrículos, se llama taquicardia ventricular. Si comienza encima de los ventrículos, se llama taquicardia supraventricular. 


\section{Frecuencia cardiaca}

Aunque suene un poco extraño, los niños desarrollan también hipertensión, esta puede surgir a partir de varios factores de riesgo o puede ser hipertensión secundaria, como resultado de un problema de salud subyacente, esta se denomina hipertensión secundaria en niños, causada por ciertas enfermedades, así como algunos medicamentos, pueden causar presión arterial alta en los niños.

Otro de los factores hereditarios o relacionados con el estilo de vida, aunque la causa exacta no se diagnostica fácilmente, los médicos se dan cuenta de que una variedad de factores puede contribuir a la afección, que incluyen:

Historia familiar: Enfermedades genéticas

Exceso de peso u obesidad: Modo de vida de vida sedentario y exceso de consumo de azucares y grasas

Raza: al igual que los adultos afroamericanos, los niños afroamericanos también corren un mayor riesgo de presión arterial alta. Obtenga más información sobre los afroamericanos y la presión arterial alta.

\section{Tabla 7. Tabla Ritmo cardiaco}

\begin{tabular}{|c|c|c|}
\hline \multicolumn{3}{|c|}{ Heart Rate } \\
\hline \multicolumn{3}{|c|}{$\begin{array}{c}\text { Normal Heart Rate by Age (beats/minute) } \\
\text { Reference: PALS Guldellnes, 2015 }\end{array}$} \\
\hline Age & $\begin{array}{c}\text { Awake } \\
\text { Rate }\end{array}$ & $\begin{array}{c}\text { Sleeplng } \\
\text { Rate }\end{array}$ \\
\hline Neonate (<28 d) & $100-205$ & $90-160$ \\
\hline Infant (1 mo-1 y) & $100-190$ & $90-160$ \\
\hline Toddler (1-2 y) & $98-140$ & $80-120$ \\
\hline Preschool (3-5 y) & $80-120$ & $65-100$ \\
\hline School-age (6-11 y) & $75-118$ & $58-90$ \\
\hline Adolescent (12-15 y) & $60-100$ & $50-90$ \\
\hline
\end{tabular}

Fuente: Developed by Chris Novak and Peter Gill for PedsCases.com. April 21, 2016. 
Tabla 8. Tensión arterial, según edad

\begin{tabular}{|c|c|c|c|}
\hline \multicolumn{4}{|c|}{ Blood Pressure } \\
\hline \multicolumn{4}{|c|}{$\begin{array}{l}\text { Normal Blood Pressure by Age }(\mathrm{mm} \mathrm{Hg}) \\
\text { Reference: PALS Guldellnes, } 2015\end{array}$} \\
\hline Age & Systollc Pressure & Dlastollc Pressure & Systollc Hypotenslon \\
\hline Birth $(12 \mathrm{~h},<1000 \mathrm{~g})$ & $39-59$ & $16-36$ & $<40-50$ \\
\hline Birth $(12 \mathrm{~h}, 3 \mathrm{~kg})$ & $60-76$ & $31-45$ & $<50$ \\
\hline Neonate $(96 \mathrm{~h})$ & $67-84$ & $35-53$ & $<60$ \\
\hline Infant (1-12 mo) & $72-104$ & $37-56$ & $<70$ \\
\hline Toddler (1-2 y) & $86-106$ & $42-63$ & $<70+$ (age in years $\times 2$ ) \\
\hline Preschooler (3-5 y) & $89-112$ & $46-72$ & $<70+$ (age in years $\times 2$ ) \\
\hline School-age (6-9 y) & $97-115$ & $57-76$ & $<70+$ (age in years $\times 2$ ) \\
\hline Preadolescent (10-11 y) & $102-120$ & $61-80$ & $<90$ \\
\hline Adolescent (12-15 y) & $110-131$ & $64-83$ & $<90$ \\
\hline $\begin{array}{l}\text { For diagnosis of hypertensi } \\
\text { oro/guidelines/current/hype }\end{array}$ & $\begin{array}{l}\text { fer to the NHBPEP } \\
\text { ion-pediatric-jnc-4/b }\end{array}$ & $\begin{array}{l}\text { rence tables: http: } / / w \text { ' } \\
\text {-pressure-tables. }\end{array}$ & nhlbi.nih.gov/health- \\
\hline
\end{tabular}

Fuente: Developed by Chris Novak and Peter Gill for PedsCases.com. April 21, 2016.

\section{Tensión arterial.}

La tensión arterial se define como la cantidad de presión que se ejerce en las paredes de las arterias al desplazarse la sangre por ellas. Se mide en milímetros de mercurio (mmHg). el rango normal de la presión arterial en una persona adulta es 120/80 o menos. La presión arterial alta es de 140/90 o más. Si la presión arterial está entre 120/80 y 140/90, tiene lo que se llama "prehipertensión", lo que significa que está en las primeras etapas de la presión arterial alta y que está en riesgo de tener esta afección.

La presión arterial de un niño es 110/70 mmHg, 110 es la presión arterial sistólica y 70 es la presión arterial diastólica. La presión arterial alta (hipertensión) significa que la presión dentro de las arterias es demasiado alta. (Kang)

\section{Tensión Arterial Sistólica}

Según la American Heart Asociation (AHA), esta indica cuánta presión está ejerciendo la sangre contra las paredes arteriales cuando late el corazón. (AHA, 2018)

Tensión Arterial Diastólica 
Según la AHA, esta se refiere a (el número más bajo): indica cuánta presión está ejerciendo sobre la sangre contra las paredes arteriales mientras el corazón descansa entre los latidos. (AHA, 2018)

Tabla 9. Valores tensión arterial

\begin{tabular}{l|cc}
\multicolumn{1}{c}{ PAS } & \multicolumn{1}{c}{ PAD } \\
\hline NORMAL - & $120 \mathrm{mmHg}$ & $-80 \mathrm{mmHg}$ \\
ELEVADA & $120-129$ & $-80 \mathrm{mmHg}$ \\
& $\mathrm{mmHg}$ & \\
HIPERTENSIÓN 1 & $130-139$ & $80-89 \mathrm{mmHg}$ \\
& $\mathrm{mmHg}$ & \\
HIPERTENSIÓN 2 & $>140 \mathrm{mmHg}$ & $>90 \mathrm{mmHg}$ \\
& & \\
CRISIS DE & $>180 \mathrm{mmHg}$ & $>120 \mathrm{mmHg}$ \\
HIPERTENSIÓN & &
\end{tabular}

Fuente: AHA asosiation heart american (2015)

La única forma de saber (diagnosticar) si tiene presión arterial alta (HTA o hipertensión) es someterse a la prueba de presión arterial, siendo interpretados por un profesional de la salud que comprenda los indicadores para diagnosticar y controlarla en condiciones de vida regulares ara cualquier sujeto

Rangos de presión arterial saludables y no saludables

Edad: los adolescentes más pesados y sexualmente maduros tienden a tener una presión arterial más alta. Según la investigación, los adolescentes que son obesos y tienen presión arterial alta pueden desarrollar arterias más gruesas a los 30 años. (AHA, 2018) 
Tabla 10. Límite máximo de presión arterial normal según edad

\begin{tabular}{|l|l|l|}
\hline \multicolumn{1}{|c|}{ EDAD } & HOMBRES & MUJERES \\
\hline Pretérmino & $80 / 45$ & $80 / 45$ \\
Término & $90 / 60$ & $90 / 60$ \\
1 a 3 meses & $100 / 65$ & $100 / 65$ \\
4 a 6 meses & $110 / 70$ & $110 / 70$ \\
7 a 9 meses & $115 / 75$ & $115 / 75$ \\
10 a 12 meses & $120 / 75$ & $120 / 75$ \\
1 a 5 años & $130 / 80$ & $125 / 80$ \\
6 años & $130 / 80$ & $125 / 80$ \\
7 años & $130 / 80$ & $125 / 80$ \\
8 años & $130 / 80$ & $130 / 80$ \\
9 años & $130 / 80$ & $130 / 80$ \\
10 años & $135 / 80$ & $130 / 80$ \\
11 años & $140 / 80$ & $140 / 80$ \\
12 años & $140 / 85$ & $140 / 80$ \\
13 años & $140 / 90$ & $140 / 85$ \\
14 años & $140 / 90$ & $140 / 90$ \\
15 años y más & $140 / 90$ & $140 / 90$ \\
\hline
\end{tabular}

Fuente: https://www.slideshare.net/orialethajotnap/hipertension-arterial-pediatria (2014)

Valores promedio (mm. Hg) de los percentiles 90 y 95 PAS y PAD en fase V por grupos de edad y sexo en niños

Tabla 11. Clasificación de presión arterial: niños y jóvenes

\begin{tabular}{|lccc|}
\hline Edad & $\begin{array}{c}\text { PA normal a alta } \\
(\mathbf{m m H g})\end{array}$ & $\begin{array}{c}\text { HTA significativa } \\
(\mathbf{m m H g})\end{array}$ & Severa \\
\hline RN 7 dias & $104-111$ PAS & $104-109$ PAS & $\geq 110$ PAS \\
RN 8-30 días & $104-111 / 70-73$ & $112-117 / 74-81$ & $\geq 118 / 82$ \\
$<2$ años & $108-115 / 70-75$ & $116-123 / 76-83$ & $\geq 124 / 84$ \\
$3-5$ años & $114-121 / 74-77$ & $122-129 / 78-85$ & $\geq 130 / 86$ \\
$6-9$ años & $122-125 / 78-81$ & $126-133 / 82-89$ & $\geq 134 / 90$ \\
$10-12$ años & $130-135 / 80-85$ & $136-143 / 86-91$ & $\geq 144 / 92$ \\
$13-15$ años & $136-139 / 84-89$ & $140-149 / 90-97$ & $\geq 150 / 98$ \\
$16-18$ años & & & \\
\hline
\end{tabular}


Fuente: Universidad de La Frontera Tecnología Médica Módulo de Cardiovascular. Paulina Pérez, Evelyn Yáñez, Rodrigo Rodríguez, Daniel San Martín, Claudio Vásquez, Franklin Vidal. (2014)

\section{Horas de sueño}

Los bebés, los niños y los adolescentes necesitan dormir mucho más que los adultos para apoyar su rápido desarrollo mental y físico, para la mayoría de los padres este es un dato importante, pero muchos no saben cuántas horas requieren los niños y qué impacto puede tener la pérdida de tan solo 30 a 60 minutos de sueño.

Una de las razones por las que es tan difícil saber cuándo un niño no duerme lo suficiente es que los niños somnolientos no necesariamente disminuyen la velocidad de la forma en que lo hacemos, la somnolencia puede parecerse a los síntomas del trastorno por déficit de atención con hiperactividad (TDAH). Los niños a menudo actúan como si no estuvieran cansados, resistiendo la hora de acostarse y volviéndose hiperactivos a medida que avanza la noche. Todo esto puede suceder porque el niño está cansado.

Existen algunas afecciones psiquiátricas subyacentes, como el trastorno por déficit de atención con hiperactividad (TDAH), que pueden causar pérdida de sueño en los niños. Los investigadores y los médicos también están encontrando que la apnea del sueño, que la mayoría de la gente tiende a pensar como un trastorno del sueño en adultos, también es relativamente común en los niños.

Una persona que tiene apnea del sueño se despierta muchas veces cada hora, muy brevemente, mientras luchan por respirar. La mayoría de las personas no saben que están experimentando estos eventos a menos que les digan o se hagan una prueba para confirmar la apnea del sueño. Los niños que roncan pueden estar en riesgo de padecer apnea del sueño o sufren actualmente, por lo que la Academia Estadounidense de Pediatría recomendó recientemente que los pediatras pregunten sobre este trastorno del sueño en los niños durante las visitas rutinarias. 
Si ha y sospecha de que un niño no está durmiendo lo suficiente, es importante que que haya un control médico por parte de un pediatra, y en caso de presentarse un trastorno subyacente del sueño u otra afección médica en juego, el médico puede remitirlo a un especialista en sueño para analizar diversas opciones de tratamiento. En muchos casos, sin embargo, la privación del sueño en los niños puede ser ayudada con los cambios en el entorno y los hábitos que rodean la hora de acostarse.

Tabla 12. Horas de sueño recomendadas para niños, según edad

\begin{tabular}{|c|c|c|c|}
\hline Edad & $\begin{array}{c}\text { Tiempo total de } \\
\text { dormir }\end{array}$ & $\begin{array}{l}\text { Horas de dormir por } \\
\text { la noche }\end{array}$ & Horas de siesta de dia \\
\hline Recien nacido - 2 meses & $16-18$ horas & $8-9$ horas & $7-9$ horas ( $3-5$ siestas) \\
\hline 2 - 4 meses & $14-16$ horas & $9-10$ horas & $4-5$ horas ( 3 siestas) \\
\hline 4 - 6 meses & 14 - 15 horas & 10 horas & $4-5$ horas ( $2-3$ siestas $)$ \\
\hline 6 - 9 meses & 14 horas & $10-11$ horas & $3-4$ horas ( 2 siestas) \\
\hline 9 - 12 meses & 14 horas & $10-12$ horas & $2-3$ horas (2 siestas) \\
\hline 12 - 18 meses & $13-14$ horas & $11-12$ horas & $2-3$ horas ( 1 - 2 siestas) \\
\hline 18 meses - 2 años & $13-14$ horas & 11 horas & 2 horas ( 1 siesta) \\
\hline 2 - 3 afios & 12 - 14 horas & $10-11$ horas & $1-2$ horas (1 siesta) \\
\hline 3 - 5 af́os & $11-13$ horas & [10-11] $10-13$ horas & $0-1$ hora ( 1 siesta max) \\
\hline 5 - 12 afios & $10-11$ horas & $10-11$ horas & No siesta, idealmente \\
\hline
\end{tabular}

Fuente: Lucile Packar del Children's Hospital en la Universidad de Stanford y la National Sleep Foundation de los EUA (2017)

El sueño es un proceso restaurativo modulador de la función neuroendocrina y del metabolismo, por lo tanto, es tan importante para la buena salud y el rendimiento escolar como lo son los buenos hábitos alimenticios y el ejercicio.

Según (Owens, 2017) experta en salud infantil

Las investigaciones son claras en mostrar que los adolescentes que duermen lo suficiente corren menos riesgo de sufrir de sobrepeso o depresión, tienen menos probabilidad de estar involucrados en un accidente automovilístico, sacan mejores calificaciones y puntajes en pruebas estandarizadas, y generalmente llevan una mejor calidad de vida

En las investigaciones que relacionan el déficit o exceso de sueño nocturno, con el sobrepeso y las alteraciones fisiológicas en adolescentes se evidencia claramente una 
desregulación del organismo a nivel hormonal y metabólico que favorece la ingesta de alimentos.

Estudios respaldan la hipótesis que sostiene que la cantidad y calidad del sueño nocturno serían factores relevantes relacionados con la obesidad, actualmente los países industrializados han disminuido su cantidad de sueño nocturno. Datos estadounidenses muestran que los adultos han reducido entre 1 y 2 horas su cantidad de sueño y más de un tercio de los adultos jóvenes refieren dormir menos de 7 horas fenómeno igualmente reportado en niños y adolescentes (Humanos, 2016)

En ese sentido se considera que los elementos referidos al sueño son necesarios, por cuanto se convierten en uno de los factores que ayudan en la conservación de algunas funciones vitales, así como de los elementos de restauración y cuidado del cuerpo, al respecto dice la Dra. St-Onge, citada por (Hand, 2016)

Definieron el sueño inadecuado como menos de 7 horas por noche. Sin embargo, el sueño prolongado, definido como nueve o más horas por noche, se ha vinculado a obesidad, hipertensión y diabetes. Estudios aleatorizados controlados han demostrado que la pérdida de peso mediante intervenciones en la conducta o quirúrgicas podría tener efectos positivos sobre el trastorno respiratorio durante el sueño, señalan los investigadores. Los cardiólogos "debieran decir a sus pacientes que no tomen el sueño a la ligera y que procuren dormir lo suficiente, siguiendo las recomendaciones de dormir al menos 7 horas por noche", dijo la Dra. St-Onge.

De ahí que si bien es cierto el sueño es un factor reparador en la medida exacta de promedio 7 horas, es cierto también que abusar de el, puede conllevar a riesgos cardiacos o inclusive de obesidad.

La OMS en sus últimas publicaciones recomienda una media de 11 horas de sueño en los niños de 6 a 12 años Durante la infancia es muy importante que se respeten las horas de sueño recomendadas por la Organización Mundial de la Salud (OMS). De acuerdo con la Asociación Americana de (pediatría, 2017), estas serían las horas de sueño 
habituales (incluyendo siestas) que deben tener los bebés, niños y adolescentes a diario de acuerdo con su edad:

- Bebés de 4 a 12 meses, de 12 a 16 horas

- Infantes de 1 a 2 años, de 11 a 14 horas

- $\quad$ Niños de 3 a 5 años, 10 a 13 horas

- Menores de 6 a 12 años, de entre 9 y 12 horas

- Adolescentes de entre 13 y 18 años, de 8 a 10 horas (pediatría, 2017)

Se puede decir que el término fue acuñado por el ganador del premio Nobel, el Dr. Linus Pauling, afirma que se debe absorber la cantidad correcta de nutrientes de acuerdo a la necesidad de cada individuo, y no solo una cantidad promedio o establecida, para otros médicos algunas personas necesitan 1000 veces la cantidad de vitamina B o C, por ejemplo, que otros individuos.

Las razones de esta amplia variación pueden incluir dificultad para absorber nutrientes, desequilibrios metabólicos, tipos genéticos o metabólicos, la presencia de enfermedades, productos químicos tóxicos, estilos de vida estresantes u otras situaciones que consumen más nutrientes.

El concepto ortomolecular es una gran mejora con respecto a la idea única de las cantidades diarias recomendadas o los requisitos mínimos diarios, es en ese sentido que se debe reconocer la individualidad bioquímica y la importancia del estilo de vida, la digestión, el nivel de estrés y otros factores que influyen en la bioquímica y la nutrición, como factores de una buena dieta o de llegar a los límites de la morbilidad por obesidad.

Aunque el concepto es excelente, en sí mismo no ayuda a determinar las necesidades nutricionales, esto lleva a una serie de sistemas nutricionales que pueden 
ayudar a determinar las necesidades individuales según diversos conceptos, pruebas u otras metodologías de evaluación.

Para los nutricionistas la alimentación es fundamental dentro del procesos de adquisición de energía para el cuerpo que posteriormente se encarga de metabolizarla, es por ello que a continuación se muestra un ejemplo de cómo alimentarse en un día, según la FdaH

\section{Comidas al día}

Muchos niños pasan durante el día disfrutando de un refrigerio interminable, los refrigerios son buenos para los niños porque los ayudan a mantenerse concentrados en la escuela y sus tareas, les dan los nutrientes necesarios y mantienen el hambre a raya. Para muchos niños y adolescentes, un bocadillo es una bolsa de papas fritas, algunas galletas o algún otro alimento de bajo contenido nutricional. En cambio, piense en los aperitivos como mini comidas.

Las comidas no planeadas y al azar pueden provocar problemas, especialmente con el peso. Comer bocadillos sin parar interfiere con el apetito de los niños y puede alterar su instinto natural de experimentar hambre y plenitud. Cuando se cronometra correctamente, los refrigerios en realidad pueden ayudar a los niños a mantener un peso saludable.

Las grasas saludables contienen ácidos grasos esenciales como omega-3 y omega-6 que no se pueden producir en el cuerpo y deben provenir de la dieta, por ello siempre la recomendación es cocinar con aceites vegetales como canola, oliva y / o soya, estas también se encuentran en aderezos para ensaladas, margarinas no hidrogenadas, mantequillas y mayonesa.

Muchas grasas que son sólidas a temperatura ambiente contienen más grasas trans y saturadas que pueden aumentar su riesgo de enfermedad cardíaca, es por ello recomendable limitar la mantequilla, las margarinas duras y la manteca, por ello es importante leer las 
etiquetas y evite las grasas trans o saturadas que se encuentran en muchos productos comprados en la tienda, como galletas, donas y galletas saladas.

Es necesario limitar el consumo de las carnes procesadas, como las salchichas y las fiambres, que también son ricas en grasas, sodio (sal) y nitratos (conservantes de los alimentos).

\section{Consumo de tabaco}

Los análisis de los efectos de los contaminantes atmosféricos en la salud para evaluar la asociación entre la exposición pasiva al humo del cigarrillo y el crecimiento físico entre los 6 y 11 años, dentro de cada medida de altura esta fue ajustada por sexo y edad según los estándares antropométricos de NCHS. Las alturas ajustadas de cada niño se volvieron a expresar como el nivel de altura alcanzado y la tasa de crecimiento. La altura alcanzada mostró una relación dosis-respuesta con la cantidad de tabaquismo materno actual (p menor que 0.001). Los niños cuyas madres fumaban diez o más cigarrillos al día eran aproximadamente $0,65 \mathrm{~cm}$ más cortos que los hijos de los no fumadores, mientras que los niños cuyas madres fumaban entre 1 y 9 cigarrillos por día eran $0,45 \mathrm{~cm}$ más cortos. Sin embargo, fumar pasivamente no se correlacionó con la tasa de crecimiento del niño. La exposición al tabaquismo paterno no se asoció significativamente con la altura, ni en términos del nivel alcanzado ni de la tasa de crecimiento. Estos resultados indican que el tabaquismo pasivo en el niño de 6 a 11 años no continúa afectando la tasa de crecimiento de estatura y que la asociación observada entre la altura alcanzada y el comportamiento tabáquico materno se debe a exposiciones en el útero y / o durante la infancia y los años preescolares.

Algunos niños están expuestos a los tóxicos del humo de tabaco desde el momento de la concepción. El monóxido de carbono, la nicotina y muchas otras sustancias tóxicas (mercurio, cadmio o plomo, entre otros) pasan al feto a través de la placenta, reduciendo la llegada de oxígeno, acelerando su ritmo cardíaco y alterando el crecimiento y el desarrollo normal de algunos órganos. Los hijos de madres que fuman en el embarazo tienen más probabilidad de nacer con bajo peso que los hijos de madres no fumadoras. El consumo de 
tabaco durante el embarazo se asocia también con mayor riesgo de muerte perinatal (feto muerto y síndrome de muerte súbita del lactante), menor desarrollo del pulmón, alteración en el desarrollo del cerebro (que estaría relacionado con un mayor riesgo de trastornos de aprendizaje y de conducta en la niñez y adolescencia) y algunas malformaciones congénitas (labio leporino y paladar hendido y defectos en el corazón). A largo plazo aumenta el riesgo de que los hijos sean fumadores al llegar a la adolescencia. (Ministerio de salud de Argentina, 2015)

De esta manera es posible decir que la prevalencia del tabaquismo para niños es posible de entender desde una posición anterior inclusive al nacimiento y que se puede ver reforzada por hábitos de los padres incidiendo en bajas de peso o de talla, cuestiones abordadas en este estudio.

\section{Tabaquismo}

Según varios autores se puede definir como una enfermedad que se produce debido a la adicción al tabaco generado por una sustancia llamada nicotina convirtiendo a la persona en un fumador cuyas principales manifestaciones clínicas son: trastornos cardiovasculares, trastornos respiratorios y aparición de tumores en diversas localizaciones. Tiene una alta prevalencia que varía en los diferentes países de acuerdo a criterios sociales, económicos y culturales.

\section{Para (Cogollo-Milanés \& Gómez-Bustamante, 2014)}

Es necesario considerar al tabaco como parte de las sustancias que provocan un incremento de morbilidad y de mortalidad evitable, con gran repercusión social y económica, constituyéndose en uno de los problemas de salud más graves en el mundo y uno de los principales retos que tiene planteados la salud pública. Igualmente, en su estudio realizado en la ciudad de Cartagena con escolares entre 10 y 18 años. Se evidencia que los jóvenes consumen tabaco por primera vez entre los 10 y 14 años. Los adolescentes que empiezan a consumir cigarrillo a una edad temprana tienen más probabilidad de fumar en la edad adulta, mayor será su riesgo de convertirse en fumador regular, desarrollar dependencia y sufrir consecuencias a largo plazo derivadas del consumo. 
Según (García, 2017) la relación entre el consumo de tabaco y los valores de los índices aterogénicos se centra principalmente en el efecto sobre los niveles de adiponectina: la adiponectina es una adipocina cuyos niveles en concentraciones bajas se relacionan con un perfil de riesgo cardiovascular adverso.

Los componentes del humo de tabaco se clasifican en: Monóxido de carbono: Interfiere con la capacidad transportadora de oxígeno al formar carboxihemoglobina, disminuyendo el aporte de oxígeno al miocardio, incluyen sustancias irritantes y agentes cancerígenos (policarburos aromáticos, nitrosaminas, compuestos heterocíclicos, etc.). Alquitrán (definido como las partículas que quedan atrapadas en un filtro tipo Cambridge, menos el agua y la nicotina). Nicotina: produce liberación de norepinefrina y aumento de adrenalina circulante, con una elevación inmediata de la presión arterial y la resistencia periférica.

Tabaquismo pasivo.

Según la definición de (Flórez, 2017) es aquel en el que la persona no elige activamente la inhalación del humo del tabaco existente en espacios cerrados, sino que lo asume como parte de la inhalación de otro.

Teniendo en cuenta que no solamente los fumadores afectan su salud, sino que también las personas que comparten el mismo espacio y para efectos de esta investigación y de acuerdo con la entrevista realizada a los escolares acerca de la convivencia con personas fumadoras se toma el estudio según (Flórez, 2017) en el cual los resultados hallados relacionan el tabaquismo pasivo con numerosas enfermedades cardiovasculares y factores de riesgo, como por ejemplo cardiopatía isquémica e hipertensión arterial, a corto, medio y largo plazo, mediante distintos mecanismos de acción que incluyen la alteración de la función endotelial, activación plaquetaria, alteración del sistema nervioso autónomo e hipoxia tisular entre otras.

En esa medida se puede decir que para evaluar el grado de exposición al tabaco existe una prueba de laboratorio que puede medir la presencia e incluso la concentración de cotinina en sangre, orina, pelo o saliva de una persona que no fuma. La cotinina es un biomarcador y el principal metabolito de la nicotina y que tiene una vida media en adultos de hasta $48 \mathrm{~h}$ 
tras la exposición, pudiendo ser en niños de hasta más de 6 días12 (Flórez, 2017, pág.

10)

Así se puede decir que los principales tóxicos del humo del tabaco inhalado por no fumadores son la nicotina y el monóxido de carbono, siendo el principal efecto de la nicotina la adicción tras su unión al receptor, y el del monóxido de carbono el aumento en la producción de carboxihemoglobina e hipoxia. Ostras sustancias, como el tiocianato, los metabolitos de la nicotina y algunas aminas también juegan un fuerte papel en el daño. De ahí que sea importante destacar que las células miocárdicas y endoteliales son las dianas de estos tóxicos y su daño morfológico es irreversible en el momento. (Lanas, 2012)

En Chile, la prevalencia de tabaquismo en mayores de 15 años es 40,6\%. El tabaquismo activo y pasivo provoca enfermedad cardiovascular como consecuencia del efecto del monóxido de carbono y nicotina a través de inducción de un estado de hipercoagulación, aumento del trabajo cardíaco, vasoconstricción coronaria, liberación de catecolaminas, alteración del metabolismo de los lípidos y alteración de la función endotelial. (Labbé, 2014)

Dentro de los elementos para tener en cuenta dentro de un estudio de morbilidad por obesidad es claro que se debe tener en cuenta el nivel de actividad física que tiene el infante, unas veces mediado por sí mismo, en otros casos por la escuela, así como por la relación social establecida con la alimentación, de ello habría que decir que estos últimos han sufrido una serie de variaciones, tanto en la manera como se producen, así como en su composición, terminando muchos de ellos siento tóxicos para los menores que los consumen.

Otro de los elementos que se pueden asociar a la obesidad está ligado al consumo de tabaco, que el niño sería pasivo, por cuanto no es una práctica recurrente, ni voluntaria, sino asociada a la cercanía con un adulto que si lo haga, de ahí que aparezca "La IPHT(inhalación pasiva del humo del tabaco) puede provocar diferentes enfermedades en el niño, algunas de las cuales aparecerán más de 20 años después del contacto inicial con el tóxico" (Labbé, 2014), quién determina que los niños al estar expuestos a este factor puden llegar a generar problemas cardiacos e inclusive respiratorios. 
Dentro de los estudios hechos por diferentes científicos entre ellos el mencionado, cabe decir que, no es únicamente el niño, quién esta expuesto dentro de su entorno, sino que igualmente la madre en estado de gestación podría verse afectada tanto por ser la madre fumadora activa en algún momento de su vida, así como por encontrarse en contacto con sujetos que igualmente lo hacen.

La repercusión cardiovascular de la IPHT es objeto de recientes estudios. Geerts et al, en Holanda, estudiaron en 259 recién nacidos la repercusión vascular del tabaquismo durante el embarazo. Midieron el grosor íntima-media (GIM) de la carótida común y su distensibilidad. Los niños cuya madre ha fumado durante el embarazo presentan un mayor GIM, de 18,8_m, y una menor distensibilidad. Este efecto se observa fundamentalmente en caso de tabaco in utero y es más importante si los dos padres han fumado durante el embarazo, con un GIM mayor de 27,7 _m y una distensibilidad un $21 \%$ menor. Observaron una clara tendencia entre la intensidad de la anomalía vascular y el número de cigarrillos fumados durante el embarazo. Todos ellos han analizado las consecuencias endoteliales del tabaquismo parental en jóvenes adolescentes. Estudiaron una muestra de niños de 3-18 años, valorados (Lanas, 2012)

De esta manera la situación inicialmente expuesta con respecto a los elementos de riesgo que se asocian a la enfermedad cardiovascular, se mantendrá en el tiempo, ya que con posteriores seguimientos a esta población que inicialmente se encontraba en riesgo de padecer de alguna enfermedad cardiovascular, la proyección a 30 ó 40 años llevo a entender que los factores de riesgo, terminan siendo reales y dados por poca actividad física, tendencia a la obesidad genética mórbida, dependiendo la etapa vital en la cual se encuentra el sujeto, ya que "de nuevo entre 19 y 27 años o más tarde, cuando tenían de28 a 45 años de edad. El criterio objetivo empleado fue la medida de la dilatación mediada por el flujo (FMD) de la arteria braquial" (pág. 36), se da a entender que si un infante proviene de una madre fumadora, o de un ambiente en el cual este era algo naturalizado, se pueden encontrar elementos metabólicos similares de riesgo en la etapa adolescente, así como en la predisposición metábolica que se genera en el tiempo. 
Frente a este tema hay muchos estudios en distintas latitudes del mundo que hacen la comparación de los riesgos a los cuales se encuentran expuestos los individuos, ya sea en la etapa fetal, recién nacidos o niños, para posteriormente proyectarlo hacia la adolescencia y la adultez.

De esta manera el estudio de (Raghuveer, 20012), sobre riesgos cardiovasculares afirma que los niños que están expuestos al humo del tabaco pueden desarrollar ECV debido al deterioro en la funcionalidad de los vasos sanguíneos, disminuyendo su esperanza de vida hasta en 20 años.

Según (Bárcena, 2016, pág. 14), se menciona acerca de una investigación de carácter longitudinal de 20 años en donde el tabaquismo pasivo aumenta el riesgo de enfermedad coronaria en un 45\% (Índice de Confianza (IC) 95\% 10-200\%), pudiendo llegar hasta un 57\% (IC 95\% 8-228\%) según el nivel de exposición.

Así mismo el (Ministerio de salud de Cuba , 2016) en un estudio sobre las patologías cardiacas en la isla encontró que más de 1500 muertes fueron causadas por tabaquismo pasivo, así como unas 1350 fueron causadas por enfermedad cardíaca, derivada de la acción de inhalar humo de cigarrillo ó tabaco con fines recreativos, o también por actividad pasiva cercana a este tipo de población.

Es evidente de esta manera que uno de los factores de riesgo que se pueden asociar a patologías cardiacas es el referido al tabaquismo, ya sea de manera activa o pasiva, ya que todos estos estudios demuestran que la exposición al humo del tabaco en recintos cerrados afecta notablemente la salud cardiovascular y teniendo en cuenta la población infante, así como la juvenil para efectos de esta investigación se hace más grave la misma según los elementos que se han presentado, por estudios de diferentes países y científicos.

\section{Actividad fisica}

Es muy común en la actualidad encontrar evidencia significativa que sugiere que los niños en el mundo y en el caso colombiano cada día tienen una menor actividad física, lo 
cual no suficiente para una buena salud y bienestar óptimos, desde ahí muchas iniciativas buscan el aumento de los niveles de actividad y los hábitos saludables de estudiantes y, en parte, abordar cuestiones relacionadas, como enfermedades crónicas.

Estas iniciativas sobre sobre los niveles de actividad física de los estudiantes y el desarrollo de hábitos saludables como parte del primer nivel del estudio de evaluación, esto

Conlleva a tener presentes unos elementos de estudio al respecto como: el de la identificación de las herramientas de recopilación de datos que son apropiadas para su uso con niños y jóvenes en un entorno escolar, que sean son capaces de confiable medir los impactos a corto, mediano y largo plazo de la Iniciativa de aumento y fortalecimiento de la actividad cardio respiratoria y muscular en escolares para identificar prácticas de intervenciones con resultados a largo plazo que se puedan utilizar en las escuelas.

Para mejorar la aptitud cardiorrespiratoria y muscular, la salud ósea y los biomarcadores de salud cardiovascular y metabólica la (ONU - OMS, 2017) se consideran los siguientes factores:

- Los niños y jóvenes de 5 a 17 años deben acumular al menos 60 minutos de actividad física de intensidad moderada a vigorosa diariamente.

- Las cantidades de actividad física mayores a 60 minutos brindan beneficios adicionales para la salud.

- La mayor parte de la actividad física diaria debe ser aeróbica. Deben incorporarse actividades de intensidad vigorosa, incluidas aquellas que fortalecen los músculos y los huesos, al menos 3 veces por semana.

- $\quad$ Para este grupo de edad, las actividades de carga de huesos se pueden realizar como parte de juegos, correr, dar vueltas o saltar.

La actividad física, se puede definir como "cualquier movimiento corporal asociado con la contracción muscular que incrementa el gasto de energía por encima de los niveles de reposo", según (Claros, Vélez Álvarez, Sandoval Cuellar, \& Alfonso Mora, 2011). O también, como "todos los movimientos de la vida diaria, incluyendo el trabajo, la recreación, el ejercicio y las actividades deportivas". 
A pesar de que los niños y jóvenes son más activos y, por ello, tienen una mayor tendencia a la práctica de actividad física, no es menos cierto que la forma de vida actual lleva a que, incluso en este tramo de edades, se desarrolle poca actividad física, por diferentes motivos expuestos anteriormente, lo cual es perjudicial para su salud y conlleva al deterioro de su calidad de vida, por ser propensos a ser diabéticos, o hipertensos, según las escalas dadas en el capítulo anterior.

Actividad física en la infancia y adolescencia. La literatura mundial es muy amplia con respecto a la relación entre la actividad física, la obesidad y otros factores de riesgo; para efectos de esta investigación es muy importante tener en cuenta la caracterización que hace la OMS en grupos etarios en la cual los niños y jóvenes de 5 a 17 años deberían acumular un mínimo de 60 minutos diarios de actividad física.

No obstante, es necesario determinar también las intensidades con la que se desarrollan, de acuerdo a los tres tipos de actividad física: ligera, moderada y vigorosa y a su vez es importante diferenciar en lo que se refiere a Condición Física. Un estudio realizado en niños españoles puso en evidencia si la actividad física realizada o el grado de condición física (capacidad aeróbica y fuerza) están asociados con su perfil lipídicometabólico. (Claros, Vélez Álvarez, Sandoval Cuellar, \& Alfonso Mora, 2011)

De acuerdo a este estudio, la actividad física no mostró asociación con el índice lipídico-metabólico en ninguno de los dos sexos, este se relacionó inversamente con la capacidad aeróbica en los varones $(\mathrm{p}=0,003)$ de acuerdo al grado de actividad física y la fuerza muscular, en las mujeres, un perfil lipídico-metabólico más cardiosaludable se asoció con una mayor fuerza muscular $(\mathrm{p}=0,048)$ tras ajustar por la capacidad aeróbica. Es así que los grados de condición física son los más relevantes y no la actividad física, además de asociar una alta capacidad aeróbica en varones y un alto grado de fuerza muscular en mujeres se asocian con un menor riesgo lipídico-metabólico de enfermedad cardiovascular. (García-Artero, Ortega, Ruiz, Mesa, \& Delgado, 2017)

En el caso colombiano uno de los estudios que muestra que es la condición física la que determina los perfiles de Riesgo Cardio Vascular (RCV) en niños y adolescentes se realizó en la ciudad de Cali: Se presentan los datos percentiles de la condición física en menores de 10 a 16 años, por primera vez en esta población y según sus autores (Yule \& 
Montilla Valencia, 2014) en general, en el sexo masculino hay más heterogeneidad que en el femenino, en términos de condición física mediante el VO2máx. Los resultados obtenidos indican que la condición física de este grupo de edad en Colombia, se debe mejorar para ayudar a protegerlos contra las enfermedades cardiovasculares en la edad adulta.

Actividad Física Extraescolar. Se puede definir que son todas aquellas actividades que realizan los estudiantes en jornada diferente a la académica, es decir, que no se tiene en cuenta los descansos, las clases de danzas de educación Física o cualquier otra que implique actividad física, en las cuales hay una demanda energética por encima del requerimiento basal.

Para efecto de la presente investigación se buscó indagar en los escolares su participación en escuelas de formación deportiva, clubes o ligas, igualmente aquellos que sin estar inscritos o pertenecer a alguno de los entes mencionados realizaban actividad física ligera, moderada o vigorosa, esto incluye también el medio de transporte, ya que si su desplazamiento al colegio se hace a pie o en bicicleta se debe tomar la distancia y el tiempo que demora en estos trayectos.

Es conocido que los efectos benéficos en el organismo se producen después de 10 minutos de actividad física continua, es decir que, si el desplazamiento del colegio a la casa y viceversa estaba en este rango, ya se puede considerar como Actividad física extraescolar.

En un estudio piloto con niños de edad preescolar en España hecho por (Delgado \& Montes, 2015) se pudo determinar que es muy bajo el porcentaje que realiza actividad física extraescolar, su estudio arroja datos preocupantes, especialmente teniendo en cuenta que la actividad física que se realiza dentro de los colegios no es suficiente para lograr cambios significativos en la salud de los niños y adolescentes.

De la misma manera muchos especialistas afirman sobre la necesidad realizar actividades físicas extraescolares con el propósito de reducir los riesgos de enfermedad coronaria a largo plazo, para lo cual es vital que el docente de Educación Física lidere los procesos, motivando a sus estudiantes y creando conciencia en la comunidad educativa acerca de los beneficios que produce para los niños y jóvenes la práctica de actividades 
deportivas, recreativas y lúdicas que generen un gasto energético representativo en pro de la disminución del sedentarismo y el mejoramiento de la salud.

En la actualidad toda actividad física o de ejercicios ocurre en la escuela, sin embargo, como se mencionó anteriormente no se asegura un mínimo de horas semanales recomendadas, es decir que se hace imperativo el aumentar considerablemente los tiempos en la práctica de actividad física en jornada contraria a la académica y los fines de semana.

Para poder cumplir con lo recomendado los niños y jóvenes deberían incrementar semanalmente 180 minutos para garantizar los 300 sugeridos por la OMS.

Motivar a los niños a permanecer activos se ha convertido en un objetivo importante para los padres, maestros y profesionales de la salud.

Según (Luebbers, 2003) se puede decir que los elementos de trabajo alrededor de la actividad física

Todos podemos desempeñar un papel a la hora de promover la actividad física entre niños, niñas y adolescentes, con inclusión de los padres y madres, tutores, profesores, entrenadores, monitores de actividad/campamento, administradores escolares, supervisores de deportes y de ocio de la comunidad y profesionales de la salud.

Análisis de la situación en inactividad física y salud en Colombia y Bogotá.Según los resultados de la ENSIN hecho por él (Instituto Colombiano de Bienestar Familiar, 2010), en Colombia, solamente el $26 \%$ de la población cumple con el mínimo de actividad física recomendada en el grupo de edad de 13 a 17 años; este porcentaje aumenta a 42,6\% entre los 18 y 64 años; sin embargo, llama la atención que la actividad física en tiempo libre solamente fue practicada por el 8,6\% de la población entre 13 y 17 años, y en un 5,9\% entre 18 y 64 años. Sumado a este panorama, el 56,3\% de los niños entre 5 y 12 años dedican 2 o más horas diarias a ver televisión. 


\title{
CAPÍTULO III.
}

\author{
Diseño Metodológico
}

\section{Estudio descriptivo analítico transversal (cross-sectional study).}

La fase 1 del macroproyecto se centra en el análisis de variables antropométricas y hemodinámicas que permitan determinar la presencia de obesidad o sobrepeso en la población de escolares. De la misma forma, se incluye el análisis de variables que pueden convertirse en factor protector o de riesgo según su comportamiento en la misma población.

Este es un estudio unietápico por conglomerados.

\section{Población de estudio}

La población a estudio son los escolares del colegio Paulo VI IED, jornada mañana (1359 estudiantes) de los grados quinto a once con edades comprendidas entre los 10 a 19 años.

La investigación pretende que todos los estudiantes puedan ser medidos y evaluados para determinar sus factores de riesgo y/o de protección cardiovascular relacionada con sobrepeso y obesidad. No obstante, no se tuvieron en cuenta las estudiantes en condición de embarazo, ni aquellos cuyos padres o acudientes no autorizaran la toma de datos a través del consentimiento informado (ver Anexo 2).

De acuerdo con los criterios de exclusión, la población total de estudiantes participantes fue de 417 escolares, lo cual representa el 30,6\% de la población. 


\section{Definición de variables}

Las variables de estudio en esta investigación fueron:

Tabla 13. Variables de investigación.

VARIABLE DEFINICIÓN OPERACIONAL INDICADORES/BAREMOS

Características sociodemográficas:

\begin{tabular}{lll}
\hline Edad & Tiempo de vida desde el nacimiento & Rango de 10 a 19 años \\
& hasta la fecha actual &
\end{tabular}

\begin{tabular}{llll}
\hline Género & Características fisiológicas y sexuales & 1 & Femenino \\
& 2 & Masculino
\end{tabular}

con las que nacen mujeres

2 Masculino

(femenino) y hombres ( masculino)

\begin{tabular}{|c|c|c|}
\hline Grado & $\begin{array}{l}\text { Nivel escolar en el que se encuentra } \\
\text { matriculado un estudiante }\end{array}$ & $\begin{array}{l}5^{\circ}, 6^{\circ}, 7^{\circ}, 8^{\circ}, 9^{\circ}, 10^{\circ}, 11^{\circ} \\
\text { Jornada mañana }\end{array}$ \\
\hline Núcleo familiar & $\begin{array}{l}\text { Vínculos de relación o } \\
\text { parentesco más estrechos entre quienes } \\
\text { conforman un hogar (relaciones } \\
\text { paternas/maternas y filiales). } \\
\text { Igualmente, el concepto se extiende a } \\
\text { la unidad de personas en interacción no } \\
\text { necesariamente parentales que } \\
\text { comparten una vivienda y otras } \\
\text { necesidades básicas. }\end{array}$ & $\begin{array}{ll} & \text { Vive con } \\
1 & \text { Padres } \\
2 & \text { Familiares } \\
3 & \text { Otros }\end{array}$ \\
\hline $\begin{array}{l}\text { Antecedentes } \\
\text { médicos }\end{array}$ & $\begin{array}{l}\text { Información sobre el estado de } \\
\text { salud de una persona, enfermedades, } \\
\text { cirugías, alergias tratamientos. }\end{array}$ & $\begin{array}{ll}0 & \text { Ninguno } \\
1 & \text { Cardíacos } \\
2 & \text { Respiratorios } \\
3 & \text { Osteomusculares } \\
4 & \text { Otros } \\
\end{array}$ \\
\hline $\begin{array}{l}\text { Consumo de } \\
\text { medicamentos }\end{array}$ & $\begin{array}{l}\text { Ingesta de medicamentos como } \\
\text { tratamiento para tratar alguna } \\
\text { enfermedad }\end{array}$ & $\begin{array}{l}1 \mathrm{SI} \\
2 \mathrm{NO}\end{array}$ \\
\hline
\end{tabular}


Factores de riesgo y/o protectores:

\begin{tabular}{|c|c|c|}
\hline $\begin{array}{l}\text { Horas } \\
\text { de sueño }\end{array}$ & $\begin{array}{l}\text { Número de horas del día para } \\
\text { determinar el tiempo que se dedica al } \\
\text { sueño. }\end{array}$ & 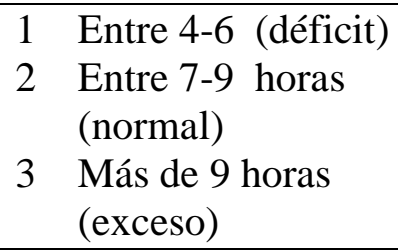 \\
\hline $\begin{array}{l}\text { Actividad física } \\
\text { extraescolar }\end{array}$ & $\begin{array}{l}\text { Actividad física que realiza un } \\
\text { estudiante fuera del espacio- ambiente } \\
\text { académico y/o Escolar }\end{array}$ & $\begin{array}{l}1 \mathrm{SI} \\
2 \mathrm{NO}\end{array}$ \\
\hline $\begin{array}{l}\text { Tabaquismo } \\
\text { personal }\end{array}$ & $\begin{array}{l}\text { Consumo de tabaco de manera } \\
\text { individual, voluntaria. }\end{array}$ & $\begin{array}{l}1 \mathrm{SI} \\
2 \mathrm{NO}\end{array}$ \\
\hline $\begin{array}{l}\text { Tabaquismo } \\
\text { pasivo }\end{array}$ & $\begin{array}{l}\text { Ingesta de humo como } \\
\text { consecuencia de terceros que } \\
\text { consumen tabaco y lo hacen en su } \\
\text { mismo ambiente vital. }\end{array}$ & $1 \mathrm{SI}$ \\
\hline Dieta & $\begin{array}{l}\text { Ingesta de alimentos en relación } \\
\text { con las necesidades energéticas del } \\
\text { organismo }\end{array}$ & $\begin{array}{l}\text { 1. }<\text { de } 3 \text { comidas } \\
\text { 2. } 3 \text { comidas } \\
\text { 3. }>3 \text { comidas }\end{array}$ \\
\hline
\end{tabular}

\section{Variables antropométricas:}

\begin{tabular}{|c|c|c|}
\hline \multirow[t]{2}{*}{$\begin{array}{l}\text { Índice de masa } \\
\text { corporal }\end{array}$} & $\begin{array}{l}\text { Medida matemática que asocia el peso } \\
\text { y la talla de una persona } \\
\text { peso }\end{array}$ & $\begin{array}{l}\text { Bajo peso: percentil < } 3 \\
\text { Normal: percentil } 3 \text { a } 84 \\
\text { Sobrepeso: percentil } 85 \text { al } 97 \\
\text { Obesidad: percentil > } 97\end{array}$ \\
\hline & $\mathrm{IMC}=\frac{}{\text { Estatura }_{2}}$ & \\
\hline $\begin{array}{l}\text { Indice cintura } \\
\text { talla }\end{array}$ & $\begin{array}{l}\text { Cociente entre la circunferencia } \\
\text { de la cintura y la altura, ambos } \\
\text { medidos en las mismas unidades. Es } \\
\text { una medida de la distribución de la } \\
\text { grasa corporal. Valores más altos }\end{array}$ & $\begin{array}{l}\text { Delgado sano: } \\
\text { Mujer } 0,35 \text { a } 0,41 \\
\text { Hombre } 0,35 \text { a } 0,42 \\
\text { Sano: }\end{array}$ \\
\hline
\end{tabular}


indican mayor riesgo de obesidad

relacionado con enfermedades

cardiovasculares, correlacionadas con

la obesidad abdominal.
Mujer 0,42 a 0,48

Hombre 0,43 a 0,52

Sobrepeso

Mujer 0,49 a 0,53

Hombre 0,53 a 0,57

Obesidad

Mujer $<0,54$

Hombre $>0,58$

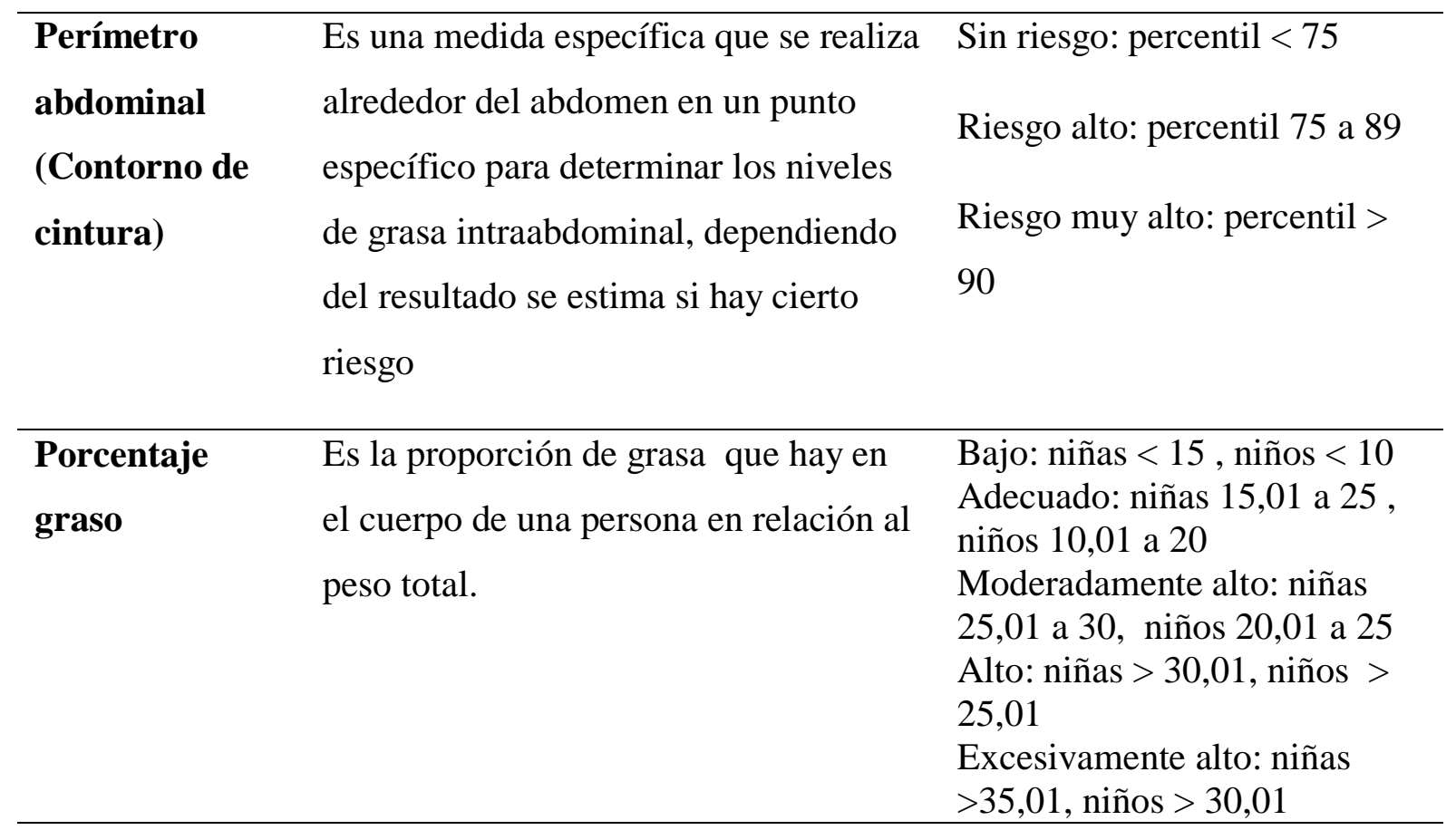

Variables hemodinámicas y respiratorias:

\begin{tabular}{lll}
\hline Frecuencia & Es la mínima cantidad de pulsaciones & Rangos entre $50-130$ \\
cardíaca basal & por minuto que puede tener una & Bradicardia: \\
& pujeres 50 a 66 puls $/ \mathrm{min}$ \\
& vitales. & Hombres: 50 a 74 puls $/ \mathrm{min}$ \\
& Normal : \\
& Mujeres 66 a 118 puls $/ \mathrm{min}$ \\
& Hombres: 75 a 124 puls $/ \mathrm{min}$ \\
& Taquicardia: \\
& Mujeres $>118$ puls $/ \mathrm{min}$ \\
& Hombres: $>124$ puls $/ \mathrm{min}$
\end{tabular}

\begin{tabular}{lll}
\hline Tensión & Corresponde al valor máximo de & Rangos entre 60 - 179 \\
arterial & la presión arterial en sístole (cuando & Hipotenso: $90-109$ \\
& & Normotenso: $102-140$ \\
\hline
\end{tabular}




\begin{tabular}{lll}
\hline sistólica & el corazón se contrae) & Hipertenso: 123 - 179 \\
& La cantidad de presión que ejerce la & Hipotensión sistólica: 77-88 \\
& sangre en las arterias cuando el corazón & \\
& late & \\
\hline Tensión & La presión que ejerce la sangre sobre & Rangos entre 50 - 121 \\
arterial & las paredes de las arterias entre latidos, & Normotenso : $60-90$ \\
diastólica & cuando el corazón descansa & Hipotenso: $50-63$ \\
& &
\end{tabular}

Fuente de elaboración propia

\section{Instrumentos de recolección de la información}

La recolección de la información, entendida como el procedimiento y las actividades que dan al investigador la información necesaria para llegar al cumplimiento del objetivo propuesto, se realiza a través del diligenciamiento de un formulario con los datos obtenidos de cada una de las mediciones propuestas.

El formulario (ver Anexo 2) consta de tres partes: la primera parte tiene los datos de caracterización sociodemográfica de los escolares en la cual se mencionan los datos de edad, género, régimen de salud y localidad; la segunda parte se centra en la obtención de datos de factores de riesgo o de protección de la población, dichos datos fueron obtenidos a través de entrevista guiada a los escolares, dentro de las preguntas generadas se encuentra una relacionada con el núcleo familiar, así como los antecedentes médicos y el consumo de medicamentos, igualmente aquí se registra: tabaquismo, alimentación, horas de sueño, y actividad física extraescolar; la parte final del formulario, recolecta los datos de las mediciones de las características antropométricas y hemodinámicas realizadas a los escolares. 


\section{Prueba Piloto}

La prueba piloto se llevó a cabo con cuatro estudiantes de grado preescolar de la Jornada Mañana y seis de grado 11 de la Jornada Tarde del colegio Paulo VI IED, los días

3 y 11 de noviembre del año 2016 respectivamente, en donde se aplicó todo el formulario previsto para la investigación. Dicha prueba tuvo una duración de 15 minutos aproximadamente con cada uno, desde el momento de ingreso del estudiante al lugar de evaluación hasta la salida del mismo. Posterior a la evaluación del instrumento se toma la decisión de modificar los siguientes aspectos:

a. Ordenar las variables de medición en el formato, acorde con los resultados que arroja la báscula para facilitar la escritura de datos y evitar cometer errores de digitación.

b. No tener en cuenta los datos de porcentaje de agua, grasa y hueso, sino solamente el peso en las mediciones realizadas a los niños menores de 10 años, ya que la báscula no arroja datos para poder programarla con estas edades.

Posterior a la realización de la prueba piloto, se dio inicio al diligenciamiento de los consentimientos informados (ver Anexo 1), a partir de una jornada de sensibilización tanto a padres de familia (3 de febrero del año 2017), estudiantes y comunidad académica del colegio.

\section{Trabajo de campo}


El trabajo de campo de la investigación tuvo lugar entre los meses de febrero y abril de 2017, previa autorización de las directivas del Colegio y de los docentes directores de grupo.

La investigación fue realizada en su totalidad dentro de las instalaciones de la institución escolar. La logística utilizada para hacer las mediciones se determinó iniciando con la obtención de los datos sociodemográficos y de factores de riesgo y protectores, a través de una entrevista guiada a los escolares.

La toma de datos de las características antropométricas y hemodinámicas se hizo siguiendo el protocolo que se establece a continuación:

Tabla 14. Protocolo de medición

\begin{tabular}{|c|c|c|}
\hline VARIABLE & PROTOCOLO & INSTRUMENTO \\
\hline Talla & $\begin{array}{l}\text { Se ubica al paciente en posición erguida } \\
\text { completamente, la espalda pegada al } \\
\text { tallímetro sin calzado y con los pies juntos } \\
\text { sin levantar los talones y con la mirada al } \\
\text { frente barbilla derecha. Se toma la altura } \\
\text { con una regla en la misma dirección de la } \\
\text { coronilla (parte más alta de la cabeza) al } \\
\text { tallímetro. Ver figura } 1\end{array}$ & $\begin{array}{l}\text { Tallímetro en acrílico doble } \\
\text { escala para pared marca } \\
\text { Kramer, graduado en mm } \\
\text { modelo } 1337802 \text { referencia } \\
2104\end{array}$ \\
\hline Peso & $\begin{array}{l}\text { El paciente estará en camiseta y } \\
\text { pantaloneta y descalzo sin ningún } \\
\text { elemento adicional como relojes anillos o } \\
\text { manillas. Se sube a la báscula ubicando } \\
\text { los pies simétricos y en posición erguida } \\
\text { sin moverse. Ver figura } 2\end{array}$ & $\begin{array}{l}\text { Báscula digital marca Super } \\
\text { Look Professional } \\
\text { referencia SLP 521-BK }\end{array}$ \\
\hline $\begin{array}{l}\text { Perímetro } \\
\text { de cintura }\end{array}$ & $\begin{array}{l}\text { Se solicita al paciente que se ubique de pie } \\
\text { y de frente al evaluador quien estará } \\
\text { sentado, se le pide que se levante la } \\
\text { camiseta, posterior a esta acción se ubica } \\
\text { la cinta métrica alrededor del abdomen en } \\
\text { la misma línea del ombligo se le dice al } \\
\text { evaluado que respire normalmente y que } \\
\text { no apriete el abdomen. Ver figura } 3\end{array}$ & $\begin{array}{l}\text { Cinta métrica flexible } \\
\text { genérica }\end{array}$ \\
\hline $\begin{array}{l}\text { Frecuencia } \\
\text { cardiaca } \\
\text { basal } \\
\text { Presión }\end{array}$ & $\begin{array}{l}\text { De forma simultánea se tomará junto con } \\
\text { el oxímetro, para lo cual ver protocolo de } \\
\text { presión arterial sistólica. Ver figura } 4 \\
\text { Se solicita al paciente que se siente en }\end{array}$ & $\begin{array}{l}\text { Tensiómetro digital } \\
\text { OMRON modelo BP71ON } \\
\text { referencia: HEM -7121-Z } \\
\text { Tensiómetro digital }\end{array}$ \\
\hline
\end{tabular}




\begin{tabular}{|c|c|c|}
\hline $\begin{array}{l}\text { arterial } \\
\text { sistólica }\end{array}$ & $\begin{array}{l}\text { posición erguida frente al evaluador, se le } \\
\text { pide que extienda el brazo derecho en } \\
\text { relajación para colocar el tensiómetro } \\
\text { apoyado sobre una mesa que estará a una } \\
\text { altura inferior a la altura de su codo. Ver } \\
\text { figura } 4\end{array}$ & $\begin{array}{l}\text { OMRON modelo BP71ON } \\
\text { referencia: HEM -7121-Z }\end{array}$ \\
\hline $\begin{array}{l}\text { Presión } \\
\text { arterial } \\
\text { diastólica }\end{array}$ & $\begin{array}{l}\text { Es el mismo protocolo anterior ya que los } \\
\text { resultados se dan de manera simultánea. } \\
\text { Ver figura } 4\end{array}$ & $\begin{array}{l}\text { Tensiómetro digital } \\
\text { OMRON modelo BP71ON } \\
\text { referencia: HEM -7121-Z }\end{array}$ \\
\hline
\end{tabular}

Fuente de elaboración: Propia

Ilustración 2. Medición talla

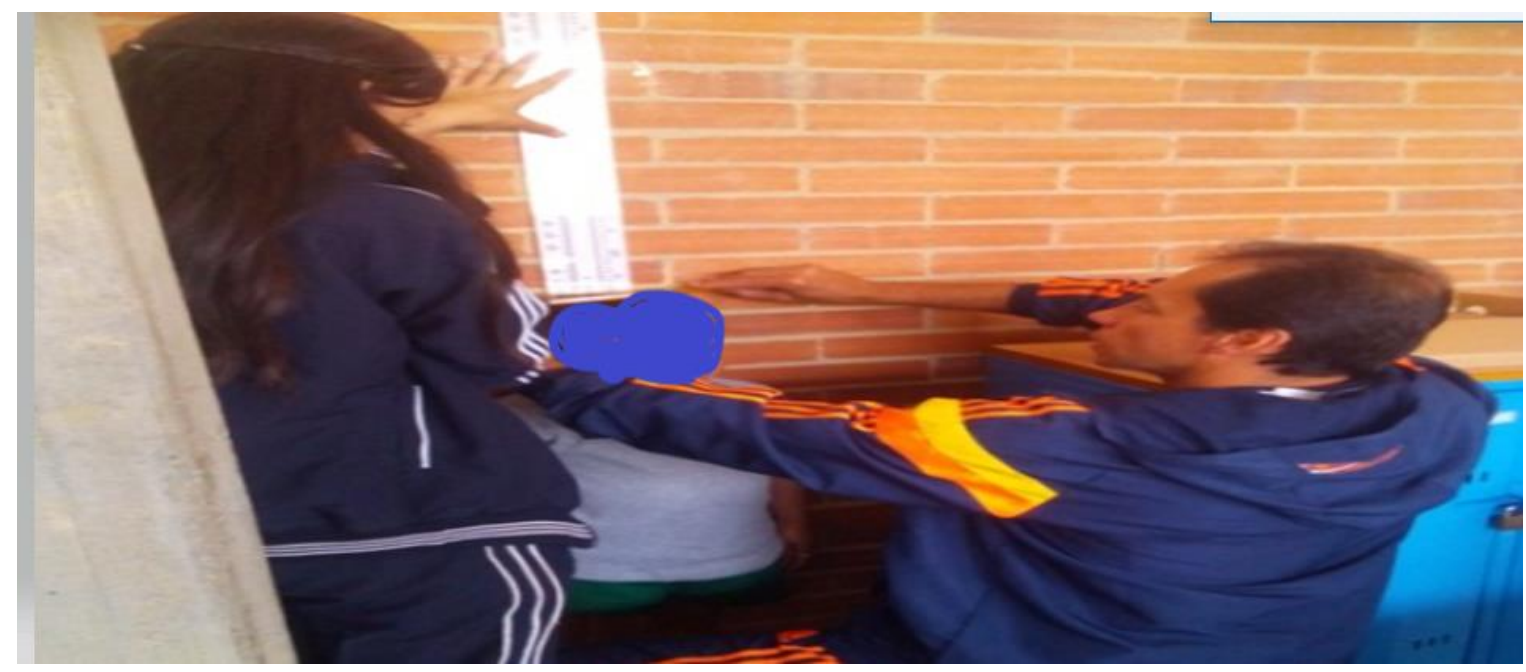


Ilustración 3. Medición peso

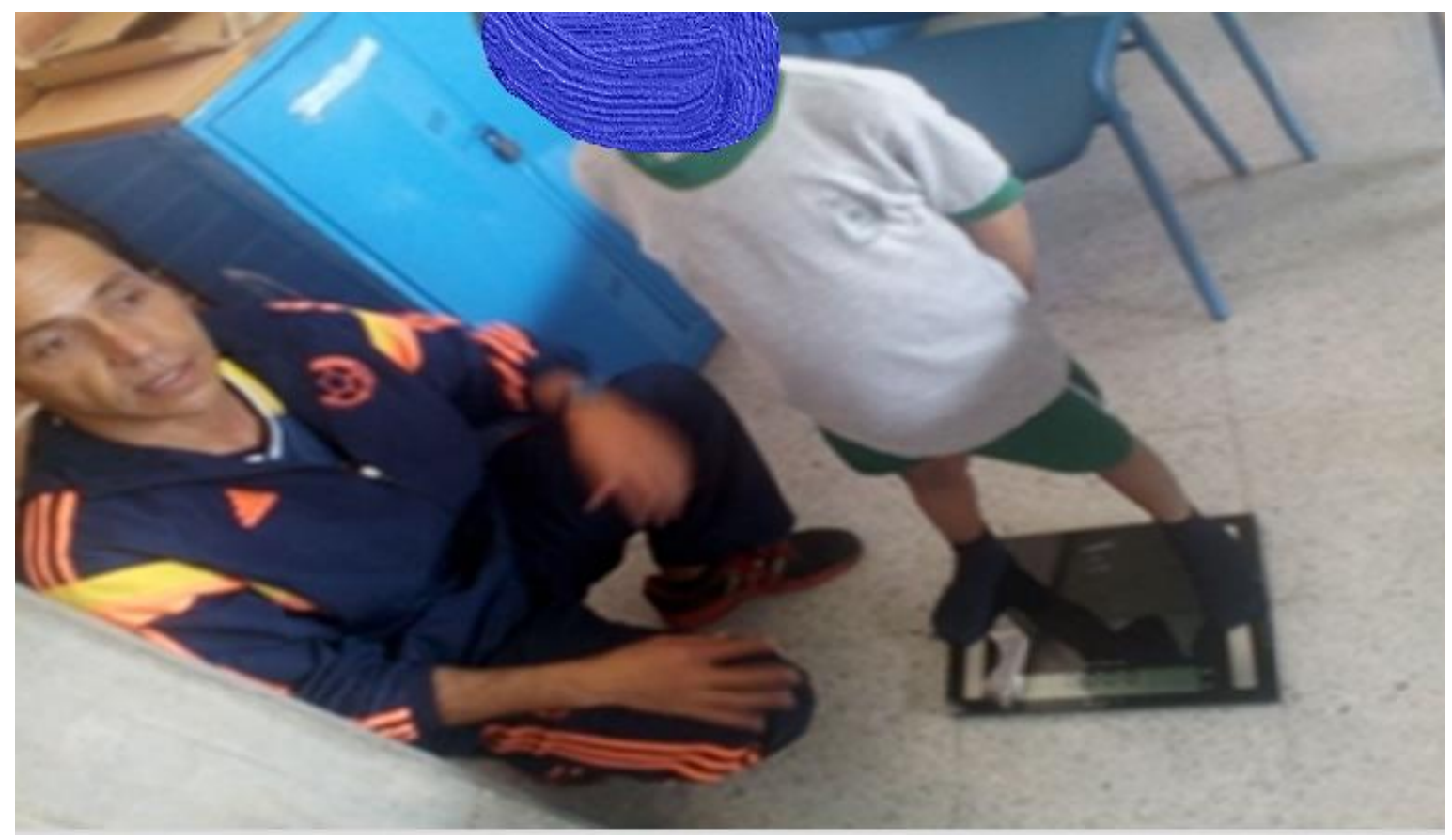

Ilustración 4. Medición contorno de cintura

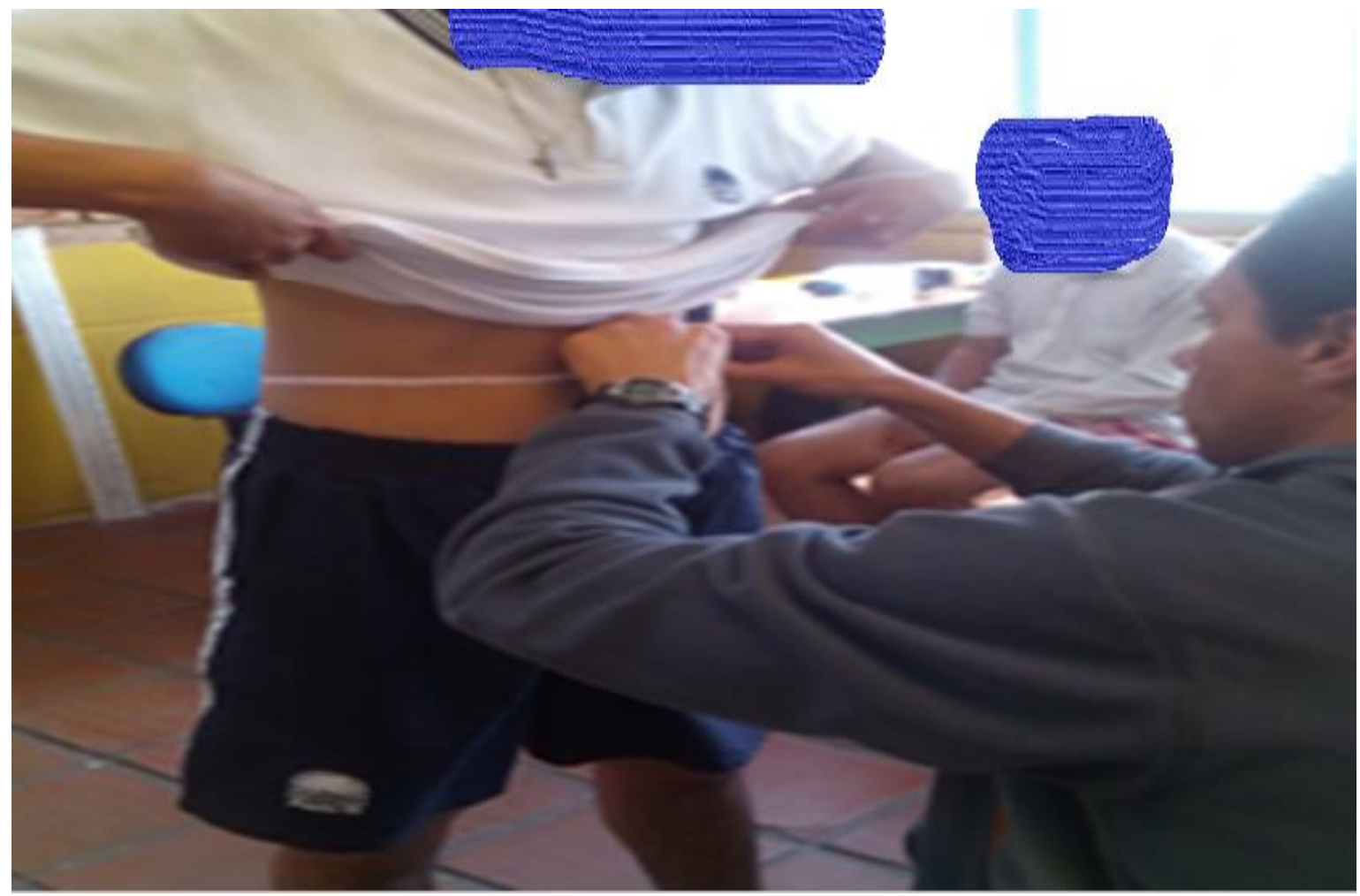


Ilustración 5. Medición presión arterial

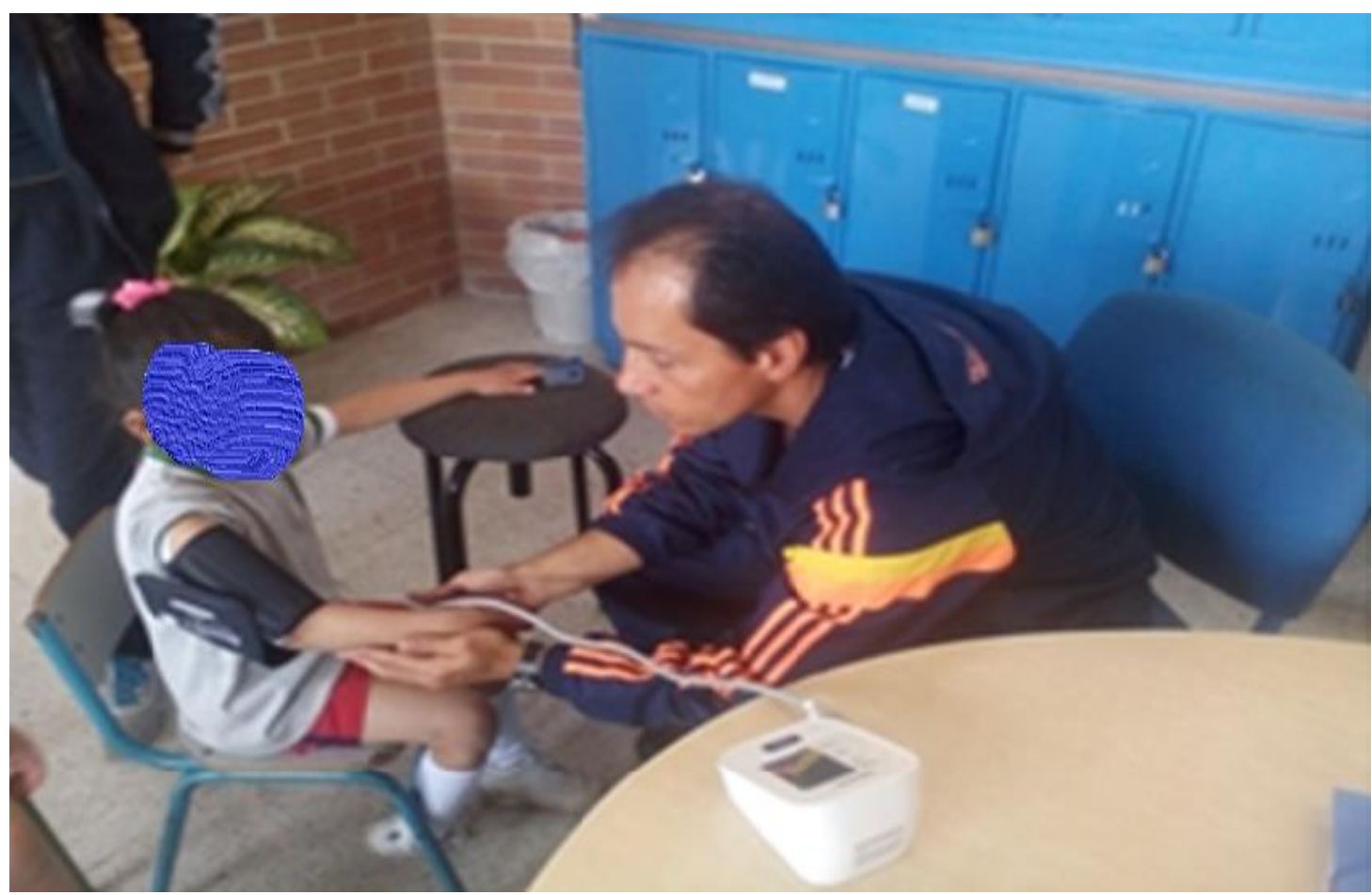

Fuente: Propia

Análisis de Datos

Las variables relacionadas con riesgos cardiovasculares fueron categorizadas de acuerdo con las recomendaciones establecidas por la Organización mundial dela Salud OMS, American Hearth Association AHA (2017). Se aplicaron análisis descriptivos, frecuencias y porcentajes para las variables cualitativas, y promedios con desviaciones estándar para las variables cuantitativas. Posterior a esto, se realizaron pruebas bivariadas entre las categorías de mayor interés, la prueba seleccionada fue el Chi cuadrado, ya que permite medir la relación entre las variables. Los datos se muestran en tablas de contingencia, lo que permite comparar las proporciones por columna mediante el estadístico z. El nivel de significancia seleccionado es de $p \leq 0,05$ y se empleó el software 
IBMSPSS versión 24 (Licencia Universidad Santo Tomás) para el tratamiento de la información.

\section{CAPÍTULO IV}

\section{Descripción de Resultados}

La descripción y el análisis de resultados expuestos en este capítulo atienden al proceso llevado cabo con la recopilación de la información la caracterización de la población de la muestra con los respectivos hallazgos que evidencia el contexto de la Institución Paulo VI IED. En la primera parte se plasma el número de la población con sus edades, género, igualmente, los antecedentes en salud, medicación y los factores de riesgo: tabaquismo, sueño, dieta y actividad física. Para la segunda parte se hace al análisis de las tablas de contingencia, con las diferentes probabilidades de cruces pertinentes determinantes de riesgo cardiovascular en los escolares.

A continuación, se aprecia la relación de las edades y los porcentajes de acuerdo con el total de la muestra.

Características sociodemográficas

\section{Grado escolar}

Tabla 15. Distribución de la población según grado escolar

\begin{tabular}{lll}
\hline Variable & Frecuencia absoluta & Frecuencia Relativa (\%) \\
\hline $\begin{array}{l}\text { Número de estudiantes } \\
\text { por grado: }\end{array}$ & & \\
\hline Preescolar & 250 & $9,82 \%$ \\
\hline Primero & 161 & $6,32 \%$ \\
\hline
\end{tabular}




\begin{tabular}{lll}
\hline Segundo & 226 & $8,84 \%$ \\
\hline Tercero & 237 & $9,31 \%$ \\
\hline Cuarto & 218 & $8,56 \%$ \\
\hline Quinto & 217 & $8,52 \%$ \\
\hline Sexto & 331 & $13 \%$ \\
\hline Séptimo & 240 & $9,43 \%$ \\
\hline Octavo & 244 & $9,58 \%$ \\
\hline Noveno & 150 & $5,89 \%$ \\
\hline Décimo & 170 & $6,67 \%$ \\
\hline Undécimo & 101 & $3,96 \%$ \\
\hline TOTAL & 2545 & $99,90 \%$ \\
\hline
\end{tabular}

Fuente de elaboración: Propia

Figura 6. Distribución de la población según grado escolar

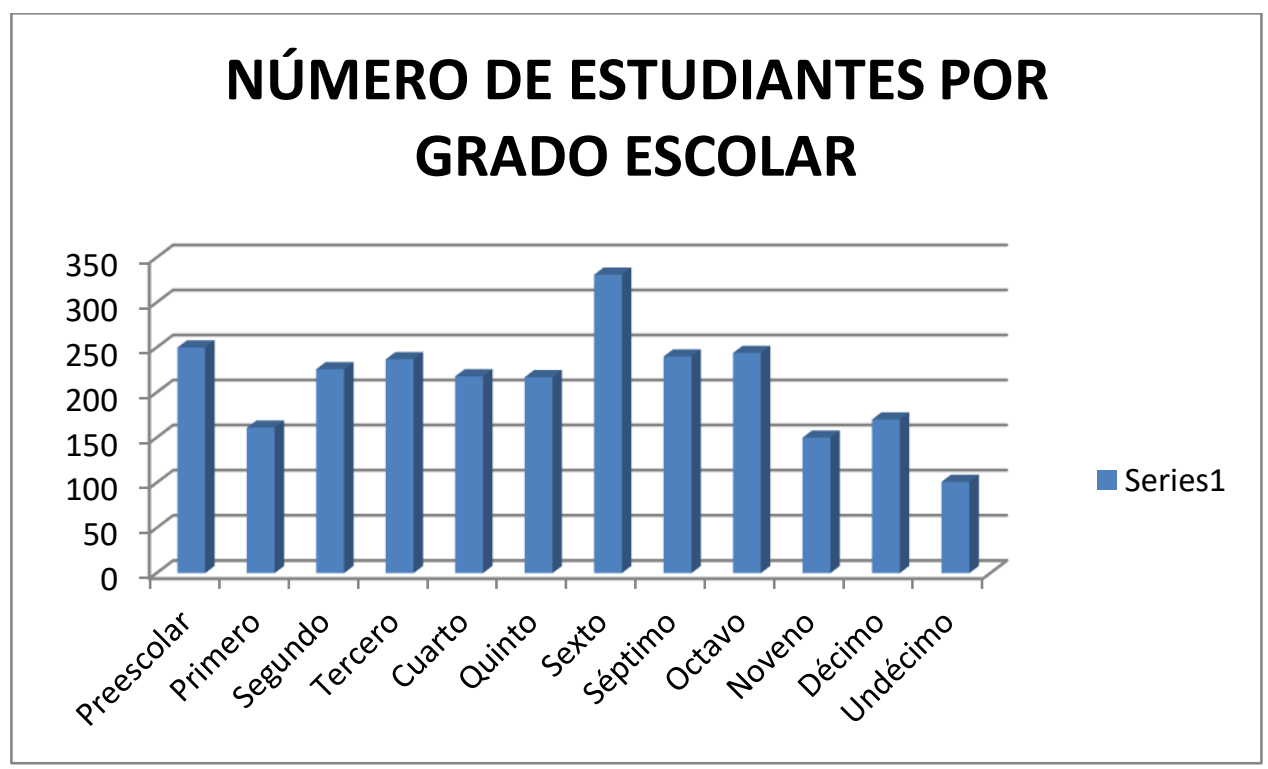

Fuente de elaboración: Propia

La distribución de la población según grado escolar muestra un mayor número de estudiantes en los grados sextos con un porcentaje del 13\%. Igualmente, la población menos numerosa se encuentra en los grados novenos y undécimos con 5,89\% y 3,96\% respectivamente.

Edad 
Tabla 16. Distribución de la población según edad

\begin{tabular}{lll}
\hline Variable & Frecuencia absoluta & Frecuencia Relativa (\%) \\
\hline $\begin{array}{l}\text { Número de estudiantes } \\
\text { por edad: }\end{array}$ & & \\
\hline 5 años & 0 & 0 \\
\hline 6 años & 0 & 0 \\
\hline 7 años & 0 & 0 \\
\hline 8 años & 0 & 0 \\
\hline 9 años & 0 & 0 \\
\hline 10 años & 65 & 15,58 \\
\hline 11 años & 65 & 15,58 \\
\hline 12 años & 62 & 14,86 \\
\hline 13 años & 37 & 8,87 \\
\hline 14 años & 58 & 13,90 \\
\hline 15 años & 50 & 11,99 \\
\hline 16 años & 37 & 8,87 \\
\hline 17 años & 27 & 6,47 \\
\hline 18 años & 14 & 3,35 \\
\hline 19 años & 2 & 0,47 \\
\hline TOTAL & 417 & 99,94 \\
\hline Fun & &
\end{tabular}

Fuente de elaboración: Propia

Figura 7. Distribución de la población según la edad

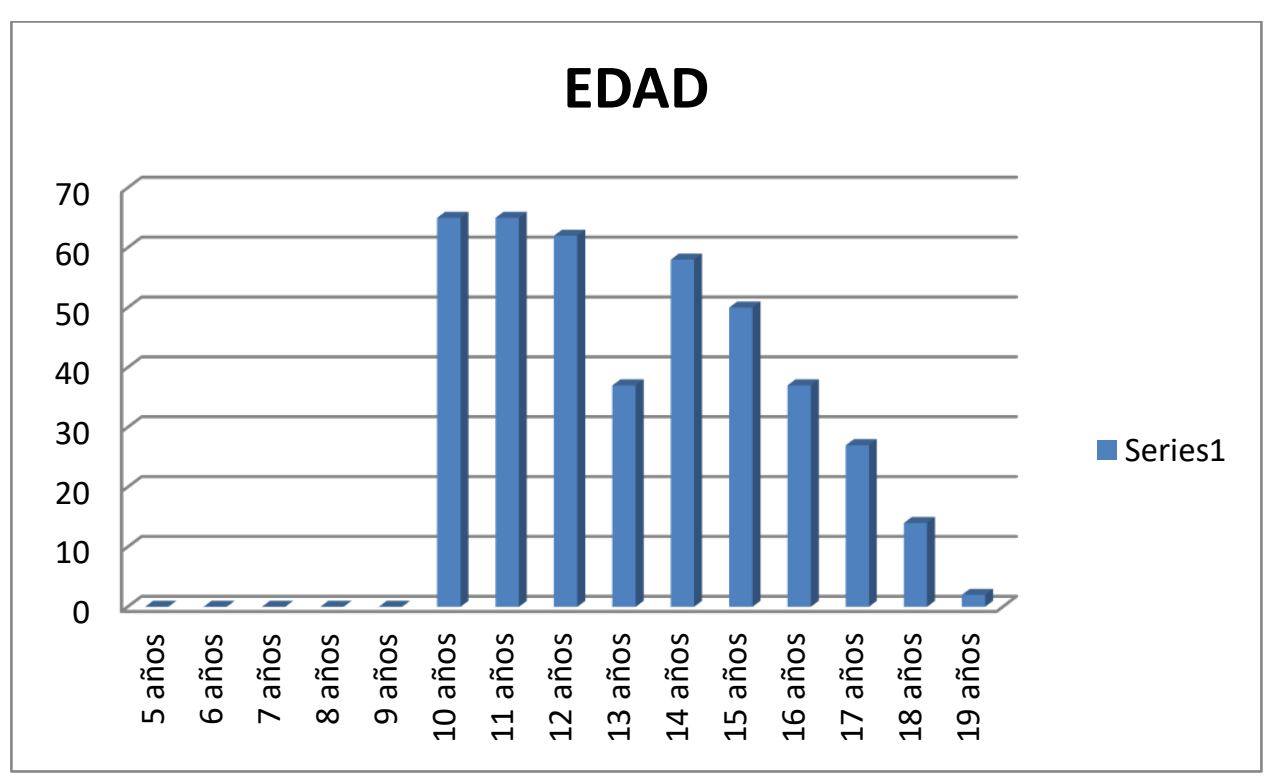

Fuente de elaboración: Propia 
La edad promedio de la población estudiada es de 13,17 \% con un rango entre 10 y 19 años con mayor distribución en la población de 10 y 11 años con un porcentaje de 15,58 en cada uno para total de $31,16 \%$

\section{Género biológico}

Tabla 17. Distribución de la población según género biológico

\begin{tabular}{lll}
\hline Variable & Frecuencia absoluta & Frecuencia Relativa (\%) \\
\hline $\begin{array}{l}\text { Número de estudiantes } \\
\text { por género biológico: }\end{array}$ & & \\
\hline Femenino & 211 & 50,59 \\
\hline Masculino & 206 & 49,40 \\
\hline TOTAL & 417 & 99,99 \\
\hline
\end{tabular}

Fuente de elaboración: Propia

Figura 8. Distribución de la población según género biológico

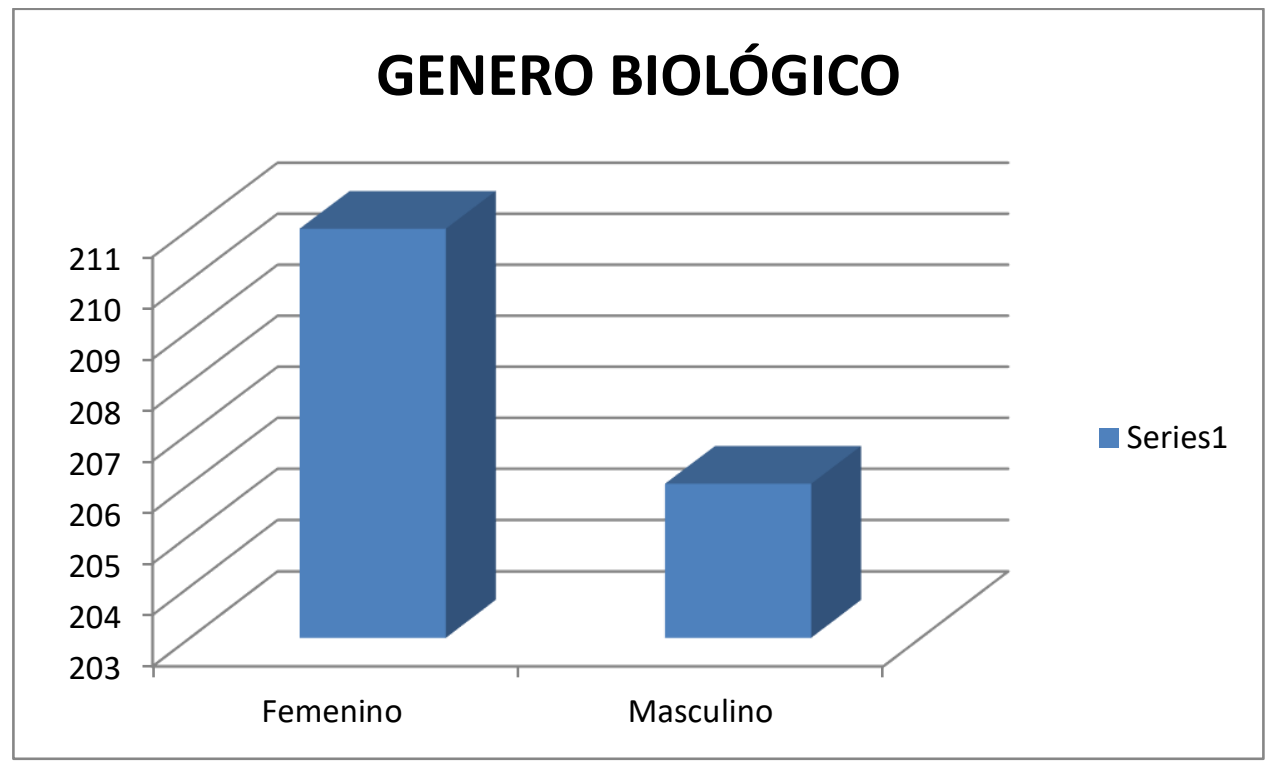

Fuente de elaboración: Propia

La población estudiada es ligeramente más numerosa con 50,59\% de género femenino y $49,40 \%$ masculino.

\section{Núcleo familiar}


Tabla 18. Distribución de la población según organización del Núcleo familiar

\begin{tabular}{lll}
\hline Variable & Frecuencia absoluta & Frecuencia Relativa (\%) \\
\hline $\begin{array}{l}\text { Número de estudiantes } \\
\text { por organización del } \\
\text { núcleo familiar: }\end{array}$ & & \\
\hline Con padres & 396 & 94,96 \\
\hline Con Familiares & 20 & 4,79 \\
\hline Con no familiares & 1 & 0,02 \\
\hline TOTAL & 417 & 99,77 \\
\hline
\end{tabular}

Fuente de elaboración: Propia

Figura 9. Distribución de la población según organización del Núcleo familiar

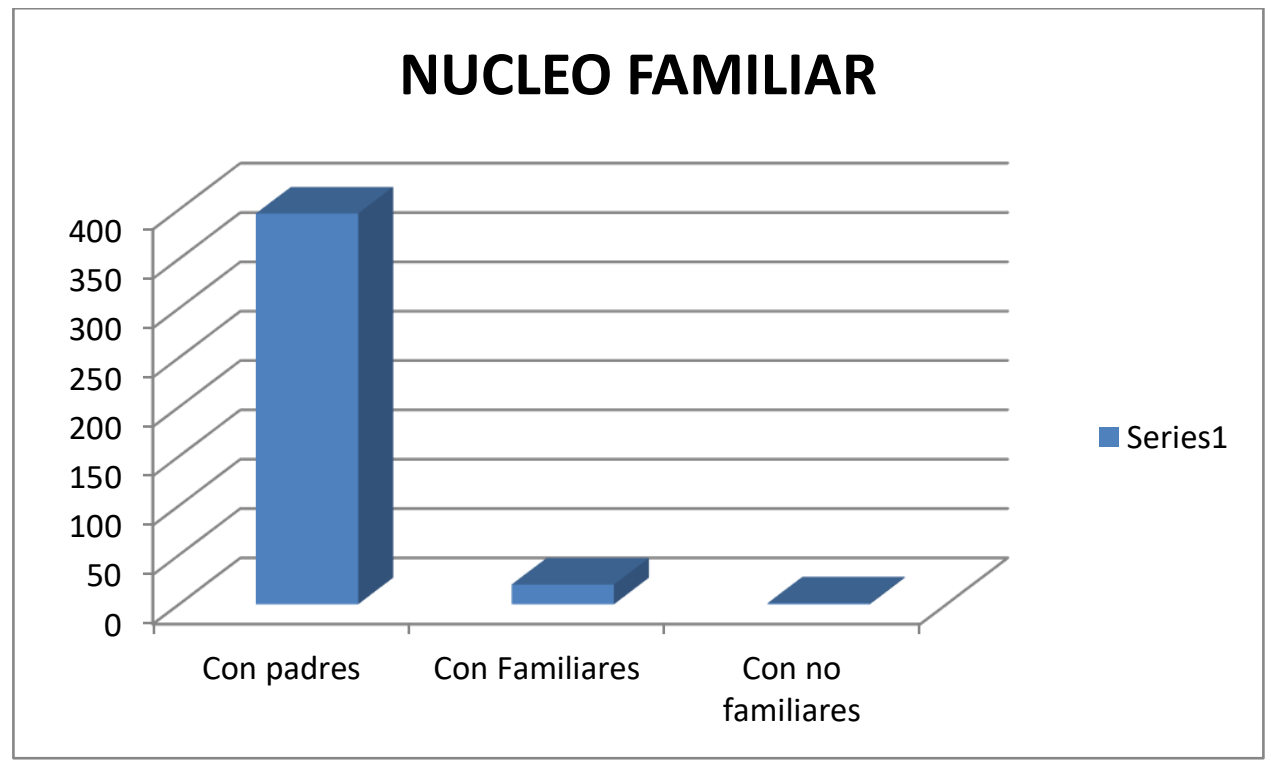

Fuente de elaboración: Propia

El estudio muestra que una gran mayoría de estudiantes viven con sus padres representado en un $94,96 \%$ El restante 4,79 vive con familiares diferentes a los padres y $0,02 \%$ vive con no familiares.

Antecedentes médicos 
Tabla 19. Distribución de la población según antecedentes médicos

\section{Variable}

Número de estudiantes por antecedentes médicos:

Ninguno

Cardiacos

Respiratorios

Osteomusculares

Otros

TOTAL

\begin{tabular}{|l|l} 
Frecuencia absoluta \\
\\
334 \\
6 \\
21 \\
19 \\
37 \\
417
\end{tabular}

Fuente de elaboración: Propia

\begin{tabular}{|l|} 
Frecuencia Relativa $(\%)$ \\
\\
\\
80,09 \\
1,43 \\
5,03 \\
4,55 \\
8,87 \\
99,97
\end{tabular}

\section{Figura 10. Distribución de la población según antecedentes médicos}

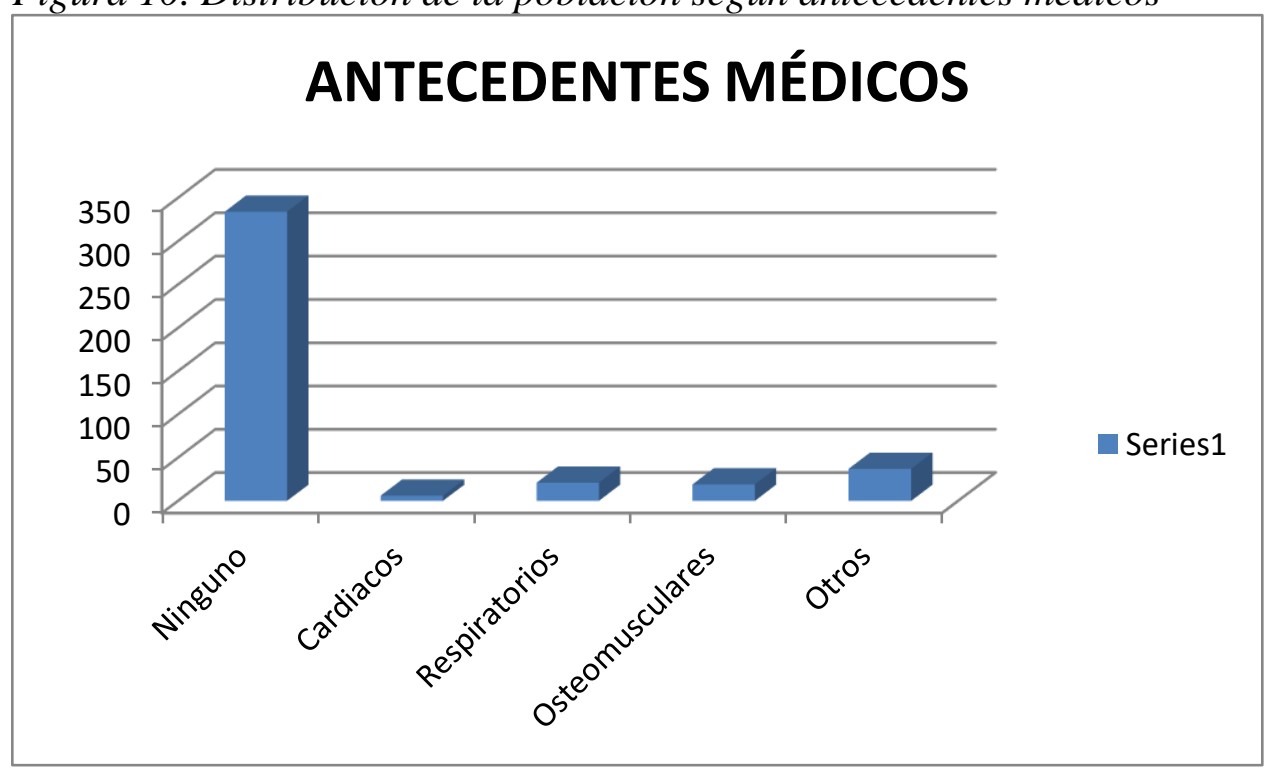

Fuente de elaboración: Propia

La población que no reportó antecedentes médicos corresponde a la gran mayoría, representada en el 80\%; en orden de prevalencia se encuentran las enfermedades respiratorias y los problemas osteomusculares con 5 y $4 \%$ respectivamente, $4,3 \%$ refirió antecedentes cardiovasculares y el 8,87\% corresponde a antecedentes como fracturas, gastritis, migraña, entre otros.

\section{Medicación}


Tabla 20. Distribución de la población según consumo de medicamentos

\begin{tabular}{lll}
\hline Variable & Frecuencia absoluta & Frecuencia Relativa (\%) \\
\hline $\begin{array}{l}\text { Número de estudiantes } \\
\text { que utilizan medicación: }\end{array}$ & & \\
\hline Si & 18 & 4,31 \\
\hline No & 399 & 95,68 \\
\hline TOTAL & 417 & 99,99 \\
\hline
\end{tabular}

Fuente de elaboración: Propia

Figura 11. Distribución de la población según consumo de medicamentos

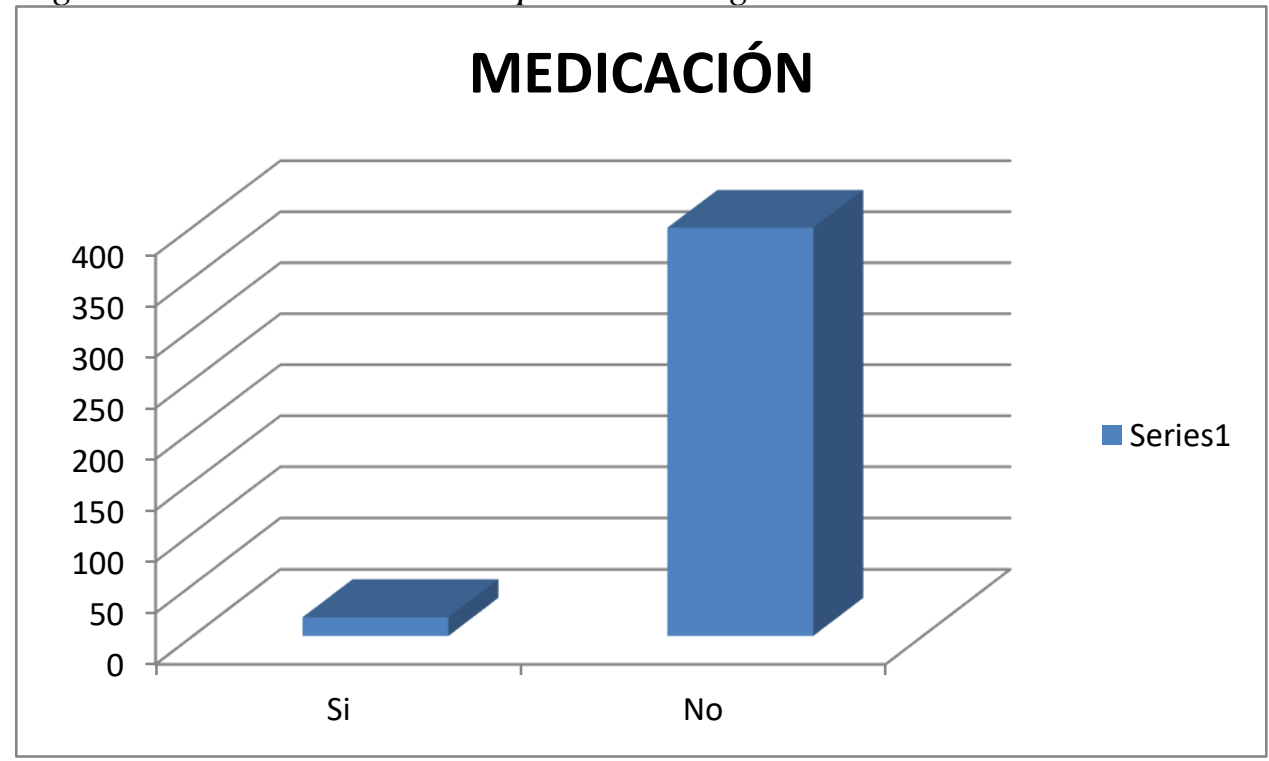

Fuente de elaboración: Propia

El porcentaje de estudiantes sin medicación es del 95,68\%, los estudiantes

medicados son la minoría y corresponde al 4,31\%

Encuesta factores de riesgo y protectores

Horas de sueño 
Tabla 21. Distribución de la población según horas de sueño

\begin{tabular}{lll}
\hline Variable & Frecuencia absoluta & Frecuencia Relativa (\%) \\
\hline $\begin{array}{l}\text { Número de estudiantes } \\
\text { por horas de sueño: }\end{array}$ & & \\
\hline Entre 4 y 6 horas & 95 & 22,78 \\
\hline Entre 7 y 9 horas & 301 & 72,18 \\
\hline Más de 9 horas & 21 & 5,03 \\
\hline TOTAL & 417 & 99,99
\end{tabular}

Fuente de elaboración: Propia

Figura 6. Distribución de la población según horas de sueño

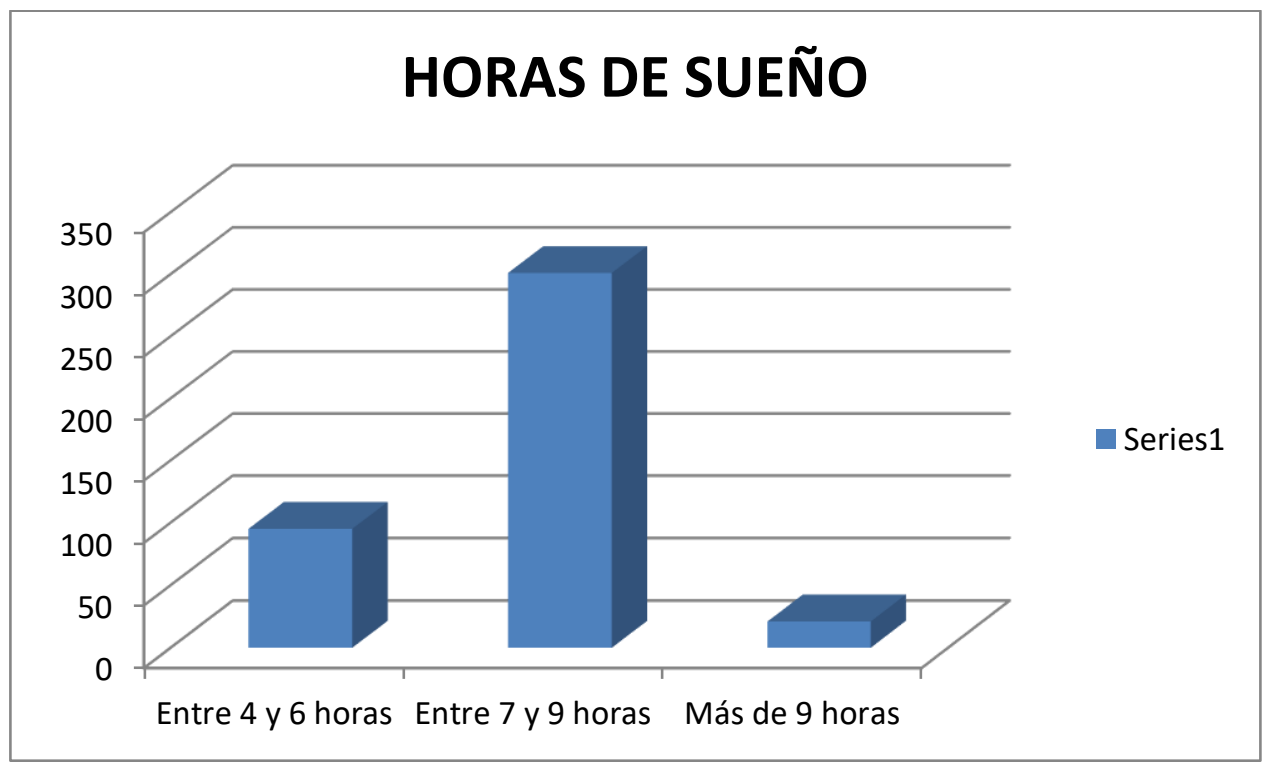

Fuente de elaboración: Propia

La distribución de la población se sitúa en un rango de 72,18 \% para aquellos estudiantes que duermen en promedio 8 horas. $22,78 \%$ entre 4 y 6 horas y 5,03\% para los escolares que reportan más de 9 horas de sueño diario.

\section{Dieta}

Tabla 22. Distribución de la población según dieta

\begin{tabular}{lll}
\hline Variable & Frecuencia absoluta & Frecuencia Relativa (\%) \\
\hline $\begin{array}{l}\text { Número de comidas } \\
\text { diarias realizadas por los } \\
\text { estudiantes: }\end{array}$ & & \\
\hline Solo una comida & 12 & 2,87 \\
\hline Hasta tres comidas & 224 & 53,71 \\
\hline
\end{tabular}


Más de tres comidas

181

43,40

TOTAL

417

99,98

Fuente de elaboración: Propia

Figura 73. Distribución de la población según dieta

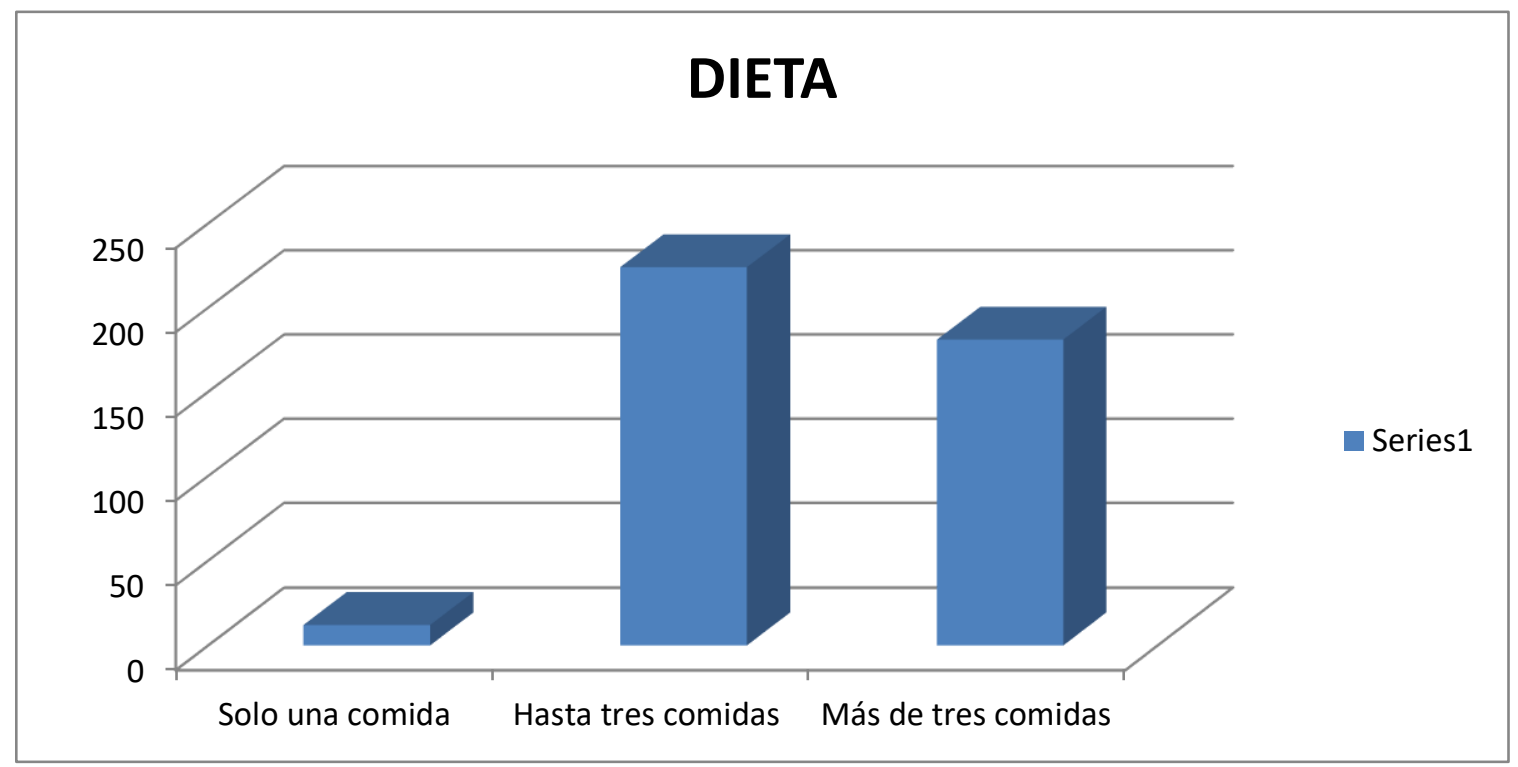

Fuente de elaboración: Propia

La población que representa el mayor porcentaje corresponde al ítem de tres comidas con $53,71 \%$, en segundo lugar, con 43,40 \% están los estudiantes que consumen más tres comidas diarias, quiere decir, que incluyen presuntamente en su dieta algún refrigerio y en tercer lugar con una sola comida se reporta el 2,87\%.

Tabaquismo familiar y personal

Tabla 23. Distribución de la población según tabaquismo personal y pasivo

\begin{tabular}{lll}
\hline Variable & Frecuencia absoluta & Frecuencia Relativa (\%) \\
\hline $\begin{array}{l}\text { Número de estudiantes/ } \\
\text { familiares de tabaquismo: }\end{array}$ & \\
\hline Tabaquismo familiar & & 99,99 \\
\hline SI & 94 & 22,54 \\
\hline No & 323 & 77,45 \\
\hline Tabaquismo personal & & 99,99 \\
\hline Si & 8 & 1,91 \\
\hline
\end{tabular}




\begin{tabular}{llc}
\hline No & 409 & 98,08 \\
\hline TOTAL & 417 &
\end{tabular}

Fuente de elaboración: Propia

Figura 14. Distribución de la población según tabaquismo personal y pasivo

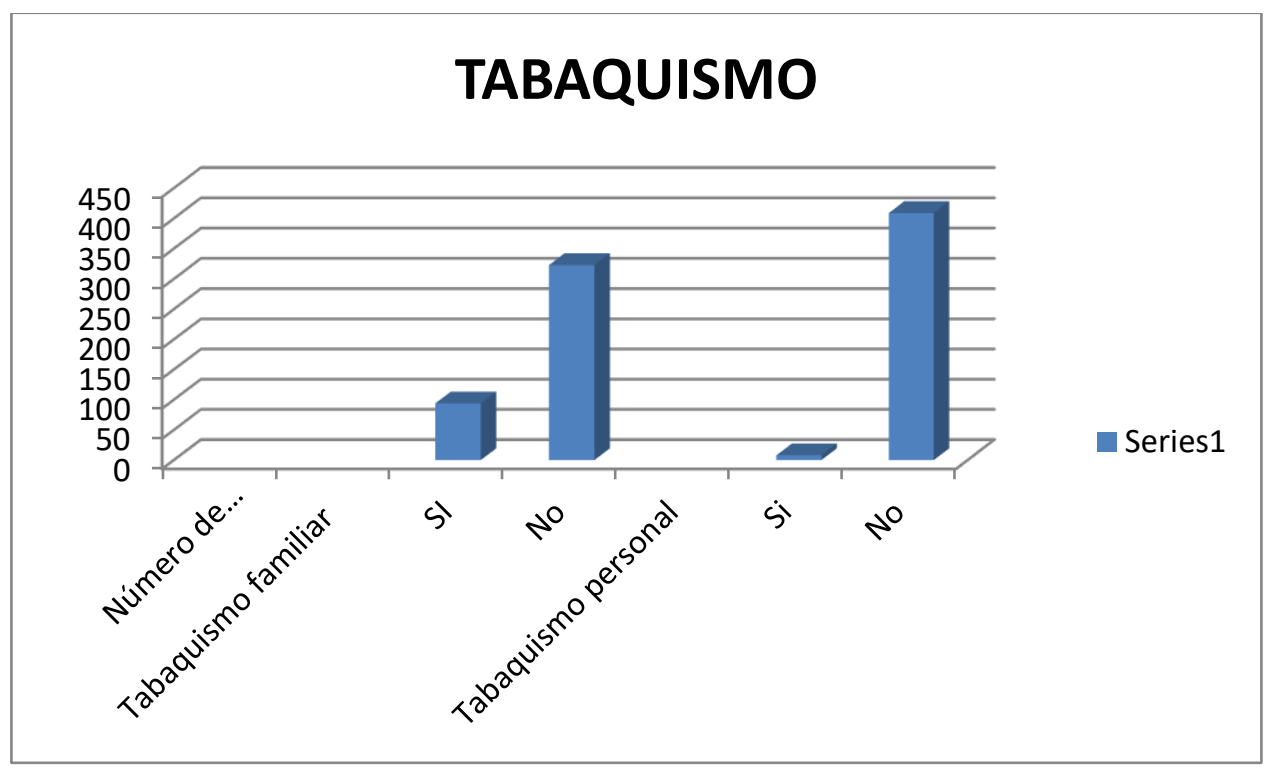

Fuente de elaboración: Propia

La población con mayor consumo de tabaquismo, atendiendo a personas de la familia que fuman compartiendo el mismo espacio corresponde a un 22,54\%. La cantidad de no fumadores es del $77,45 \%$

En cuanto a consumo personal la gran mayoría de estudiantes representada en un 98,08\% no relaciona ningún tipo de consumo. El 1,91\% corresponde a los estudiantes que presentan consumo.

Actividad física extraescolar

Tabla 24. Distribución de la población según práctica de actividad física extraescolar

\begin{tabular}{lll}
\hline Variable & Frecuencia absoluta & Frecuencia Relativa (\%) \\
\hline Número estudiantes por & & \\
\hline
\end{tabular}


actividad física extraescolar:

\begin{tabular}{lll}
\hline Si & 280 & 67,14 \\
\hline No & 137 & 32,85 \\
\hline TOTAL & 417 & 99,99 \\
\hline
\end{tabular}

Fuente de elaboración: Propia

Figura 15. Distribución de la población según Actividad física extraescolar

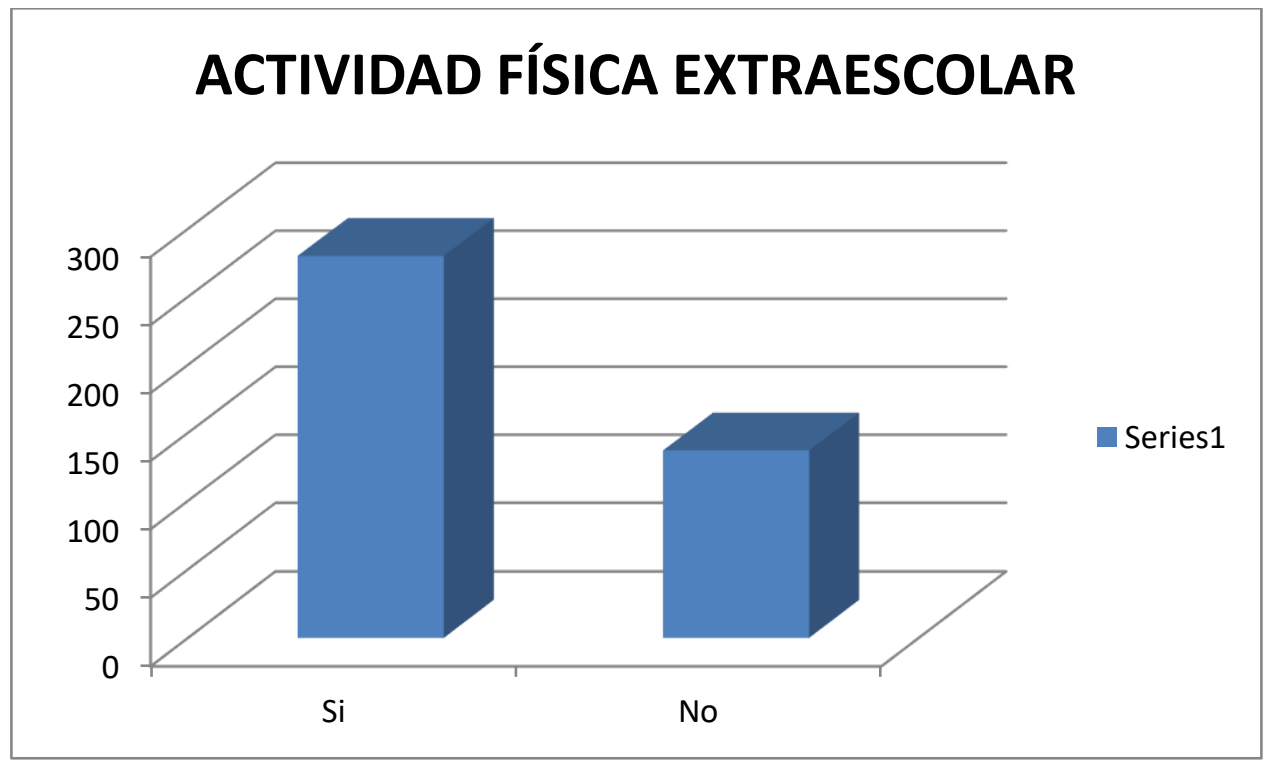

Fuente de elaboración: Propia

La distribución de la población estudiada en cuanto a actividades físicas

extracurriculares corresponde a 67,14\% para aquellos que realizan alguna actividad física o deportiva independiente a la clase regular de Ed. Física. El 32,85\% hace referencia a aquellos estudiantes que no realizan actividad física extraescolar.

Características Antropométricas

IMC - Índice de masa corporal

Tabla 25. Distribución de la población según interpretación del IMC

\begin{tabular}{lll}
\hline Variable & Frecuencia absoluta & Frecuencia Relativa (\%) \\
\hline
\end{tabular}


Número estudiantes por

riesgo según IMC:

\begin{tabular}{lll}
\hline Bajo peso & 10 & 2,39 \\
\hline Normal & 300 & 71,94 \\
\hline Sobrepeso & 78 & 18,70 \\
\hline Obesidad & 29 & 6,95 \\
\hline TOTAL & 417 & 99,98 \\
\hline
\end{tabular}

Figura 16. Distribución de la población según interpretación del IMC

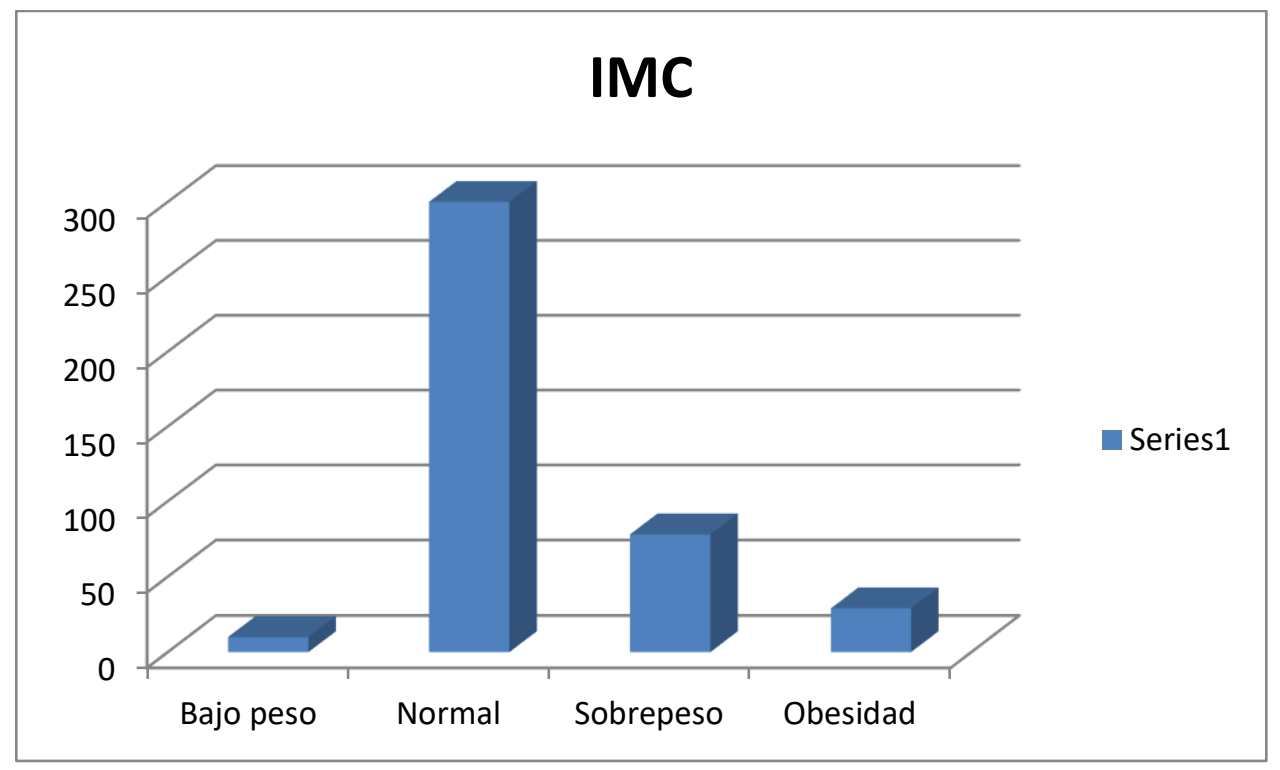

Fuente: Propia

La distribución de la población según la interpretación de los percentiles del índice de masa corporal se sitúa en el rango normal en un 71,94\%. En la gráfica se puede observar dos grupos con riesgo representado en sobrepeso y obesidad con 18,70 y $6,95 \%$ respectivamente, los estudiantes con infra peso se encuentran en un porcentaje del 2,39\%.

El promedio de la población estudiada es de 19,80\%.

Contorno de cintura

Tabla 26. Distribución de la población según interpretación contorno de cintura

\begin{tabular}{lll}
\hline Variable & Frecuencia absoluta & Frecuencia Relativa (\%) \\
\hline Número estudiantes por & & \\
\hline
\end{tabular}


riesgo según contorno de cintura:

\begin{tabular}{lll}
\hline Sin riesgo & 318 & 76,25 \\
\hline Riesgo alto & 79 & 18,94 \\
\hline Riesgo muy alto & 20 & 4,79 \\
\hline TOTAL & 417 & 99,98
\end{tabular}

Figura 8. Distribución de la población según interpretación contorno de cintura

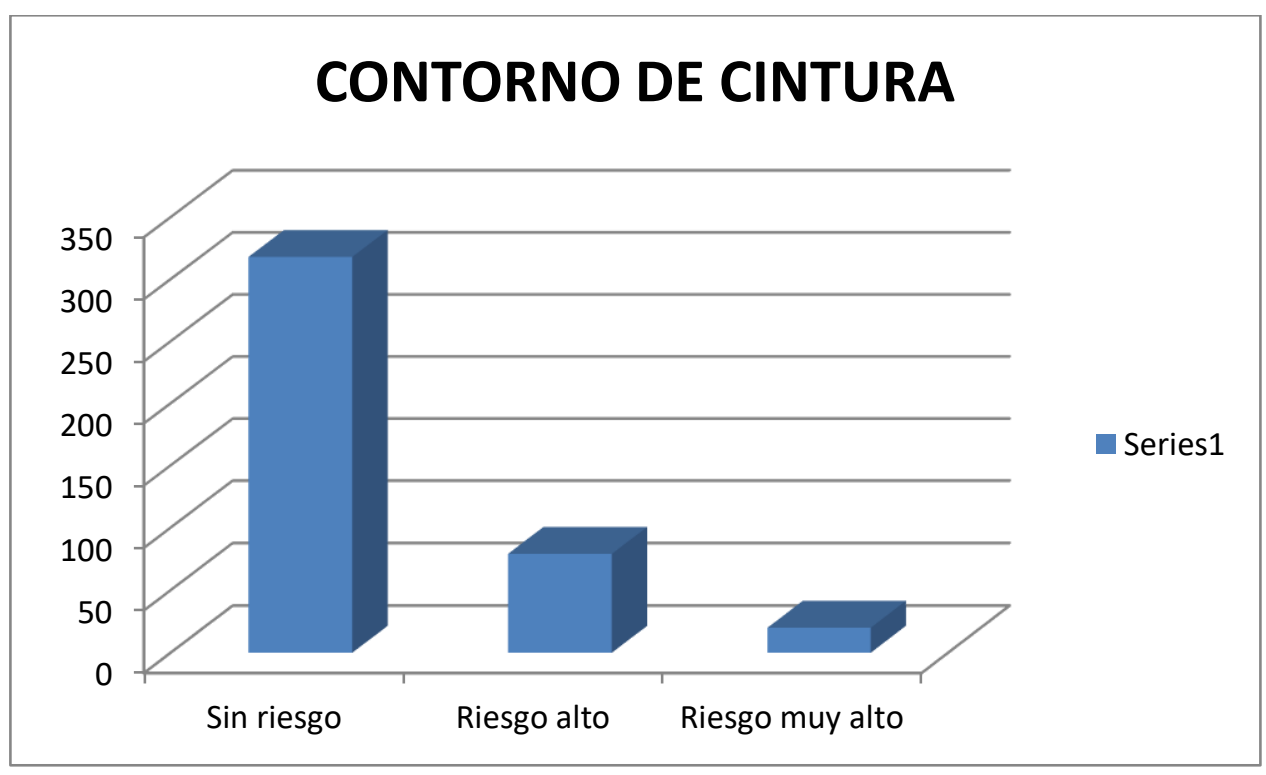

La distribución de la población según la interpretación de los percentiles del contorno de cintura se sitúa en el rango sin riesgo en un 76,25 \%. La población en riesgo se sitúa en un rango del $23 \%$ correspondiente a alto y muy alto con el 18,94 y 4,79 respectivamente. El promedio de la población estudiada es de 71,41 \% Índice cintura talla

Tabla 27. Distribución de la población según interpretación índice cintura-talla

\begin{tabular}{lll}
\hline Variable & Frecuencia absoluta & Frecuencia Relativa (\%) \\
\hline $\begin{array}{l}\text { Número estudiantes por } \\
\text { riesgo según índice de } \\
\text { cintura - talla: }\end{array}$ & & \\
\hline Extremadamente delgado & 0 & \\
\hline Delgado sano & 140 & 0 \\
\hline Sano & 114 & 33,57 \\
\hline
\end{tabular}




\begin{tabular}{lll}
\hline Sobrepeso & 66 & 15,82 \\
\hline Obesidad & 97 & 23,26 \\
\hline TOTAL & 417 & 99,98 \\
\hline
\end{tabular}

Figura 9. Distribución de la población según interpretación índice cintura-talla

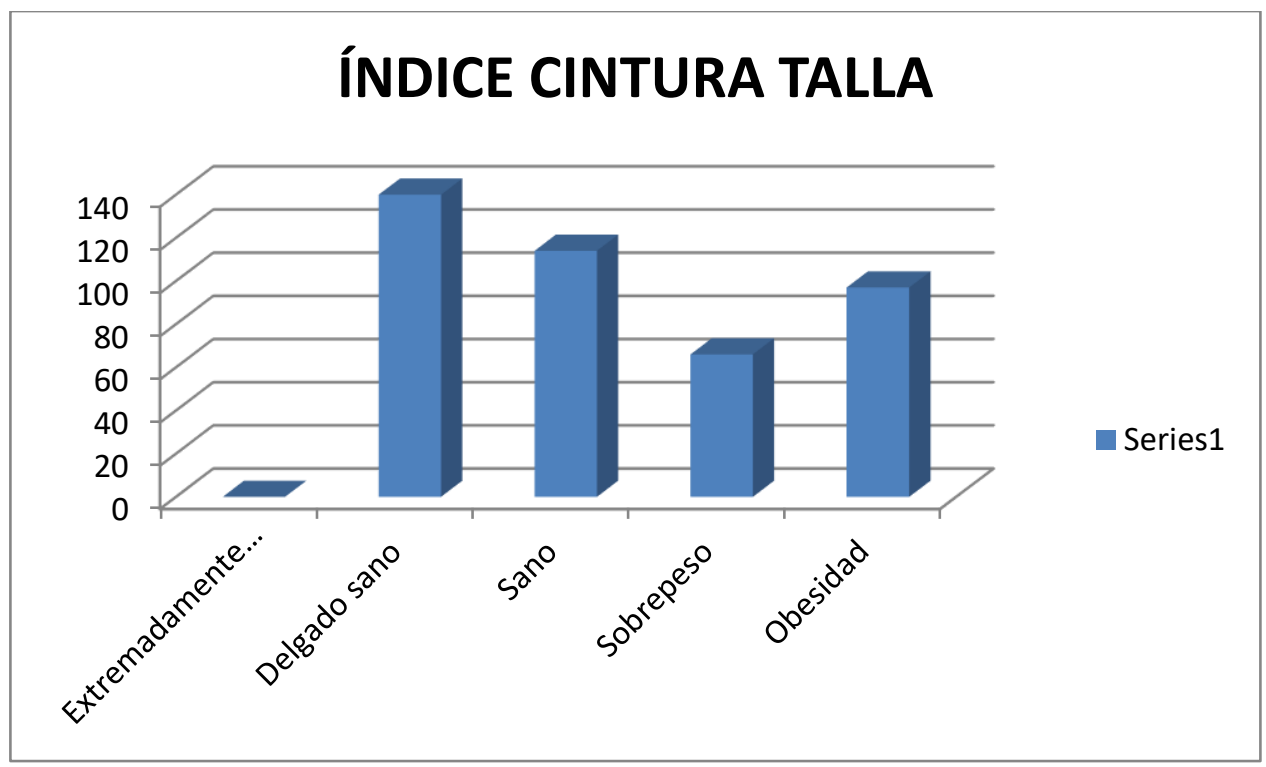

La distribución de la población según la interpretación de los percentiles del índice cintura talla se sitúa en el rango delgado sano y sano en un 33,57 y $27,33 \%$ respectivamente. La población en riesgo está representada en un 15,82 \% con sobrepeso y 23,26\% con obesidad. El promedio de la población estudiada es de $0,47 \%$

Porcentaje graso

Tabla 13. Distribución de la población según interpretación de porcentaje graso.

\begin{tabular}{lll}
\hline Variable & Frecuencia absoluta & Frecuencia Relativa (\%) \\
\hline $\begin{array}{l}\text { Número estudiantes por } \\
\text { riesgo según porcentaje } \\
\text { graso: }\end{array}$ & & \\
\hline Adecuado & 202 & 48,44 \\
\hline Alto & 69 & 16,54 \\
\hline Moderadamente alto & 122 & 29,25 \\
\hline Excesivamente alto & 24 & 5,75 \\
\hline
\end{tabular}


Figura 109. Distribución de la población según interpretación de porcentaje graso

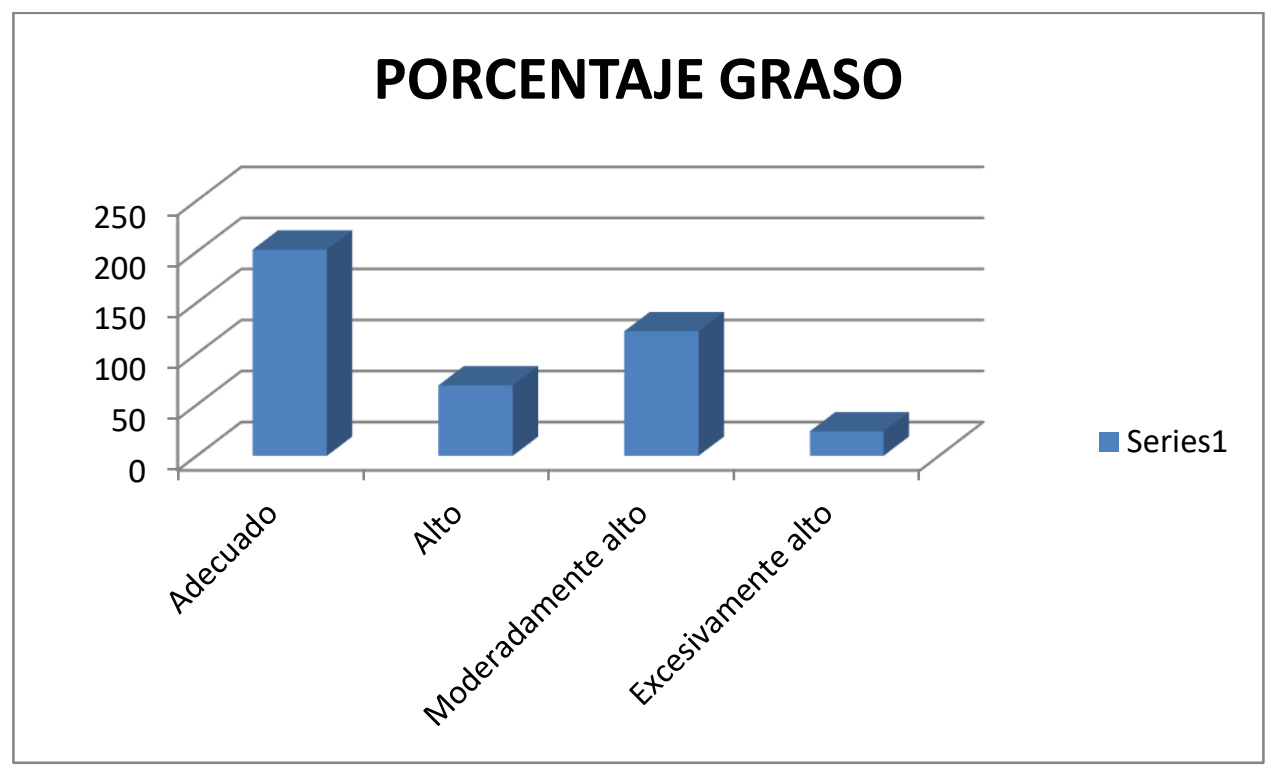

La distribución de la población según la interpretación de los percentiles de 'porcentaje graso se sitúa en el rango adecuado en un 48,44\%, alto en un $16,54 \%$, moderadamente alto en un 29,25\% y excesivamente alto 5,75\%. El promedio de la población estudiada es de $23,84 \%$

Tabla 29. Estadísticos de características antropométricas

\begin{tabular}{lll|l|l|l} 
& IMC & CC & ICT & \% graso \\
\hline $\mathrm{N}$ & Válido & 417 & 417 & 417 & 417 \\
\cline { 2 - 6 } & Perdidos & 0 & 0 & 0 & 0 \\
\hline Media & 19,7588 & 71,42 &, 4678 & 23,8355 \\
\hline Mediana & 19,2000 & 70,00 &, 4600 & 23,7900 \\
\hline Moda & $17,20^{a}$ & 70 &, 43 & 24,61 \\
\hline Desviación estándar & 3,54662 & 9,404 &, 05366 & 6,22122 \\
\hline Varianza & 12,578 & 88,431 &, 003 & 38,704 \\
\hline
\end{tabular}


Fuente: Propia

Las características antropométricas de la población estudiada demuestran que, según la interpretación de los percentiles prevalecen: IMC se sitúa en el rango normal con un $71,94 \%$, el promedio del IMC de la población estudiada es de 19,7, contorno de cintura se sitúa en el rango sin riesgo $76,25 \%$, el promedio de contorno de cintura de la población estudiada es de 71.42, índice de cintura y talla se sitúa en el rango delgado sano con 33,57\%, el promedio del índice de cintura - talla de la población es de 0,46 , porcentaje graso prevalece el rango Adecuado con $48,44 \%$, el promedio del porcentaje graso de la población estudiada es de $23,83 \%$.

Características Hemodinámicas

Frecuencia cardiaca

Tabla 30. Distribución de la población según interpretación de FC basal por AHA

\begin{tabular}{lll}
\hline Variable & $\begin{array}{l}\text { Frecuencia } \\
\text { absoluta }\end{array}$ & $\begin{array}{l}\text { Frecuencia Relativa } \\
(\boldsymbol{\%})\end{array}$ \\
\hline $\begin{array}{l}\text { Número estudiantes por riesgo según } \\
\text { porcentaje graso: }\end{array}$ & & \\
\hline Bradicardia & 37 & 8,87 \\
\hline Normal & 336 & 80,57 \\
\hline Taquicardia & 44 & 10,55 \\
\hline TOTAL & 417 & 99,99 \\
\hline
\end{tabular}


Figura 20. Distribución de la población según interpretación de FC basal por AHA

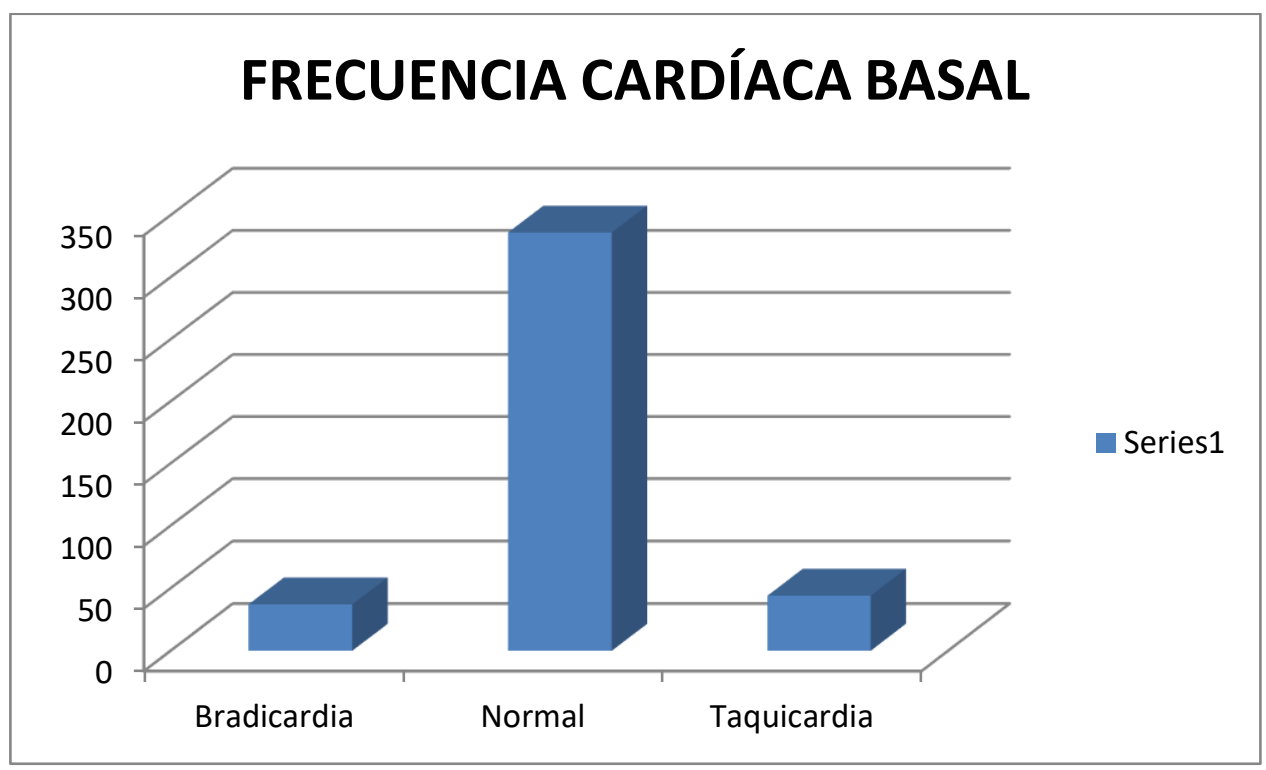

La distribución de la población según la interpretación de los percentiles en

frecuencia cardíaca se sitúa en el rango normal en un 80,57 \%, bradicardia en un 8,87 \%, y taquicardia en un 10,55 \% El promedio de la población estudiada es de 81,55 \%

Presión arterial sistólica

Tabla 31. Distribución de la población según interpretación de PAS por AHA

\begin{tabular}{lll}
\hline Variable & Frecuencia absoluta & Frecuencia Relativa (\%) \\
\hline $\begin{array}{l}\text { Número estudiantes por } \\
\text { riesgo según presión } \\
\text { arterial sistólica: }\end{array}$ & & \\
\hline Hipotensión sistólica & 17 & 4,07 \\
\hline Hipotenso & 135 & 32,37 \\
\hline Normotenso & 236 & 56,59 \\
\hline Hipertenso & 29 & 6,95 \\
\hline TOTAL & 417 & 99,98 \\
\hline
\end{tabular}


Figura 21. Distribución de la población según interpretación de PAS por AHA

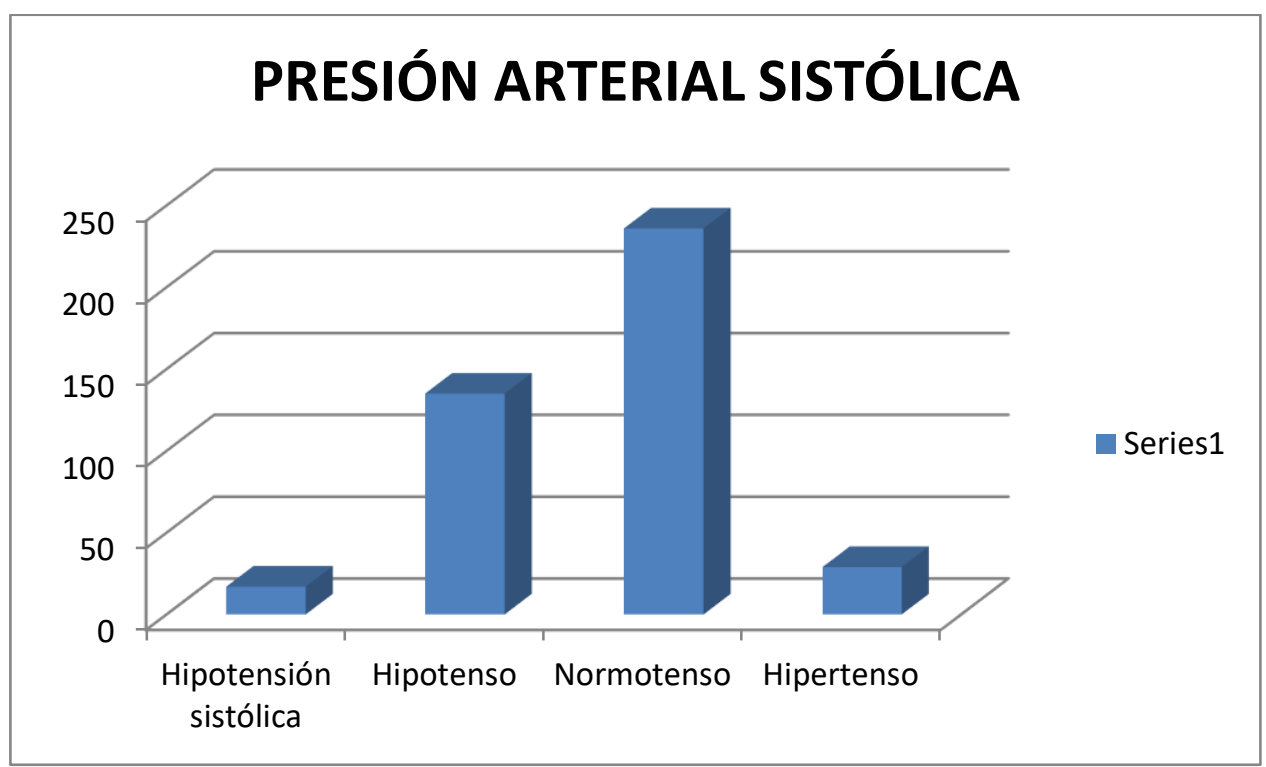

La distribución de la población según la interpretación de los percentiles en presión arterial sistólica se sitúa en el rango normotenso en un 56,59 \%, hipotensión sistólica 4,07 $\%$, hipotensión en un 32,37 \% e hipertensión en 6,95\%. El promedio de la población estudiada es de $110,74 \%$

\section{Presión arterial diastólica}

Tabla 32. Distribución de la población según interpretación de PAD por AHA

\begin{tabular}{lll}
\hline Variable & Frecuencia absoluta & Frecuencia Relativa (\%) \\
\hline $\begin{array}{l}\text { Número estudiantes por } \\
\text { riesgo según presión } \\
\text { arterial diastólica: }\end{array}$ & & \\
\hline Hipotensión diastólica & 0 & 0 \\
\hline Hipotenso & 71 & 17,02 \\
\hline Normotenso & 311 & 74,58 \\
\hline Hipertenso & 35 & 8,39 \\
\hline TOTAL & 417 & 99,99 \\
\hline
\end{tabular}


Figura 22. Distribución de la población según interpretación de PAD por AHA

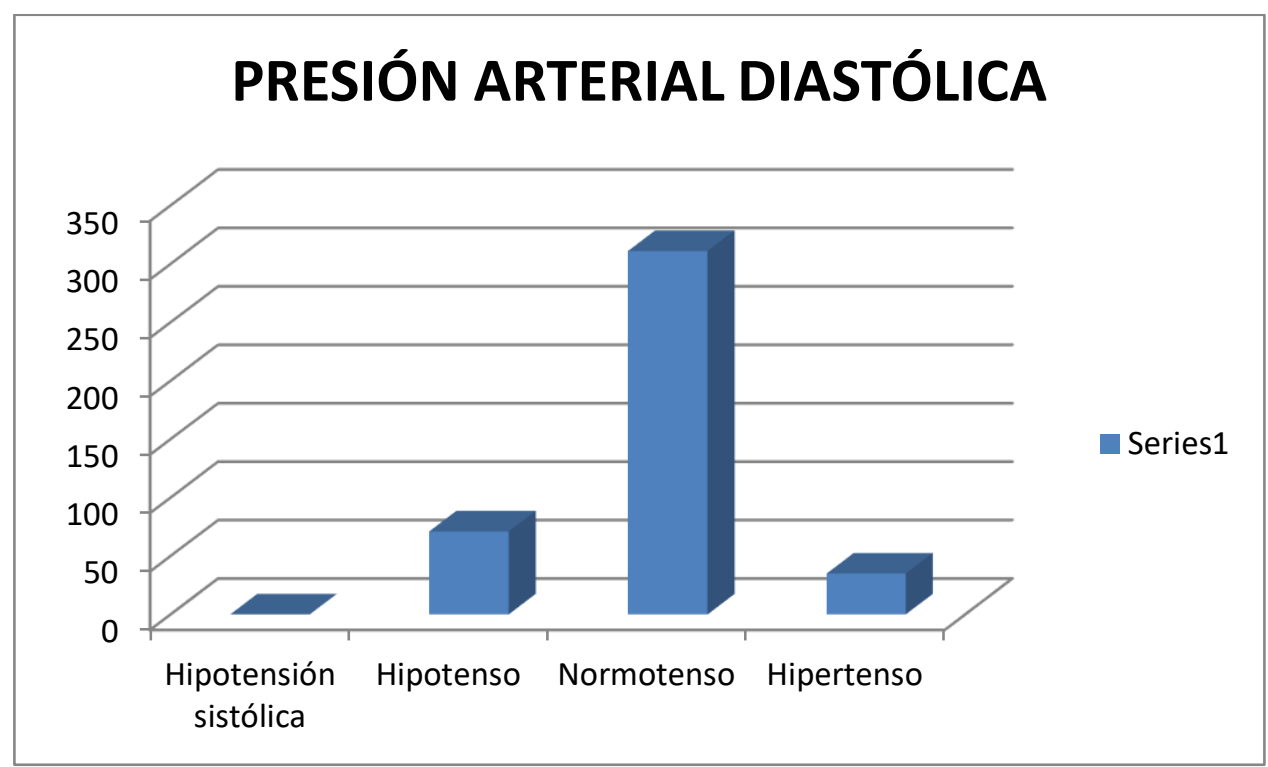

La distribución de la población según la interpretación de los percentiles en presión arterial diastólica se sitúa en el rango normotenso en un 74,58 \%, hipotensión diastólica 0 $\%$, hipotensión en un 17,02 \% e hipertensión en 8,39 \%. El promedio de la población estudiada es de $70,45 \%$

Tabla 33. Estadísticos de características hemodinámicas

\begin{tabular}{lll|l|l} 
& & FCB & PAS & PAD \\
\hline N & Válido & 417 & 417 & 417 \\
\cline { 2 - 5 } & Perdidos & 0 & 0 & 0 \\
\hline Media & 81,56 & 110,75 & 70,45 \\
\hline Mediana & 80,00 & 110,00 & 70,00 \\
\hline Moda & 84 & 106 & 70 \\
\hline Desviación estándar & 13,553 & 14,097 & 9,593 \\
\hline Varianza & 183,680 & 198,737 & 92,017 \\
\hline
\end{tabular}

Fuente: Propia 
Resumen de características hemodinámicas. Las características hemodinámicas de la población estudiada según la interpretación de American Hearth Association AHA demuestran que en la frecuencia cardiaca basal (FCB) prevalece el rango Normal $80 \%$. El promedio de la frecuencia cardiaca basal de la población estudiada es de 81,56 en la presión arterial sistólica (PAS) prevalece Normotenso con 56,59\%. El promedio de la Presión arterial Sistólica de la población estudiada es de 110,75. La presión arterial diastólica (PAD) prevalece Normotenso con 74,58\% El promedio de la presión arterial diastólica de la población estudiada es de 70,45.

\section{Cruce de Variables.}

Con respecto a las variables involucradas en este estudio, se realizaron tablas de contingencia con pruebas bivariadas entre las categorías de mayor interés para conocer los porcentajes de cada nivel o estrato de algunas variables y también medir estadísticamente la asociación o no entre ellas, esta medida se calcula con el estadístico chi cuadrado, el test exacto o la prueba exacta de Fisher según sea el caso. El nivel de significancia seleccionado es de $\mathrm{p} \leq 0,05$.

Entonces se plantean las hipótesis estadísticas como sigue:

\section{Cruce de variables relacionadas frente al género biológico}

\section{Relación índice de masa corporal- género biológico}

Tabla 34. Interpretación del Índice masa corporal y género

\begin{tabular}{|c|c|c|c|c|c|c|c|c|}
\hline \multirow[b]{2}{*}{ Género } & \multicolumn{8}{|c|}{ Interpretación del IMC } \\
\hline & Bajo peso & $\%$ & Normal & $\%$ & Obesidad & $\%$ & sobrepeso & $\%$ \\
\hline Femenino & 5 & $50,0 \%$ & 146 & $48,7 \%$ & 17 & $58,6 \%$ & 43 & $55,1 \%$ \\
\hline Masculino & 5 & $50,0 \%$ & 154 & $51,3 \%$ & 12 & $41,4 \%$ & 35 & $44,9 \%$ \\
\hline Total & 10 & $100,00 \%$ & 300 & $100,00 \%$ & 29 & $100,00 \%$ & 78 & $100,00 \%$ \\
\hline
\end{tabular}

Tabla 35. Pruebas de chi-cuadrado Interpretación del Índice masa corporal y género 


\begin{tabular}{|c|c|c|c|c|}
\hline & Valor & df & $\begin{array}{l}\text { Significación } \\
\text { asintótica } \\
\text { (bilateral) }\end{array}$ & $\begin{array}{c}\text { Significación } \\
\text { exacta } \\
\text { (bilateral) }\end{array}$ \\
\hline $\begin{array}{l}\text { Chi-cuadrado de } \\
\text { Pearson }\end{array}$ & $1,836^{a}$ & 3 &, 607 &, 628 \\
\hline Razón de verosimilitud & 1,842 & 3 & ,606 & ,633 \\
\hline Prueba exacta de Fisher & 1,876 & & & ,613 \\
\hline $\mathrm{N}$ de casos válidos & 417 & & & \\
\hline
\end{tabular}

a. 1 casillas $(12,5 \%)$ han esperado un recuento menor que 5 . El recuento

Fuente de elaboración: Propia

Como se expone en la tabla 35 el porcentaje de la frecuencia observada en la tabla cruzada para estas variables es de $12,5 \%$, entonces, se toma el valor $\mathrm{p}$ de la prueba chi cuadrado que es $0,607>0,05$, es decir, la prueba no es significante al $5 \%$ y se concluye que con una confianza del 95\% no se rechaza la hipótesis nula, es decir, el género y el IMC no están asociados.

\section{Relación contorno de cintura- género}

Tabla 36. Interpretación del contorno de cintura y género

\begin{tabular}{llllllll}
\hline \multicolumn{7}{c}{ Interpretación Contorno cintura } & \\
Género & Riesgo alto & $\%$ & Riesgo muy alto & $\%$ & Sin riesgo & $\%$ \\
\hline Femenino & 45 & $57,0 \%$ & 13 & $65,0 \%$ & 153 & $48,1 \%$ \\
Masculino & 34 & $43,0 \%$ & 7 & $35,0 \%$ & 165 & $51,9 \%$ \\
Total & 79 & $100,00 \%$ & 20 & $100,00 \%$ & 318 & $100,00 \%$ \\
\hline
\end{tabular}

Fuente de elaboración: Propia 
Tabla 37. Pruebas de Chi-cuadrado Interpretación del contorno de cintura y género

\begin{tabular}{|c|c|c|c|c|}
\hline & Valor & $\mathrm{df}$ & $\begin{array}{l}\text { Significación } \\
\text { asintótica } \\
\text { (bilateral) }\end{array}$ & $\begin{array}{l}\text { Significación } \\
\text { exacta (bilateral) }\end{array}$ \\
\hline Chi-cuadrado de Pearson & $3,725^{\mathrm{a}}$ & 2 & ,155 &, 153 \\
\hline Razón de verosimilitud & 3,758 & 2 &, 153 &, 153 \\
\hline Prueba exacta de Fisher & 3,678 & & &, 155 \\
\hline $\mathrm{N}$ de casos válidos & 417 & & & \\
\hline
\end{tabular}

a. 0 casillas $(, 0 \%)$ han esperado un recuento menor que 5 . El recuento mínimo esperado es 9,88 .

Fuente de elaboración: Propia

De acuerdo con los resultados de la tabla 37 el valor p de la prueba chi cuadrado proporcionada por SPSS es $0,153>0,05$, es decir, la prueba no es significante y se concluye que con una confianza del $95 \%$ no se rechaza la hipótesis nula por consiguiente el género y el $\mathrm{CC}$ son independientes.

\section{Relación índice cintura-talla- género}

Tabla 38. Interpretación del índice cintura-talla con el género

\begin{tabular}{llllllllll}
\hline \multicolumn{3}{c}{ Interpretación del ICT } & & & & & \\
Género & delgado sano & $\%$ & Obesidad & $\%$ & sano & $\%$ & sobrepeso & $\%$ \\
\hline Femenino & 19 & $13,6 \%$ & 63 & $64,9 \%$ & 88 & $77,2 \%$ & 41 & $62,1 \%$ \\
\hline Masculino & 121 & $86,4 \%$ & 34 & $35,1 \%$ & 26 & $22,8 \%$ & 25 & $37,9 \%$ \\
Total & 140 & $100,00 \%$ & 97 & $100,00 \%$ & 114 & $100,00 \%$ & 66 & $100,00 \%$ \\
\hline
\end{tabular}

Fuente de elaboración: Propia 
Tabla 39. Prueba de Chi cuadrado interpretación del índice cintura-talla con el género

\begin{tabular}{ll|l|l|l} 
& & & $\begin{array}{l}\text { Significación } \\
\text { asintótica } \\
\text { (bilateral) }\end{array}$ & $\begin{array}{l}\text { Significación } \\
\text { exacta (bilateral) }\end{array}$ \\
\hline & Valor & Df &, 000 &, 000 \\
\hline Chi-cuadrado de Pearson & $120,540^{\mathrm{a}}$ & 3 &, 000 &, 000 \\
\hline Razón de verosimilitud & 131,170 & 3 & &, 000 \\
\hline Prueba exacta de Fisher & 129,937 & & & \\
\hline N de casos válidos & 417 & & & \\
\hline
\end{tabular}

a. 0 casillas $(, 0 \%)$ han esperado un recuento menor que 5 . El recuento mínimo esperado es 32,60 .

En la tabla 39, ya que el porcentaje de la frecuencia esperada es $0 \%$ se utiliza en este caso la prueba chi cuadrado el valor $\mathrm{p}$ de la prueba de significación bilateral $0,000 \leq$ 0,05 , luego, la prueba es significante, es decir, que con una confianza del $95 \%$ se rechaza la hipótesis nula, entonces, el ICT y el género no son independientes.

\section{Cruces entre variables Antropométricas}

\section{Relación índice de masa corporal -contorno de cintura}

Tabla 40. Interpretación del IMC con el contorno de cintura

\begin{tabular}{|c|c|c|c|c|c|c|}
\hline \multirow{3}{*}{$\begin{array}{l}\text { Interpretación } \\
\text { índice de Masa } \\
\text { Corporal }\end{array}$} & \multicolumn{6}{|c|}{ Categorías contorno de cintura } \\
\hline & Riesgo alto & $\%$ & riesgo muy alto & $\%$ & Sin riesgo & $\%$ \\
\hline & & & & & & \\
\hline Bajo peso & 0 & $0,0 \%$ & 0 & $0,0 \%$ & 10 & $3,1 \%$ \\
\hline Normal & 10 & $12,7 \%$ & 0 & $0,0 \%$ & 290 & $91,2 \%$ \\
\hline Obesidad & 11 & $13,9 \%$ & 17 & $85,0 \%$ & 1 & $0,3 \%$ \\
\hline Sobre peso & 58 & $73,4 \%$ & 3 & $15,0 \%$ & 17 & $5,3 \%$ \\
\hline Total & 79 & $100,00 \%$ & 20 & $100,00 \%$ & 318 & $99,96 \%$ \\
\hline
\end{tabular}


Tabla 41. Prueba de Chi cuadrado interpretación del IMC con el contorno de cintura

\begin{tabular}{ll|l|l|l} 
& & & $\begin{array}{l}\text { Significación } \\
\text { asintótica } \\
\text { (bilateral) }\end{array}$ & $\begin{array}{l}\text { Significación } \\
\text { exacta (bilateral) }\end{array}$ \\
\hline Valor & Df &, 000 &, 000 \\
\hline Chi-cuadrado de Pearson & $430,246^{a}$ & 6 &, 000 &, 000 \\
\hline Razón de verosimilitud & 317,106 & 6 & &, 000 \\
\hline Prueba exacta de Fisher & 308,041 & & & \\
\hline N de casos válidos & 417 & & & \\
\hline
\end{tabular}

a. 4 casillas $(33,3 \%)$ han esperado un recuento menor que 5 . El recuento mínimo esperado es ,48.

Como se observa en la Tabla 41, se presenta que el porcentaje de la frecuencia esperada en estas variables es de $33.3 \%>20 \%$ luego no se puede utilizar en este caso la prueba chi cuadrado ya que no cumple con los requisitos estipulados para ella, SPSS cuenta con otra alternativa para medir la hipótesis, si es tabla de 2 × 2 se utiliza la prueba exacta de Fisher y si las tablas son de i x j, se toma su ampliación como prueba exacta, en este caso, en la tabla 41 se usa el valor $\mathrm{p}$ de la prueba de significación exacta bilateral $0,000 \leq 0,05$, luego, la prueba es significante al 5\% así que con una confianza del 95\% se rechaza la hipótesis nula, entonces, el IMC y el CC si están relacionados.

\section{Relación contorno de cintura- índice cintura talla}

Tabla 42. Interpretación del contorno de cintura con el índice cintura-talla

\begin{tabular}{|c|c|c|c|c|c|c|}
\hline \multirow{2}{*}{$\begin{array}{l}\text { Interpretación } \\
\text { cintura talla }\end{array}$} & \multicolumn{6}{|c|}{ Interpretación contorno cintura } \\
\hline & Riesgo alto & $\%$ & Riesgo Muy alto & $\%$ & Sin riesgo & $\%$ \\
\hline Delgado sano & 1 & $1,3 \%$ & 0 & $0,0 \%$ & 139 & $43,7 \%$ \\
\hline obesidad & 59 & $74,7 \%$ & 19 & $95,0 \%$ & 19 & $6,0 \%$ \\
\hline Sano & 4 & $5,1 \%$ & 0 & $0,0 \%$ & 110 & $34,6 \%$ \\
\hline sobrepeso & 15 & $19,0 \%$ & 1 & $5,0 \%$ & 50 & $15,7 \%$ \\
\hline
\end{tabular}


Tabla 43. Prueba de Chi cuadrado interpretación del contorno de cintura con el índice cintura-talla

\begin{tabular}{|c|c|c|c|c|}
\hline & Valor & Df & $\begin{array}{l}\text { Significación } \\
\text { asintótica } \\
\text { (bilateral) }\end{array}$ & $\begin{array}{l}\text { Significación } \\
\text { exacta (bilateral) }\end{array}$ \\
\hline Chi-cuadrado de Pearson & $243,820^{a}$ & 6 &, 000 &, 000 \\
\hline Razón de verosimilitud & 247,036 & 6 &, 000 &, 000 \\
\hline Prueba exacta de Fisher & 235,915 & & &, 000 \\
\hline $\mathrm{N}$ de casos válidos & 417 & & & \\
\hline
\end{tabular}

a. 2 casillas $(16,7 \%)$ han esperado un recuento menor que 5 . El recuento mínimo esperado es 3,17 .

Con los resultados de la Tabla 43, el porcentaje de la frecuencia esperada para la tabla cruzada en estas variables es de $16.7 \%$ menor a $20 \%$, se toma el valor de la prueba exacta $0,000 \leq 0,05$, luego, la prueba es significante al 5\%, en conclusión, con una confianza del 95\% se rechaza la hipótesis nula, es decir, el ICT y el CC están relacionados.

\section{Relación índice de masa corporal-índice cintura talla}

Tabla 44. Interpretación del IMC con el índice cintura-talla

\begin{tabular}{|c|c|c|c|c|c|c|c|c|}
\hline \multirow{3}{*}{$\begin{array}{l}\text { Interpretación } \\
\text { índice de Masa } \\
\text { Corporal }\end{array}$} & \multicolumn{4}{|c|}{ categorías interpretación cintura talla } & \multirow{3}{*}{ Sano } & \multirow{3}{*}{$\%$} & \multirow{3}{*}{ Sobrepeso } & \multirow{3}{*}{$\%$} \\
\hline & Delgado & $\%$ & Obesidad & $\%$ & & & & \\
\hline & \multicolumn{4}{|l|}{ sano } & & & & \\
\hline Bajo peso & 9 & $6,4 \%$ & \multirow{4}{*}{$\begin{array}{l}0 \\
19\end{array}$} & $0,0 \%$ & \multirow{4}{*}{$\begin{array}{l}1 \\
104\end{array}$} & $0,9 \%$ & \multirow{4}{*}{$\begin{array}{l}0 \\
46 \\
2 \\
18\end{array}$} & $0,0 \%$ \\
\hline Normal & 131 & $93,6 \%$ & & $19,6 \%$ & & $91,2 \%$ & & $69,7 \%$ \\
\hline Obesidad & 0 & $0,0 \%$ & & $26,8 \%$ & & $0,9 \%$ & & $3,0 \%$ \\
\hline Sobre peso & 0 & $0,0 \%$ & & $53,6 \%$ & & $7,0 \%$ & & $27,3 \%$ \\
\hline
\end{tabular}


Tabla 45. Prueba de Chi cuadrado interpretación del IMC con el índice cintura-talla

\begin{tabular}{ll|l|l|l} 
& & & $\begin{array}{l}\text { Significación } \\
\text { asintótica } \\
\text { (bilateral) }\end{array}$ & $\begin{array}{l}\text { Significación } \\
\text { exacta (bilateral) }\end{array}$ \\
\hline & Valor & df &, 000 & . \\
\hline Chi-cuadrado de Pearson & $238,978^{\mathrm{a}}$ & 9 &, 000 &. $\mathrm{~b}$ \\
\hline Razón de verosimilitud & 251,738 & 9 & &. $\mathrm{~b}$ \\
\hline Prueba exacta de Fisher & . & & & \\
\hline N de casos válidos & 417 & & & \\
\hline
\end{tabular}

a. 5 casillas $(31,3 \%)$ han esperado un recuento menor que 5 . El recuento mínimo esperado es 1,58 .

b. No se puede calcular porque no hay memoria suficiente.

Tabla 46. Prueba de Chi cuadrado interpretación del IMC con el índice cintura-talla

\begin{tabular}{|c|c|c|c|c|c|c|}
\hline & & & & Sig. Monte Ca & arlo (bilat & \\
\hline & & & & & $\begin{array}{l}\text { Intervalc } \\
99 \%\end{array}$ & confianza al \\
\hline & Valor & $\mathrm{df}$ & $\begin{array}{l}\text { Significación asintótica } \\
\text { (bilateral) }\end{array}$ & Significación & $\begin{array}{l}\text { Límite } \\
\text { inferior }\end{array}$ & $\begin{array}{l}\text { Límite } \\
\text { superior }\end{array}$ \\
\hline $\begin{array}{l}\text { Chi-cuadrado de } \\
\text { Pearson }\end{array}$ & $238,978^{a}$ & 9 &, 000 &, $000^{\mathrm{b}}$ &, 000 &, 000 \\
\hline $\begin{array}{l}\text { Razón de } \\
\text { verosimilitud }\end{array}$ & 251,738 & 9 & ,000 &, $000^{\mathrm{b}}$ & 000 &, 000 \\
\hline $\begin{array}{l}\text { Prueba exacta de } \\
\text { Fisher }\end{array}$ & 236,036 & & &, $000^{\mathrm{b}}$ & ,000 &, 000 \\
\hline $\mathrm{N}$ de casos válidos & 417 & & & & & \\
\hline
\end{tabular}

a. 5 casillas $(31,3 \%)$ han esperado un recuento menor que 5 . El recuento mínimo esperado es 1,58.

b. Se basa en 10000 tablas de muestras con una semilla de inicio 1502173562 .

Como se muestra en las Tablas 45 y 46 el porcentaje de la frecuencia esperada en la tabla de contingencia para estas variables es de $31.3 \%$ mayor a $20 \%$, se maneja el valor de la prueba exacta por el método de aproximación por simulación de Montecarlo, ya que el algoritmo del programa SPSS desbordo la memoria y no fue posible el cálculo por el 
método tradicional, el valor $\mathrm{p}$ es $0,000 \leq 0,05$, entonces, la prueba es significante al $5 \%$, en conclusión, con una confianza del $95 \%$ se rechaza la hipótesis nula, es decir, el IMC y el ICT están relacionados.

\section{Variables frente a horas de sueño}

\section{Relación horas de sueño - índice de masa corporal}

Tabla 47. Interpretación del IMC con las horas de sueño

\begin{tabular}{|c|c|c|c|c|c|c|}
\hline Interpretación & Categoría & is Horas d & le sueño & & & \\
\hline índice de Masa & Entre $4 \mathrm{a}$ & $\%$ & entre $7 \mathrm{a}$ & $\%$ & Más de & $\%$ \\
\hline Corporal & 6 horas & & 9 horas & & 9 horas & \\
\hline Bajo peso & 3 & $3,2 \%$ & 6 & $2,0 \%$ & 1 & $4,8 \%$ \\
\hline Normal & 68 & $71,6 \%$ & 218 & $72,4 \%$ & 14 & $66,7 \%$ \\
\hline Obesidad & 10 & $10,5 \%$ & 18 & $6,0 \%$ & 1 & $4,8 \%$ \\
\hline Sobre peso & 14 & $14,7 \%$ & 59 & $19,6 \%$ & 5 & $23,8 \%$ \\
\hline Total & 95 & $100,00 \%$ & 301 & $100,00 \%$ & 21 & $100,00 \%$ \\
\hline
\end{tabular}

Tabla 48. Prueba de chi cuadrado interpretación del IMC con las horas de sueño

\begin{tabular}{|c|c|c|c|c|}
\hline & Valor & Df & $\begin{array}{l}\text { Significación } \\
\text { asintótica } \\
\text { (bilateral) }\end{array}$ & $\begin{array}{l}\text { Significación } \\
\text { exacta (bilateral) }\end{array}$ \\
\hline Chi-cuadrado de Pearson & $4,537^{a}$ & 6 &, 604 &, 592 \\
\hline Razón de verosimilitud & 4,258 & 6 & ,642 & ,705 \\
\hline Prueba exacta de Fisher & 5,356 & & & ,449 \\
\hline $\mathrm{N}$ de casos válidos & 417 & & & \\
\hline
\end{tabular}

a. 4 casillas $(33,3 \%)$ han esperado un recuento menor que 5 . El recuento mínimo esperado es, 50 .

Los resultados de la Tabla 48 presentan el porcentaje de la frecuencia esperada para la tabla cruzada de estas variables, el valor de $33.33 \%$ es mayor a $20 \%$, se toma entonces el valor de la prueba exacta $0,449>0,05$, es decir, la prueba no es significante al $5 \%$, 
entonces, con una confianza del $95 \%$ no se rechaza la hipótesis nula y se concluye que el IMC y las horas de sueño no están relacionadas.

\section{Relación horas de sueño- contorno cintura}

Tabla 49. Interpretación horas de sueño con contorno de cintura

\begin{tabular}{|c|c|c|c|c|c|c|}
\hline \multirow{3}{*}{$\begin{array}{l}\text { Interpretación } \\
\text { contorno de cintura }\end{array}$} & \multicolumn{6}{|c|}{ Categorías Horas de sueño } \\
\hline & entre 4 a & $\%$ & entre 7 a & $\%$ & más de & $\%$ \\
\hline & 6 horas & & 9 horas & & 9 horas & \\
\hline Riesgo muy alto & 7 & $7,4 \%$ & 12 & $4,0 \%$ & 1 & $4,8 \%$ \\
\hline Riesgo alto & 15 & $15,8 \%$ & 60 & $19,9 \%$ & 4 & $19,0 \%$ \\
\hline Sin riesgo & 73 & $76,8 \%$ & 229 & $76,1 \%$ & 16 & $76,2 \%$ \\
\hline Total & 95 & $100,00 \%$ & 301 & $100,00 \%$ & 21 & $100,00 \%$ \\
\hline
\end{tabular}

Tabla 50. Prueba de chi cuadrado interpretación horas de sueño con contorno de cintura

\begin{tabular}{|c|c|c|c|c|}
\hline & Valor & Df & $\begin{array}{l}\text { Significación } \\
\text { asintótica } \\
\text { (bilateral) }\end{array}$ & $\begin{array}{l}\text { Significación } \\
\text { exacta (bilateral) }\end{array}$ \\
\hline Chi-cuadrado de Pearson & $2,382^{\mathrm{a}}$ & 4 & ,666 &, 666 \\
\hline Razón de verosimilitud & 2,249 & 4 & ,690 & ,762 \\
\hline Prueba exacta de Fisher & 2,612 & & &, 593 \\
\hline $\mathrm{N}$ de casos válidos & 417 & & & \\
\hline
\end{tabular}

a. 3 casillas $(33,3 \%)$ han esperado un recuento menor que 5 . El recuento mínimo esperado es 1,01 .

Con los resultados de la Tabla 50 es claro que porcentaje de la frecuencia esperada para la tabla cruzada de estas variables es de $33.33 \%$ mayor a $20 \%$, se utiliza el valor de la prueba exacta $0,593>0,05$, por ende, la prueba no es significante al $5 \%$, entonces, con una confianza del 95\% no se rechaza la hipótesis nula y se concluye que el CC y las horas de sueño son independientes. 


\section{Relación horas de sueño cintura-talla}

Tabla 51. Interpretación horas de sueño con cintura-talla

\begin{tabular}{|c|c|c|c|c|c|c|}
\hline \multirow{3}{*}{$\begin{array}{l}\text { Interpretación } \\
\text { cintura talla }\end{array}$} & \multicolumn{6}{|c|}{ Categorías Horas de sueño } \\
\hline & Entre $4 \mathrm{a}$ & $\%$ & entre 7 a & $\%$ & Más de & $\%$ \\
\hline & 6 horas & & 9 horas & & 9 horas & \\
\hline Delgado sano & 25 & $26,3 \%$ & 104 & $34,6 \%$ & 11 & $52,4 \%$ \\
\hline obesidad & 30 & $31,6 \%$ & 64 & $21,3 \%$ & 3 & $14,3 \%$ \\
\hline Sano & 31 & $32,6 \%$ & 80 & $26,6 \%$ & 3 & $14,3 \%$ \\
\hline sobrepeso & 9 & $9,5 \%$ & 53 & $17,6 \%$ & 4 & $19,0 \%$ \\
\hline Total & 95 & $100,00 \%$ & 301 & $100,00 \%$ & 21 & $100,00 \%$ \\
\hline
\end{tabular}

Tabla 52. Prueba de chi cuadrado interpretación horas de sueño con cintura-talla

\begin{tabular}{ll|l|l|l} 
& & & $\begin{array}{l}\text { Significación } \\
\text { asintótica } \\
\text { (bilateral) }\end{array}$ & $\begin{array}{l}\text { Significación } \\
\text { exacta (bilateral) }\end{array}$ \\
\hline Valor & Df &, 038 &, 036 \\
\hline Chi-cuadrado de Pearson & $13,368^{\mathrm{a}}$ & 6 &, 034 &, 042 \\
\hline Razón de verosimilitud & 13,611 & 6 & &, 037 \\
\hline Prueba exacta de Fisher & 13,044 & & & \\
\hline N de casos válidos & 417 & & & \\
\hline
\end{tabular}

a. 2 casillas $(16,7 \%)$ han esperado un recuento menor que 5 . El recuento mínimo esperado es 3,32 .

Los resultados de la Tabla 52 presentan el porcentaje de la frecuencia esperada para la tabla de contingencia en las variables es de $33.33 \%$ mayor a $20 \%$, se toma entonces el valor de la prueba exacta $0,037 \leq 0,05$, por consiguiente, la prueba es significante al $5 \%$, entonces, con una confianza del 95\% se rechaza la hipótesis nula, es decir, que el ICT y las horas de sueño están relacionadas. 


\section{Variables frente a la actividad física extraescolar}

\section{Relación actividad física extraescolar-índice de masa corporal}

\section{Tabla 53. Interpretación IMC y Actividad física extraescolar}

\begin{tabular}{|c|c|c|c|c|c|c|c|c|}
\hline categorías & interpretac & ión índice & de Masa & corporal & & & & \\
\hline $\begin{array}{l}\text { actividad física } \\
\text { extraescolar }\end{array}$ & Bajo peso & $\%$ & Normal & $\%$ & Obesidad & $\%$ & Sobre peso & $\%$ \\
\hline SI & 8 & $80,0 \%$ & 208 & $69,3 \%$ & 14 & $48,3 \%$ & 50 & $64,1 \%$ \\
\hline NO & 2 & $20,0 \%$ & 92 & $30,7 \%$ & 15 & $51,7 \%$ & 28 & $35,9 \%$ \\
\hline Total & 10 & $100,0 \%$ & 300 & $100,0 \%$ & 29 & $100,0 \%$ & 78 & $100,0 \%$ \\
\hline
\end{tabular}

Tabla 54. Prueba de chi cuadrado interpretación IMC y Actividad física extraescolar

\begin{tabular}{ll|l|l|l} 
& & & $\begin{array}{l}\text { Significación } \\
\text { asintótica } \\
\text { (bilateral) }\end{array}$ & $\begin{array}{l}\text { Significación } \\
\text { exacta (bilateral) }\end{array}$ \\
\hline Valor & df &, 093 &, 093 \\
\hline Razón de verosimilitud & 6,175 & 3 &, 103 &, 115 \\
\hline Prueba exacta de Fisher & 6,096 & & &, 103 \\
\hline N de casos válidos & 417 & & & \\
\hline
\end{tabular}

a. 1 casillas (12,5\%) han esperado un recuento menor que 5 . El recuento mínimo esperado es 3,29 .

Como se infiere en la Tabla 54 el porcentaje de la frecuencia esperada en la tabla cruzada de estas variables es de $12,5 \%$ menor a $20 \%$, se toma entonces el valor de chi cuadrado $0,103>0,05$, entonces, la prueba no es significante al $5 \%$, luego, con una confianza del 95\% se rechaza la hipótesis nula, por consiguiente, el IMC y la actividad física extraescolar no están asociados.

\section{Relación actividad física- contorno cintura}


Tabla 55. Interpretación contorno de cintura y Actividad física extraescolar

\begin{tabular}{llllllll}
\hline categorías & \multicolumn{2}{l}{ interpretación contorno cintura } & & & \\
actividad física & Riesgo muy alto & $\%$ & Riesgo alto & $\%$ & Sin riesgo & $\%$ \\
extraescolar & & & & & & \\
\hline SI & 11 & $55,0 \%$ & 47 & $59,5 \%$ & 222 & $69,8 \%$ \\
NO & 9 & $45,0 \%$ & 32 & $40,5 \%$ & 96 & $30,2 \%$ \\
Total & 20 & $100,00 \%$ & 79 & $100,00 \%$ & 318 & $100,00 \%$ \\
\hline
\end{tabular}

Tabla 56. Prueba de chi cuadrado interpretación contorno de cintura y Actividad física extraescolar

\begin{tabular}{ll|l|l|l} 
& & & $\begin{array}{l}\text { Significación } \\
\text { asintótica } \\
\text { (bilateral) }\end{array}$ & $\begin{array}{l}\text { Significación } \\
\text { exacta (bilateral) }\end{array}$ \\
\hline Valor & df &, 108 &, 115 \\
\hline Chi-cuadrado de Pearson & $4,459^{a}$ & 2 &, 114 &, 125 \\
\hline Prueba exacta de Fisher & 4,529 & & &, 104 \\
\hline N de casos válidos & 417 & & & \\
\hline
\end{tabular}

a. 0 casillas $(, 0 \%)$ han esperado un recuento menor que 5 . El recuento mínimo esperado es 6,57 .

La Tabla 56 muestra el porcentaje de la frecuencia esperada en la tabla cruzada de estas variables es de $12,5 \%$ menor a $20 \%$, se utiliza el valor de la prueba chi cuadrado $0,104>0,05$, luego, la prueba no es significante al 5\%, por lo tanto, así con una confianza del 95\% no se rechaza la hipótesis nula, es decir, que el CC y la actividad física extraescolar son independientes.

\section{Relación actividad física extraescolar- índice cintura talla}

Tabla 57. Interpretación índice cintura-talla y Actividad física extraescolar

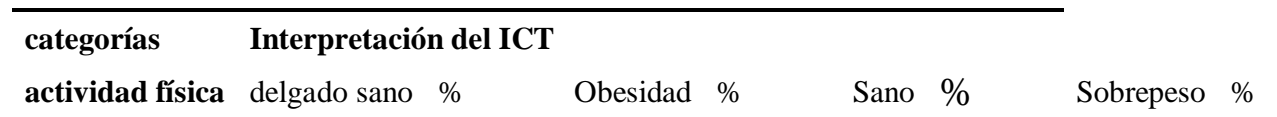




\begin{tabular}{|c|c|c|c|c|c|c|c|c|}
\hline SI & 112 & $80,0 \%$ & 53 & $54,6 \%$ & 69 & $60,5 \%$ & 46 & $69,7 \%$ \\
\hline NO & 28 & $20,0 \%$ & 44 & $45,4 \%$ & 45 & $39,5 \%$ & 20 & $30,3 \%$ \\
\hline Total & 140 & $100,00 \%$ & 97 & $100,00 \%$ & 114 & $100,00 \%$ & 66 & $100,00 \%$ \\
\hline
\end{tabular}

Tabla 58. Prueba de chi cuadrado interpretación índice cintura-talla y Actividad física extraescolar

\begin{tabular}{|c|c|c|c|c|}
\hline & Valor & df & $\begin{array}{l}\text { Significación } \\
\text { asintótica } \\
\text { (bilateral) }\end{array}$ & $\begin{array}{l}\text { Significación } \\
\text { exacta (bilateral) }\end{array}$ \\
\hline Chi-cuadrado de Pearson & $19,823^{a}$ & 3 &, 000 &, 000 \\
\hline Razón de verosimilitud & 20,373 & 3 &, 000 &, 000 \\
\hline Prueba exacta de Fisher & 20,229 & & &, 000 \\
\hline $\mathrm{N}$ de casos válidos & 417 & & & \\
\hline
\end{tabular}

a. 0 casillas $(, 0 \%)$ han esperado un recuento menor que 5 . El recuento mínimo esperado es 21,68 .

Se infiere de la Tabla 58 que el porcentaje de la frecuencia esperada para la tabla de contingencia en estas variables es de $0 \%$ menor a $20 \%$, se toma el valor de la prueba exacta $0,000 \leq 0,05$, luego, la prueba es significante al 5\%, en conclusión, con una confianza del 95\% se rechaza la hipótesis nula, es decir, el ICT y la actividad física extraescolar están asociados.

\section{CAPÍTULO V}

\section{Resultados y conclusiones}

El análisis de resultados muestra cifras interesantes para abordar desde la promoción y prevención en salud. Igualmente, la posibilidad de intervención en aquellos casos detectados como graves o especialmente críticos. 
Las características sociodemográficas de la población demuestra que no hay una diferencia significativa en el número de mujeres y hombres estudiados 211 y 216 respectivamente, igualmente los porcentajes son altos en cuanto población que vive con sus padres y familiares, de la misma manera los estudiantes con antecedentes médicos se sitúa en el rango de un $18 \%$ totalizando problemas respiratorios, cardíacos, osteomusculares y otros y finalmente los escolares que actualmente se encuentran medicados se sitúa en rangos por debajo del $5 \%$

La población estudiada reporta en sus comportamientos un número significativo en cuanto a la práctica de actividades físicas extraescolares con más del 50\%, e igualmente evidencia que la mayoría cumplen con las horas recomendadas en sueño (promedio 8) y también tienen el acceso a tres o más comidas diarias, de la misma forma hay un número reducido de población expuesta al tabaquismo o que han optado por fumar

Según las medidas antropométricas se puede determinar que existe una población en riesgo correspondiente a los altos índices presentados en el IMC, contorno de cintura y a la vez la de relación talla cintura y tejido graso mostrando porcentajes de más del $24 \%$ en IMC, $22 \%$ en contorno de cintura, más del $38 \%$ en índice cintura - talla y más del $50 \%$ en grasa corporal.

Según la medición de las variables hemodinámicas se puede determinar que existe una población en riesgo correspondiente a los índices presentados en hipertensión arterial sistólica y diastólica equivalente a 15,34 
Hay una relación muy significativa entre las variables antropométricas, cardiovasculares y hábitos saludables que potencialmente pueden presentar riesgo cardiovascular a futuro.

En los cruces relacionados con el género biológico se puede analizar:

El IMC y el género biológico no muestran en esta población una asociación dado que se presentan cifras muy similares en cuanto a número que no son significativas evidenciando porcentajes ligeramente más altos para las categorías de sobrepeso y obesidad en las niñas, sin embargo, se aprecia un IMC normal en 9 hombres más que en las niñas no siendo relevante para el cruce de la variable.

El Contorno de cintura y el género biológico tampoco presentan una relación significativa a nivel estadístico a pesar de que la tendencia es que las niñas presenten al igual que en el IMC un número mayor tanto en la categoría de riesgo muy alto y alto totalizando 17 estudiantes de diferencia.

La relación índice cintura talla y género biológico muestra estadísticamente valores significativos frente a las tablas de contingencia, es evidente que se aprecia un aumento considerable en lo correspondiente a las categorías delgado sano y sano vs género biológico. El número es representativo en 147 escolares del género masculino que registran valores sin riesgo en lo correspondiente a las categorías delgado sano y sano, con relación a las niñas quienes 104 se determinaron en riesgo por sobrepeso y obesidad, entendiéndose que el número de hombres y mujeres es similar.

En los cruces relacionados con las variables antropométricas se puede decir: 
El IMC y el contorno de cintura presentan una correlación significativa ya que 61 estudiantes se encuentran en sobrepeso y 28 con obesidad con riegos alto y muy alto, entendiéndose que la población que se encuentra sin riesgo es 318 estudiantes de 417.

En la relación contorno de cintura e índice cintura talla se presenta un fenómeno similar al cruce anterior, sin embargo la diferencia significativa está en el estadístico de obesidad (78 estudiantes) lo cual crea una alerta y muestra que esta tabla cruzada nos orienta en la aplicación de esta correlación para tener en cuenta en estudios de mayor profundidad, igualmente se relacionan 16 estudiantes categorizados en sobrepeso para un total de 94 escolares en condición de riesgo alto y muy alto.

La relación IMC índice cintura talla evidencia al igual que los dos anteriores análisis, datos significativos para tener en cuenta. Se puede inferir que hay un número significativo de estudiantes con sobrepeso y obesidad (98).

Esto permite determinar que las correlaciones antropométricas establecidas con estas tres tablas cruzadas evidencian de una manera más clara aquellos escolares que se encuentran en potencial riesgo cardiosvacular.

En cuanto a la relación de variables con las horas de sueño se puede analizar :

La tabla de contingencia IMC frente a la variable sueño no muestra valores representativos, observando que solamente 6 escolares se encuentran en el rango de más de 9 horas lo cual eventualmente podría llevar a una alteración metabólica por exceso de sueño .

Igual que el análisis anterior la relación contorno cintura y sueño no evidencia relación en riesgo ya que se observa una cantidad mínima de estudiantes (5) con más de 9 
horas de sueño, no obstante es importante tener en cuenta que aquellos estudiantes referenciados (23) en el rango de 4-6 horas también pueden presentar trastornos ocasionados por el déficit de sueño lo que pueda ocasionar una demanda excesiva en la ingesta de comida causado por los niveles bajos de leptina según muestran la investigación: la reducción del sueño como factor de riesgo para la obesidad pulicado en (Rev. Méd. Chile Vol 139 No. 7 Santiago Jul. 2011). Dadas las cifras presentadas en este estudio no es relevante dicha relación.

Para el análisis de la relación sueño frente a índice cintura -talla se determinan unos valores que si son representativos los cuales se evidencian en el número de estudiantes que mostraron cifras con obesidad y sobrepeso (39) con horas de sueño entre 4 y 6 , lo cual hace pensar que el indicador cintura - talla es mucho más válido para la comparación que solamente el contorno de cintura o el IMC, no siendo significativo el exceso de sueño (más de 9 horas) en donde se registran solamente 7 estudiantes. De hecho, estas cifras corroboran la investigación referenciada en el cruce anterior.

Finalmente se establecen las relaciones entre los indicadores antropométricos y la Actividad Física extraescolar en las cuales se apreciaron los siguientes aspectos:

Para el análisis de la relación actividad física frente a IMC se puede establecer una relación poco significativa con 43 escolares que no realizan actividad física extraescolar y están categorizados en el indicador de sobre peso y obesidad atendiendo a las medidas arrojadas por el IMC. 
En cuanto a la relación actividad física y contorno de cintura se determina que no existe una relación significativa ya que los valores mostrados en riesgo muy alto equivalen solamente a 9 estudiantes.

En el análisis actividad física frente al índice cintura talla se establece una relación significativa ya que dentro de rango de obesidad y sobrepeso y la falta de actividad física extraescolar se reporta un número de 64 estudiantes, sin embargo las cifras de los escolares que realizan actividad física extraescolar y presentan eventual riesgo por el indicador de sobrepeso y obesidad son altas, aunque se debe precisar que el número total de practicantes de actividad física extraescolar comparativamente con los que no la realizan es de proporción estadísticamente mucho mayor.

Se puede inferir entonces de acuerdo con lo expuesto y lo relacionado con los cruces que las variables que no presentan correlación son aquellas que están más asociadas al género y a las horas de sueño.

Definitivamente las variables que presentan una correlación en mayor grado son las correspondientes al índice cintura-talla.

Según los hábitos de sueño y actividad física el 67 \% reportan normalidad. Es decir, que la población que se encuentra en el $23 \%$ puede evidentemente tenerse en cuenta para asociar a las variables que reporten riesgo cardiovascular. El porcentaje es significativo en aquellos que están expuestos al tabaquismo $>22 \%$.

Las variables asociadas a la actividad física tienen una alta significación y deben ser tenidas en cuenta para la implementación de estrategias que propendan por la disminución del riesgo cardiovascular en escolares. 


\section{CAPÍtulo Vi}

\section{Discusión y recomendaciones}

Este estudio muestra de manera correlacional las cifras obtenidas en composición corporal con las obtenidas por los signos vitales y a su vez el comportamiento hemodinámico en el sujeto. El propósito de la investigación aparte de identificar los factores de riesgo cardiovascular en escolares fue la de determinar la relación entre diferentes variables, comparando los resultados obtenidos por género, edad y hábitos de salud., atendiendo a la gran cantidad de investigaciones sobre el tema se coincide en que las etapas iniciales de un ser humano: infancia y adolescencia, son fundamentales para una calidad de vida en la adultez, sin embargo esta afirmación no es suficiente en la medida que no se establezcan análisis más específicos con rigor científico que evidencien realmente los problemas de salud en edades tempranas. De hecho, es indiscutible que las cifras descritas por la Organización Mundial de la Salud y la American Hearth Association se convierten en una alerta para la población del mundo en cuanto a lo que representan las enfermedades coronarias hoy en día. Si bien es cierto que se desarrollan muchos programas de promoción y prevención, es lamentable la morbi-mortalidad que se presenta por afecciones al corazón.

En los primeros análisis de esta investigación se puede comprobar con estudios muy similares como el de (Perez, 2017) que los valores antropométricos como del IMC o CC son significativos para determinar obesidad y por consiguiente riesgo cardiovascular. Asimismo, el IMC presenta una buena correlación con la cantidad de grasa total del organismo en los escolares. 
Dadas las cifras cintura talla, y de manera muy similar al estudio hecho por (Arnaiz, 2010) se observa una aproximación más exacta a los parámetros que indicarían un estado más vulnerable a nivel cardiovascular. Esta significación está representada por el cociente talla perímetro abdominal ya que la circunferencia abdominal según cifras de la OMS para mujeres $>88 \mathrm{~cm}$ y en hombres $>102$ tendría relevancia en población adulta, sin embargo en niños y adolescentes no podría tomarse como indicador confiable y real de determinación de riesgo. De hecho, esa relación entre estatura y talla hace mucha más válida la predicción.

El cruce de variables presentado con el programa SPSS permite validar desde la perspectiva de riesgo las hipótesis de asociación entre estas. De ahí que se pueda decir que es uno de los estudios pioneros no solamente en Colombia sino en el mundo en donde se relacionan factores de riesgo y protectores con los aspectos antropométricos y cardiovasculares, incursionando en elementos que interactúan como la dieta, el sueño y la actividad física extraescolar.

Obedeciendo a lo anterior se entiende que también hay numerosas investigaciones como la realizada por (Ruíz, 2011), que relacionan la actividad física extraescolar con el IMC y el contorno cintura, encontrándose una significación de corresponsabilidad sin embargo para esta investigación la frecuencia esperada en el cruce de la variable contorno cintura y actividad física fue de 12,5\% menor a 20\% 0,104 > 0,05 lo cual arroja independencia entre las hipótesis, claro está, teniendo en cuenta que es un auto reporte del estudiante y no se verifica si evidentemente está realizando actividad física extraescolar de manera regular.

Otros estudios similares se centran en el síndrome metabólico como identificador de riesgo, no obstante el estudio que aquí se presenta no contempla métodos 
invasivos como el análisis de glucosa o triglicéridos, básicamente por la complejidad en la toma de las muestras en menores de edad, lo cual necesariamente implicaría una financiación por parte del estado o la exclusión de muchos debido a la falta de recursos económicos o a la seguridad en la aplicación de los instrumentos.

Es indiscutible que se hace necesario crear políticas educativas que promuevan hábitos de vida saludables en los escolares de las instituciones educativas del distrito de Bogotá, por lo tanto la figura del docente de educación Física se convierte en una pieza clave para lograr que la administración pública centre su atención en los graves problemas relacionados con las Enfermedades Crónicas no transmisibles (ECNT) que se encuentran en las diferentes poblaciones de los colegios de Bogotá.

De hecho el liderazgo que ejerza el maestro en los colegios seguramente redundará en el bienestar de muchos de sus educandos. No solamente se trata de gestionar ante los entes competentes sino de realizar campañas apoyadas por parte de toda la comunidad educativa para informar y prevenir todas aquellas acciones que conllevan al deterioro de la salud, dado por la mala alimentación, hábitos de sueño, sedentarismo, entre otros aspectos.

Igualmente es importante realizar estudios similares al presentado con el propósito de detectar otros factores de riesgo y así mismo tener argumentos sólidos para mostrar ante los entes pertinentes que permitan llevar a cabo acciones de intervención para disminuir la tasa de morbi- mortalidad por causa de ECNT.

En adición a lo anterior se recomienda la práctica de actividad física extracurricular como alternativa viable para incrementar las horas promedio que deben realizar los niños y 
jóvenes a la semana en actividades que demanden un gasto energético importante que contrarreste los efectos nocivos de los factores de riesgo ya expuestos detalladamente en este estudio.

También es importante gestionar alianzas por parte de los rectores de la Secretaría de Educación del Distrito, secretaría de salud y alcaldías locales, para promocionar la aplicación de métodos como la antropometría para medir la talla, peso, contorno de cintura de todos los educandos, con el fin de tomar las medidas correctivas a tiempo sobre situaciones de obesidad y sobrepeso evitando así el riesgo de padecer alguna enfermedad cardiovascular a mediano o largo plazo.

\section{Bibliografía}

Achor, M. S., Benítez Cima,, N. A., \& Bravo, E. (2009). Estudios morfológicos en adolescentes. Bogotá, Colombia : INS.

Adorno, T. W., \& Morin, E. (2006). La industria cultural. Galera.

AHA. (2018). American Heart Association. Recuperado el 6 de Mayo de 2018, de http://www.heart.org/HEARTORG/Conditions/HighBloodPressure/KnowYourNum bers/Understanding-Blood-Pressure-

Readings_UCM_301764_Article.jsp\#.WvDU64gvzIU

Arnaiz, P. (2010). Razón, cintura, estatura como predictor de riesgo cardiometabólico en niños. Revista chilena de cardiología, 1-57.

Bárcena, M. J. (2016). Influencia de la calidad del terreno en la respuesta de los pastos a la aplicación de fósforo. Revista de salud, 1-80. 
Baron, P. F., \& Márquez, E. (Enero - Febrero de 2010). Diabetes mellitus tipo 2 en niños y adolescentes. Medicina Interna de México, 26(1), 36-45.

Braguinsky, J. (2002). Prevalencia de obesidad en América Latina. Anales Sts san Navarra, 45.

Buendia, R. (2016). Perímetro de cintura y riesgo de diabetes. . Acta médica colombiana, 176-180.

Chavarria, X. (2002). La Educación Física escolar como medio para la promoción de la salud y el desarrollo personal. Barcelona: Paidotribo.

Claros, J. A., Vélez Álvarez, C., Sandoval Cuellar, C., \& Alfonso Mora, M. L. (2011). ACTIVIDAD FÍSICA: ESTRATEGIA DE PROMOCIÓN DE LA SALUD. Hacia la promción de la salud. Manizales, Colombia: Universidad de Caldas.

Cogollo-Milanés, Z., \& Gómez-Bustamante, E. M. (2014). Variables asociadas al inicio del consumo de cigarrillo en adolescentes estudiantes de básica secundaria de los colegios oficiales de la ciudad de Cartagena, Colombia. Tesis de grado. Chía, Colombia: Unisabana.

Delgado, L., \& Montes, R. (2015). Práctica de actividad física extraescolar y preferencias deportivas en niños pre escolares españoles e inmigrantes: un estudio piloto. Revista TOG Coruña, 12.

El Espectador. (26 de Junio de 2016). El 60 \% de los colombianos duermen mal. Redacción social, pág. 24.

Flórez, M. L.-B. (2017). Influencia del tabaquismo pasivo en el desarrollo de enfermedades cardiovasculares. Tesis de grado. Madrid, España: Universidad Autonoma de Madrid.

Florez, S. B. (2009). Tabaquismo y salud. Barcelona, España: Taurus.

García, M. J. (2017). El tabaco, factor prioritario de riesgo cardiovascular, síndrome metabólico y diabetes mellitus tipo 2. La "edad del corazón" como herramienta preventiva . TFM. Madrid, España: Universidad Complutense. 
García-Artero, E., Ortega, F. B., Ruiz, J. R., Mesa, J. L., \& Delgado, M. (2017). El perfil lipídico-metabólico en los adolescentes está más influido por la condición física que por la actividad física (estudio AVENA)*. SEC 2017 - El Congreso de las Enfermedades Cardiovasculares. Madrid, España: Sociedad Española de cardiología.

Gluckman, P. D. (09 de Mayo de 2017). Los riesgos de la obesidad infantil. (I. Davinson, Entrevistador) Auckland, Nueva Zelanda. Recuperado el 21 de Enero de 2018, de http://www.nzherald.co.nz/nz/news/article.cfm?c_id=1\&objectid=11851729

Hand, L. (2016). El sueño deficiente es un factor de riesgo CV relacionado con el estilo de vida: Declaración de la AHA. Menphis: Louisiana University Press.

Hernández, G. M. (2011). PREVALENCIA DE SOBREPESO Y OBESIDAD, Y FACTORES DE RIESGO, EN NIÑOS DE 7-12 AÑOS, EN UNA ESCUELA PÚBLICA DE CARTAGENA . Trabajo de grado de maestría. Bogotá, Colombia: UNAL.

Humanos, D. d. (2016). Sueño y obesidad en niños y adultos. Washington, Estados Unidos de América: US Press.

Instituto Colombiano de Bienestar Familiar. (15 de Octubre de 2010). Encuesta Nacional de la Situación Nutricional. Obtenido de ICBF: http://www.icbf.gov.co/portal/page/portal/Descargas1/Resumenfi.pdf

Instituto Colombiano de Bienestar Familiar. (2010). Encuesta Nacional de la Situación Nutricional en Colombia. Bogotá: ICBF.

Instituto Nacional del Corazón, los Pulmones y la Sangre de los Estados Unidos. (2016). Condiciones de salud y obesidad. Texas: Texas human heart.

Kang, S. (s.f.). UC San Diego Health. Obtenido de http://myhealth.ucsd.edu/Spanish/RelatedItems/90,P04709

Kaufer-Horwitz, M., \& Toussaint, G. (Noviembre - Diciembre de 2008). Indicadores antropométricos para evaluar sobrepeso y obesidad en pediatría. Boletín médico del Hospital Infantil de México, 65(6), 15-25. 
Labbé, a. (2014). Tabaquismo pasivo en el niño. EMC - Pediatría, 9(42), 1-62.

Lanas, F. (2012). Rol del tabaquismo en el riesgo cardiovascular global. Revista médica clínica Condes, 1-60.

Luebbers, P. E. (2003). Medicina deportiva y descanso como reposo. Revista del colegio americano deportivo, 1-45.

Milian, A. G. (2009). Revista Científica de las ciencias médicas..7n2 abril. Revista Cubana de Medicina General Integral(ISSN 1561-3038), 12-20. Recuperado el 17 de Enero de 2018

Ministerio de salud. (2015). Encuesta Nacional de la Situación Nutricional. Bogotá: Minsalud. Recuperado el 19 de Enero de 2018

Ministerio de salud de Argentina. (2015). Consecuencias de la exposición al humo en los niños. Buenos Aires: Prensa nacional.

Ministerio de salud de Cuba . (2016). Prevalencia de enfermedades cardiacas en la isla . La Habana: Progreso.

Muñoz, M. T. (2010). Obesidad: Tratamiento y Prevención. Lima, Perú: Hospital Niño Jesús.

Mustillo, S. (2003). Una consideración de que la obesidad infantil podría clasificarse como legalizada ... Michigan, Estados Unidos de América: Opal Dockery.

Nishtar, S. (25 de Febrero de 2016). Informe de sintomatologías asociadas a la obesidad infantil. Auckland, Nueva Zelanda: Goverment of Auckland.

$\begin{array}{lllll}\text { OMS. } & (5 & \text { de } & \text { Febrero } & \text { de }\end{array}$ http://www.who.int/dietphysicalactivity/childhood_consequences/es/. Obtenido de http://www.who.int/dietphysicalactivity/childhood_consequences/es/.

OMS. (s.f. ). Datos y cifras sobre obesidad infantil. Organización de las Naciones Unidas, Comisión contra la obesidad infantil. Nueva York: ONU Press. Recuperado el 22 de Enero de 2018 
ONU - OMS. (2017). Evaluar y gestionar a los niños en los centros de atención primaria de salud para prevenir el sobrepeso y la obesidad en el contexto de la doble carga de la malnutrición. Nueva York: UN Press. Recuperado el 22 de Enero de 2018

Organización Mundial de la Salud. (2016). Informe de la Comisión para acabar. Nueva York: UN Press. Recuperado el 20 de Enero de 2018

Owens, J. (2017). Identifying Motivating Factors for Healthy Sleep in At-Risk Adolescents . Cambridge, Massachussets, Estados Unidos de América: Harvar Press University.

Papponetti, M. (s.f.). Intramed. (Intramed, Productor) Recuperado el 20 de Enero de 2018, de http://www.intramed.net/contenidover.asp?contenidoID $=84658$

pediatría, A. a. (2017). Estudios del sueño y la apnea en niños. Penssylvania, Estads Unidos de América: AAP.

Perez, L. M. (2017). Variaciones de valores antropometricos. Bogotá: Universidad de la salle.

Raghuveer, G. (20012). Circulation . American Heart Association , 1-56.

Reyes, V. P., Pérez García, M., Loya Méndez, Y., \& Hidalgo Ruzzante, N. (2016). Perfiles psicopatológicos de niños obesos y desnutridos medidos con el CBCL/6-18. Revista Latinoamericana de Psicología, 108-116.

Rodríguez, H. (2011). Estudios de la obesidad en el Ecuador. Quito, Ecuador.

Ruíz, A. (2011). Relación actividad extraescolar y el IMC en adolescentes. Madrid, España: Universidad complutense de Madrid.

Sociedad argentina de nutrición. (s.f. ). El desafío de aprender a comer sin prohibiciones . Charlas para la comunidad. Buenos Aires, Argentina: SAN.

Unicef. (2011). Estado mundial de la infancia. NUeva York: UN Press. Recuperado el 22 de Enero de 208

Universoformulas. (s.f.). Estadistica aplicada. Obtenido de Universo de formulas: www.universoformulas.com 
Vásquez, P. D., Olivares Cortez, S., \& Santos, J. L. (2008). Influencia familiar sobre la conducta alimentaria y su relación con la obesidad infantil. ARCHIVOS LATINOAMERICANOS DE NUTRICION . Santiago, Chile: Universidad Católica de Chile.

Yule, A. M., \& Montilla Valencia, D. A. (2014). Beneficios de la actividad física acuática en la salud en la salud en general y factores de prescripción en poblaciones con enfermedades crónicas no transmisibles. Tesis de grado. Santiago de Calí, Colombia: Univalle. 
Anexo 1. Consentimiento informado

\section{UNIVERSIDAD SANTO TOMÁS \\ FACULTAD DE CULTURA FÍSICA, DEPORTE Y RECREACIÓN \\ MAESTRÍA EN ACTIVIDAD FÍSICA PARA LA SALUD}

DETERMINACIÓN DE RIESGO CARDIOVASCULAR EN NIÑOS Y ADOLESCENTES ESCOLARIZADOS

FORMULARIO DE CONSENTIMIENTO INFORMADO

Apellidos:

Nombres:

Edad

Teléfono:

Dirección:

\section{Objetivo:}

Aceptar participar voluntariamente en las pruebas para la determinación de riesgo cardiovascular que hacen parte de la investigación "Perfil de riesgo cardiovascular en escolares del Distrito Capital", cuyo objetivo es determinar el riesgo cardiovascular de los niñ@s y adolescentes en edad escolar, a partir de las siguientes mediciones:

\begin{tabular}{|l|c|}
\hline & Mediciones \\
\hline 1 & Peso \\
\hline 2 & Talla \\
\hline 3 & IMC \\
\hline 4 & Perímetro de cintura \\
\hline 5 & Tensión arterial \\
\hline 6 & Frecuencia cardiaca \\
\hline 7 & Saturación periférica de oxígeno \\
\hline 8 & $\begin{array}{c}\text { Encuesta sobre factores de riesgo y } \\
\text { protectores }\end{array}$ \\
\hline
\end{tabular}

\section{Importante:}

La realización de la encuesta y las mediciones se realizarán dentro de las instalaciones del colegio por un estudiante de la Maestría en Actividad Física para la Salud de la Universidad Santo Tomás, en compañía del director (a) de grupo de los niñ@s y/o el (la) orientador(a) del colegio.

Para la realización de la medición se requiere que los niñ@s estén en pantaloneta y camiseta.

\section{Uso Confidencial:}

Todos los datos obtenidos serán de uso confidencial y serán analizados anónimamente. Solo el equipo investigador y la persona que firma la presente estarán autorizados a acceder a los mismos, de modo que están protegidos contra cualquier uso indebido.

Soy consciente de la información incluida en este formulario, comprendo los procedimientos y consiento libremente en hacer parte de la investigación. 
Anexo 2. Entrevista

UNIVERSIDAD SANTO TOMÁS

FACULTAD DE CULTURA FÍSICA, DEPORTE Y RECREACIÓN

DETERMINACIÓN DE RIESGO CARDIOVASCULAR EN NIÑOS Y ADOLESCENTES ESCOLARIZADOS

INSTITUCIÓN ESCOLAR

DATOS PERSONALES

Nombre completo

Grado

Jornada

Edad

Lugar y Fecha de nacimiento

Género

Régimen de salud
Localidad (Barrio)

Contributivo (beneficiario) Subsidiado (Sisbén)

Estrato

ANTECEDENTES MÉDICOS:

MEDICAMENTOS:

FACTORES DE RIESGO Y PROTECTORES:

Con quién vives?

Fumas?

Si

No

Fuente de elaboración: Propia 


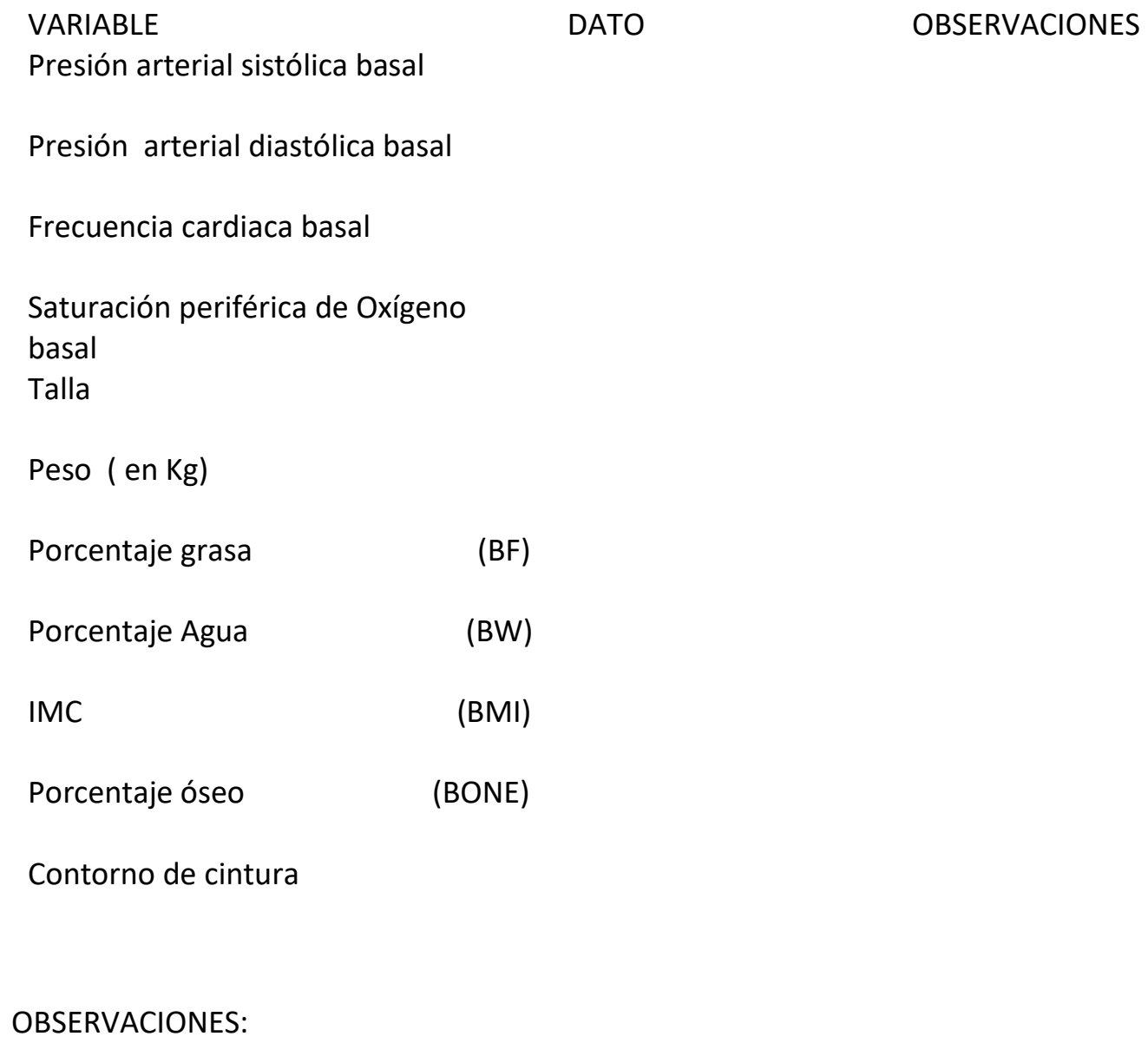

